Dr.2260

\section{LA-8649-PR}

Progress Report
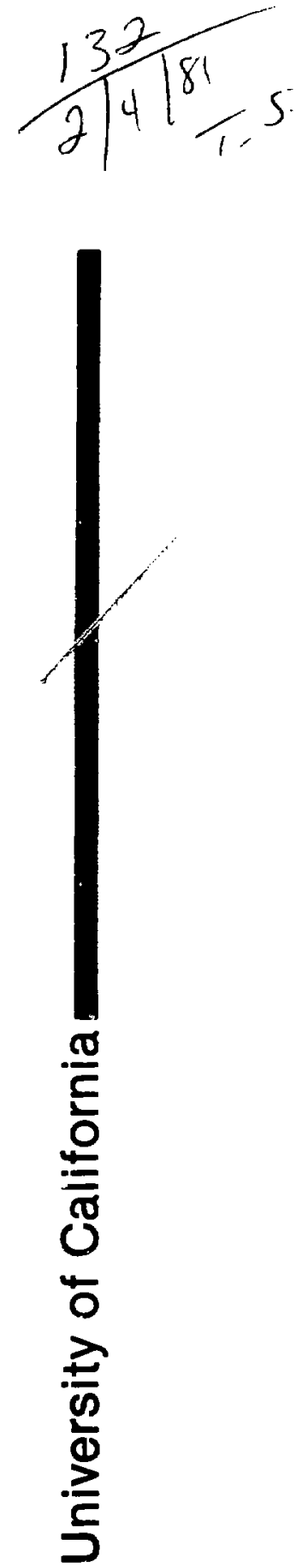

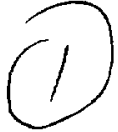

$R-17 / 3$

Reactor Technology

July-September 1980 
CONTENTS

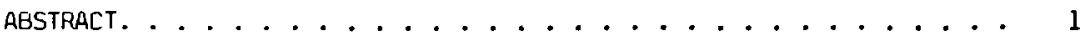

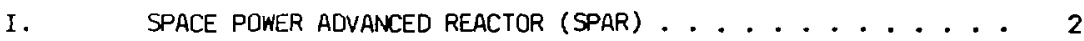

A. Executive Surmary ................... 2

B. Mission Requirements. ............. 2

C. Power Plant System Analysis . . . . . . . . . 2 2

D. Core Heat Pipe Development. . . . . . . . 6

E. Radiator Development. ............ 13

REFERENCES. ................... 14

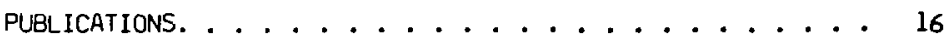

II. REACTOK SAFETY: GAS-COOLED FAST REACTOR SAFETY EXPERIMENTS. . 17

A. Executive Sumnary ............. 17

B. Program Planning. .............. 17

C. Analysis. ................. 17

D. Procurement and Fabrication .......... 17

E. Assembly, Installation, and Checkout. ....... 18

F. FLS Testing Sequence. ............ 18

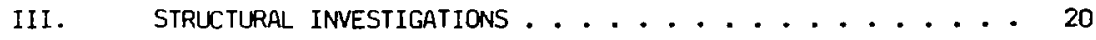

A. Executive Surmary ............. 20

B. Structural Margins to Failure - Category I

Structures program. ............ 20

c. Structural Margins to Failure - Containment

Buckling. .................. 21

D. HTGR Structural Investigation .......... 25

E. Ground Water Flow .............. 29

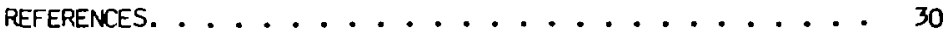

Iv. HEAT PIPE TECHNOLOGY DEVELOPMENT. ........... 31

A. Executive Sumary ................. 31

B. Ceramic Heat Pipe Technology Development Program. . . . 31

c. Heat Pipe Engineering. ............ 35

v. NUCLEAR CRITICALITY EXPERIMENTS AND SAFETY ........ 39

A. Executive Sunmary. ................ 39

B. SHEBA. .................... 39

c. Godiva IV. ................. 42

D. Comet Universal Assembly Machine .......... 46

E. Flattop. .................. 47

F. HONEYCOME. ................. 47 
G. PCA. ...................... 48

H. Cockcroft-Walton Accelerator ......... 48

I. "INRAD" Measurements of LASL weapons . . . . . . . 48

J. High-pressure HE-3 Neutron Spectrometer. . . . . . . 51

K. Leakage Neutron Spectrum at WNR. ......... 51

REFERENCES ...................... 52

FIGURES

1. Reactor and shield configuration with foreshortened shield-reactor core interspace............ 3

2. Configuration of baseline reactor and shield design. . . . 3

3. SPAR aft end core and heat pipe detail . . . . . . . . ;

4. Comparison between analysis and test for SPAR 1. . . . . . 7

5. Middle of SPAR-1 molybdenum screen tube. . . . . . . . B

6. Performance map of two-artery heat pipe for JPAR . . . . . 9

7. Bent heat pipe stainless steel envelope sectioned to reveal molybdenum screen wick............. 9

8. Possible artery configurations and positioning techniques. . 11

9. Core artery heat pipe design. . . . . . . . . . . 11

10. Effect of strain rate on tensile DBTT of molybdenum . . . 13

11. Room temperature mechanical properties of melted
Mo-Re alloys. . . . . . . . . . . . 13

12. FLS-3 test loop ...................... 17

13. Shear wall test structure ............... 21

14. Vibrational modes of shear wall test structures . . . . 22

15. Buckled cylinder in ASME arm verification experim.?nts . . 24

16. Containment building schematic. ........... 25

17. Tendon arrangeinent on the dome of the containment

18. Typical finite element in the done. . . . . . . . 26

19. Views of the finite element mesh for the containment. 27

20. Color preview of deformed shape of dome after

21. Dome deflection as a function of time ......... 28

22. Maximum principal stresses near keyway corner for steady state analysis (100\% power)........... 29

23. Finite element mesh for flow through rectangular dam. ... 30

24. Free surface contour for steady-state unconfined
flow through a porous block medium. ............. 30

25. SiC-W-Mo heat pipe performance............ 34 
26. Performance limits of gravity-assist, mercury heat pipe . . 36

27. venturi gas-ejector vertical heat pipe. . . . . . . . 37

28. Heat pipe solar collector ................... 38

29. SHEBA, a U(5) $0_{2} \mathrm{~F}_{2}$ solution critical assently. ..... 40

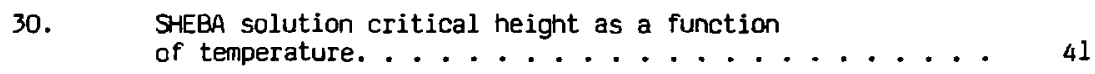

31. SHEBA reactivity addition for solution height changes... 41

32. SHEBA power calibration ................... 42

33. Schematic of GodivamPHERMEX experiment at TA-15 . . . . 44

34. Neutron room return correction factor ......... 50

35. Gamma-ray room return correction factor .......... 50

TABLS

I. SUMMARY OF CRATER VOLUME DATA ................. 15

II. DATA FOR THIN TARGETS ........................... 15

III. TITANIUMVOTASSIUM CORROSIDN EXPERIMENTS. . . . . . . 16

IV. Fls-3 TEST SEquence AND PARAMETERS. . . . . . . . . . . 19

v. GLASSES EVALUATED IN PRELIMINARY INVESTIGATION. . . . . . 34

VI. ATMOSPHERIC HEAT PIPE COLLECTOR TEST. . . . . . . . . . 37

VII. SUMMARY OF DETECTOR DATA FROM GODIVA BURSTS AT PHERMEX. . - 46

VIII. NEUTRON COUNTING WITH ${ }^{252} \mathrm{CF}$ SOURCE IN NEW

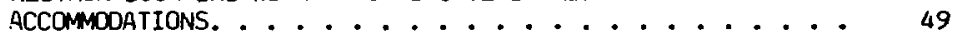

IX. GAMMA-RAY COUNTING DATA WIi 137 CS SOURCE IN NEW

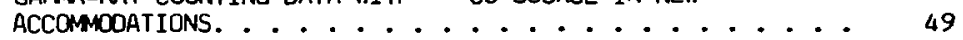




\title{
REACTOR TECHNOLOGY
}

JULY-SEPTEMBER 1980

\author{
Frepared by \\ Energy Technology Office, Energy Division \\ H. L. Kirk, Alternate Division Leader \\ C. R. Emigh, Associate Division Leader
}

\author{
Edited by \\ Michael Breslow \\ Compiled by \\ Sally Sullivan
}

ABSTRACT

Signiricant progress is reported in the Space Power Advanced Reactor (SPAR) Program with recent indications that revision of the Beo reflector configuration can reduce system weight by approximately $60 \mathrm{~kg}$. Observed boiling limit restrictions on the performance of the annular-wick core heat pipe have accelerated transition to the development of the target-design arterial heat pipe. Successful bends of core heat pipes have teen made with sodium as the mandrel material.

With the phasing out of the Gas-Cooled Fast Reactor (GCFR) Program, work on the Low Power Safety Experiments Program is now concentrated on completion of the third 37-rod Full Length Subgroup test prior to the preparation of the final report.

In the Reactor Safety/Structural Analysis area, effort on the Category I Structures Program is toward developing an experimental test plan focusing on a specific structural design. Buckling experiments on thin-walled cylindrical shells with circular cutouts have been completed and are reported. Results of a three-dimensional analysis of thermal stresses in a Fort St. Vrain core support block are presented.

Progress this quarter in the Ceramic Heat Pipe Program has incl Jed continuation of materials investigations and operation of a molybdenum-core SiC heat pipe. In the Heat Pipe Engineering Program, entrairment limits have been the subject of continuing investigation for gravity-assisted heat pipes; and feasibility studies of two heat pipe configurations having potential application to energy conservation have been initiated.

Nuclear Criticality Experiments and Safety reports construction of the new solution critical assembly, SHEBA, completed and having already provided over 100 irradiations for Goodyear Atomic Corp. and Oak Ridge Gaseous Diffusion Plant in connection with the evaluation of criticality alarm systems. Godiva IV was temporarily relocated at TA-15 to demonstrate proper synchronization of a Godiva burst, a PHEFEXX pulse, and a dynamic subcritical test assembly. The influence of scattered radiations in the test vault on InRad measurements was determined from detector scans of the vauit produced by ${ }^{252}$ Cf neutron and ${ }^{137}$ Cs gamma sources. 
I. SPACE POWER ADVANCED REACTOR (SPAR)

A. Executive Summary (W. A. Ranken, Q-15)

Components for a $10-t o-100 \mathrm{~kW}$ space nuclearreactor electric power plant are being designed, fabricated, anu tested. Such a power plant will consist of: (1) a nuclear reactor for generating heat, including heat pipes for transferring the energy from the reactor to the power conversion equipment; (2) a radiation shield to attenuate radiation to an acceptable level for the payload;

(3) thermoelectric (TE) converters to convert heat to electricity; and (4) a radiator for rejecting waste heat to space. The components being desiyned and tested, when incorporated into a power plarit, will provide a relatively inexpensive, compact power source for large, earth-orbiting satellites that the Department of Defense is evaluating for communication and surveillance.

Significant results have been obtained in the design and experimental program, including:

- Ongoing SPAR design work has detailed reactor/shield support structures and the positioning of the control rod drive assemblies and has indicated a potential method for saving $60 \mathrm{~kg}$ of system weight by moving the BeO reflector configuration to eliminate the stanjoff distance between the reactor and shield.

- Further testing of a 2-m-long, annularwick molybdenum/sodium core heat pipe has shown performance limitation above $1300 \mathrm{~K}$. This find has led to the acceleration of the transition from testing this interim design to developing and testing the target design--an arterial wick configuration. The latter is not subject to the wick-boiling limitation.

- Bending tests on 300-mm-long core heat pipe sections indicate that filling the heat pipe with sodium and bending it at a temperature just below the sodium melting point is a feasible fabrication technique. This method permits electron beam welding of heat pipe end caps to be done before the heat pipe is bent, a procedure that markedly simplifies the fabrication procedure.

- A comparative review of literature on the properties of molybdenum-rhenium alloys has revealed the existence of a ductility peak between 10 and 15 wt\% rhenium. Because this material has a ductile-brittle transition temperature of
ح $200 \mathrm{~K}$ and good weld ductility, its use in core heat pipe fabrication is expected to increase greatly their resistance to launch vibration loads. Procurement action has been initiated on Mo-13 wt\% Re wire and tubing.

B. Mission Requirements (L. Buden, Q-DO)

A draft of Safety Guidelines for tne ise of Nuclear Reactors in Space was received from the Department of Energy. These guidelines were reviewed and proposed revised guidelines prepared.

various options for directed energy electrical power requirements were reviewed. SPAR would provide too low a power level for the directed energy missions. However, SPAR with an energy storage system could satisfy the anti-satellite and satellite defense missions. For the antiballistic missile missions, a bimodal nuclear power plant using heat pipes for station keeping and propulsion modes appears feasible. Either an open- or closed-loop high power mode for ant 1 ballistic missile defense is proposed for further evaluation. The closed-loop, high power mode could support a manned space platform that could use the power to perform other missions.

\section{Power Plant System Analysis}

These studies will define the system in sufficient detail to identify materials and components requirements. Contimuing refinements will be made in the design in order to incorporate the results of analyses and experiments as well as revisions in program objectives and requirements. Reliability analysis will be uset to maximize the usefulness of the experimental propram. The system analyses will be augmented with e.oeriments using critical assemblies, models for e. amining assembly procedures, materials eyaluatior., and component designs and tests.

1. Configuration Analysis (K. L. Meier and J. T. Sena, 0-15). Continuing design siddies of the SPAR power - lant are directed toward (1) exploring alternate arrangenents of the reactorshield-converter array, (2) defining support structure, (3) simplifying fabrication and assenbly procedures, and (4) reducing system weights. Figure 1 shows the status of the design alternative currently being imestigated. It differs from the base line design of Fig. 2 prinarily in the configuration of the shield and BeO forward 


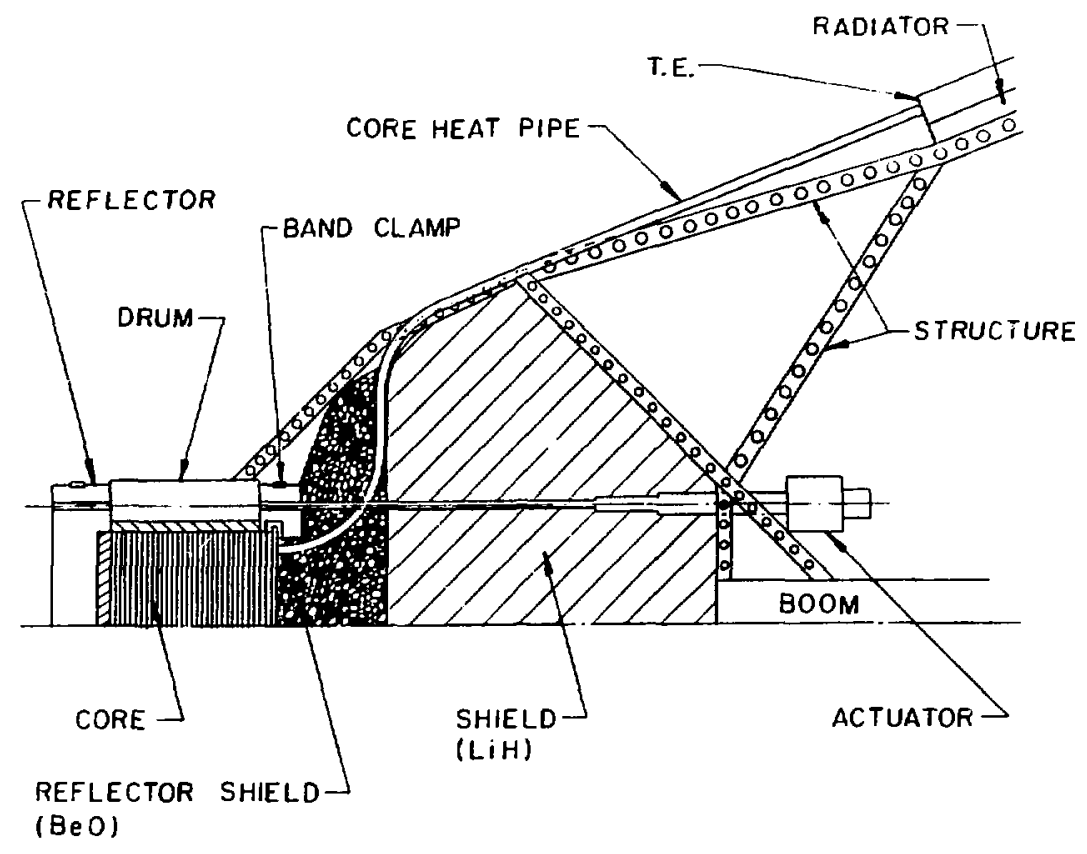

Fig. 1. Reactor and shield configuration with foreshortened shield-reactor core interspace.

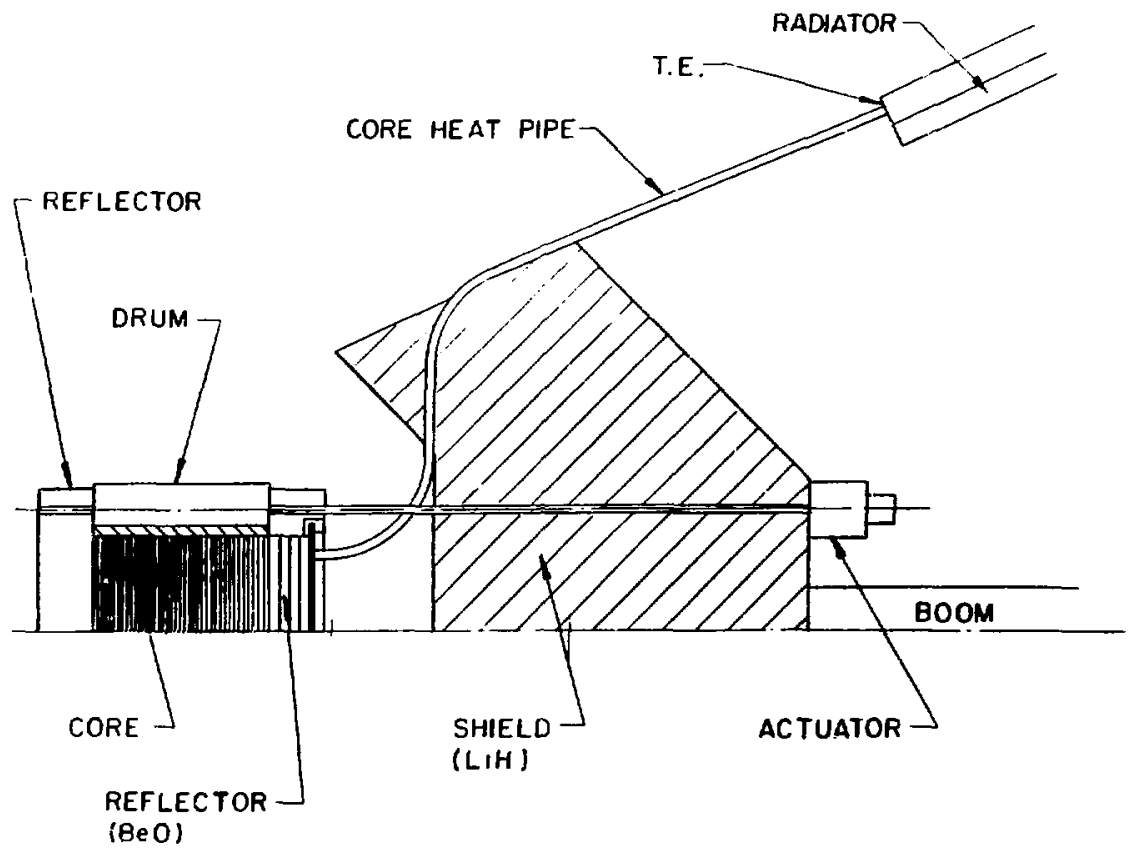

Fig. 2. Configuration of baseline reactor and shield design. 
reflector. More detailed design has been iricorporated in the aft end of the core heat pipes and in the suppcrt structure for the entire power plant.

The design alternative of Fig. 1 shows the support structure that connects the boom, shield, reactor, and converter-radiator together. The structure consists of stainless-steel I beams with lightening holes. It is somewriat complicated by the necessity of passing the beams around the outsice of the shield so as to minimize radiation leakage through cracks in the shield. The thermoelectrics and radiator minimum radius must be $1 \mathrm{~m}$ to allow sufficient circumferential space for the TEs and transition heat pipes. The axial distance from TEs to core then becomes $1.2 \mathrm{~m}$ and the structure must extend to this distance. The design retains the 12-piece segmented reflector that disintegrates upon atmospheric re-entry. There are 12 structural beams which connect the reflector segments to the rest of the power plant. The beams are fitted with fusible links that allow the segments to detach from the power plant upon reentry.

The shield half angle is $25^{\circ}$. The radiator and TE half angle is $22-1 / 2^{\circ}$ to place it inside the radiation protection of the shield. The actuators are placed beyond the shield for radiation protection. The actuator shafts are straight to avoid the additional failure modes of gears or universal joints. The shafts are of varying dianeter and are filled with LiH to avoid radiation leaks.

A weight reduction was realized by removing the $\mathrm{BeO}$ reflector tiles from the core container and replacing them with BeO beads in the region between the shield and core. This allowed the core heat pipe bends to begin at the top of the core which, in turn, allowed the shield to be placed closer to the reactor core. Th: increased BeO thickness allowed a decrease in LiH thickness. The net result is an approximate weight reduction of $60 \mathrm{~kg}$ due to the replacement of shielding material at a large radius by that at a smaller radius closer to the reactor.

The evaporator end of the core heat pipes at the aft end of the reactor core required more detalled design of several items that were not previously incorporated into the design. Figure 3 shows this portion of the core heat pipes and reflector. This end of the heat pipe has a $10 \mathrm{~mm}$ length that camot be used as an evaporator and must not receive the normal heat flux from the $\mathrm{UO}_{2}$. This $10 \mathrm{~mm}$ length consists of several items: a plug to preserve the pressure difference between the liquid in the wick and the vapor; several hafnium getter disks for removal of oxygen from the sodium; a liquid pool to allow the heat pipe to restart in space, an end cap with a closure weld; and, a small stud for proper heat pipe alignment during fin assembly. This additional 10 $\mathrm{m} m$ of heat pipe length rust be inside the core container. The length of $\mathrm{UO}_{2}$ in the reactor core is unchanged, but $10 \mathrm{~mm}$ of BeO tiles are added at the aft end. This $10 \mathrm{~mm}$ length increase causes a $10 \mathrm{~mm}$ reduction in the beryllium aft reflector thickness. There is a slight increase in the net reflective capability because lox of the beryllium in the aft reflector was changed to BeO and the latter's one-third greater density makes it a better neutron reflector by about onethird.

Two-dimensional neutronics calculations of the core were completed. These calculations effected a reduction of $18 \mathrm{~mm}$ in both the length and diameter of the core to $290 \mathrm{~mm}$. This change is also incorporated into Fig. 1 .

\section{Failure Modes and Effects Critical} Analysis (FMECA) (R. Bartholomew, Q-15). In the state-space formulation of reliability analysis discussed in previous quarterly reports (3ulySeptember 1979, Jaruary-March 1980, and April-June 1980), we showed that the SPAR reliability model can be expressed in state vector form as a set of linear, first order, differential equations, with the failure modes (inputs to the last "OR" gate of the particular component or subsystem fault tree) depicted as elements in the failure mode state vector. Mathematically, the form of the equations for every component subsystem, or complete SPAR system is

$$
\dot{F}=\underline{A} \underline{F}+\underline{B} \underline{U}(t)
$$

and

$$
\underline{T}=\underline{C} \underline{F}+\underline{D} \underline{u}(t)
$$




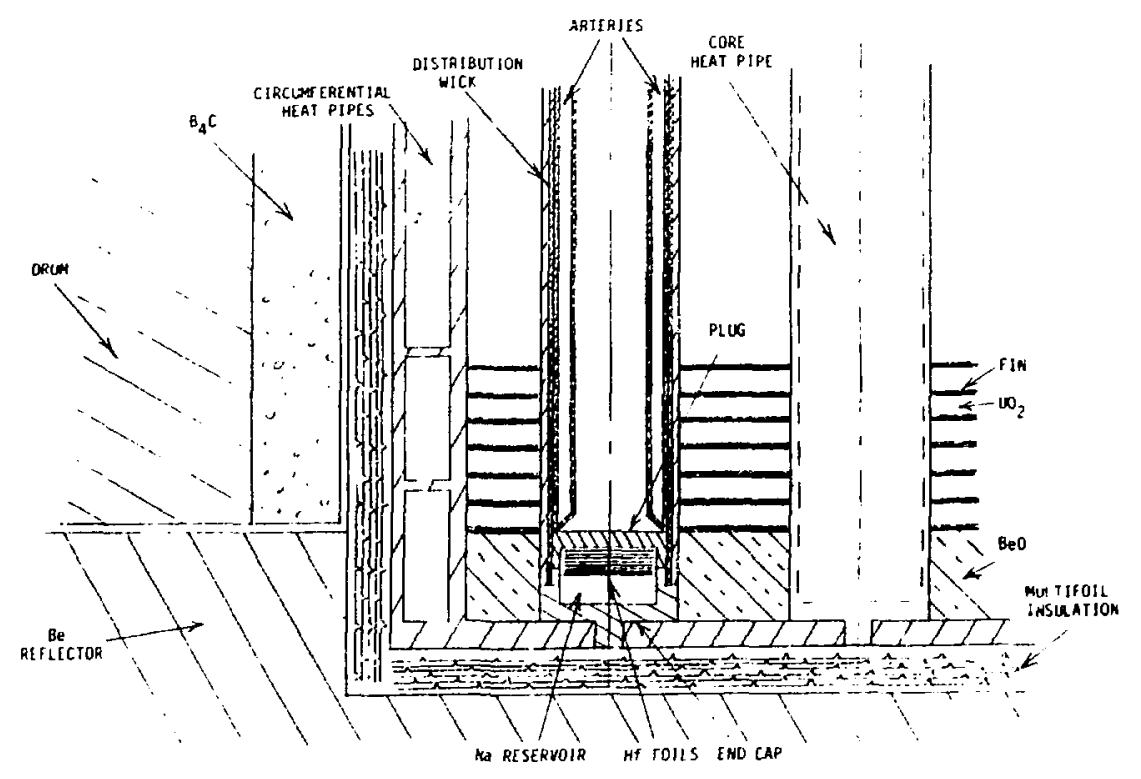

Fig. 3. SPAR aft end core and heat pipe detail.

with

$\underline{F}=$ SPAR system state vector comprising all of the component failure modes as elements in the vector $\underline{F}$.

$\underline{u}(t), \underline{I}(t)=$ SPAR system state vector comprising all of the initiator

failures that can lead to various top event failures $I(t)$.

A, $\underline{B}, \underline{C}, \underline{D}=$ Matrices of hazard functions $\left(\lambda_{i} ; i=1,2, \ldots, N\right)$, and failure mode interdependencies, and relationships between initiator events and failure modes and between initiator events and top event..

The elements of matrices $\underline{A}, \underline{B}, \underline{C}$, and $\underline{\mathrm{D}}$ have been determined for the fault tree corresponding to a core heat pipe (October-December 1979 Quarterly). these matrices are given below.

Core Heat Pipe.

$A=\left[\begin{array}{ccc}-\left(\lambda_{D}+\lambda_{c}+\lambda_{d}\right) & 0 & 0 \\ 0 & \left.-\lambda_{d}+3 \lambda_{e}+\lambda_{f}\right) & 0 \\ 0 & 0 & -\left(\lambda_{D}+\lambda_{c}+\lambda_{d}+\lambda_{e}\right)\end{array}\right]$
$\underline{E}=\left[\begin{array}{llllllllll}\frac{2 \lambda_{0}+\lambda_{c}+\lambda_{d}}{k} & 0 & 0 & 0 & 0 & 0 & 0 & 0 & 0 & 0 \\ \frac{\lambda_{0} \cdot 3 \lambda_{e}+2 \lambda_{f}}{k} & 0 & 0 & 0 & 0 & 0 & 0 & 0 & 0 & 0 \\ \frac{\lambda_{E} \cdot \lambda_{c} \cdot \lambda_{c} \cdot k_{e}}{k} & 0 & 0 & 0 & 0 & 0 & 0 & 0 & 0 & 0\end{array}\right](\Delta)$

$\underline{C}=\left[\begin{array}{lll}1 & 1 & 1\end{array}\right]$

$\underline{D}=\left[0000000-(1-k)^{2}-1-1(1-k)^{2}\right]$

The failure mode state vector for the core heat pipe is

$\underline{F}=\left[\begin{array}{lll}F_{1} & F_{2} & F_{3}\end{array}\right]^{T}$,

where

$F_{1} \triangleq$ loss of fluid in the heat pipe,

$\mathrm{F}_{2} \triangleq$ loss of pumping in the heat pipe,

$\mathrm{F}_{3} \triangleq$ increased pressure drop in the heat pipe.

The top event $I=T$ is defined as:

$T \triangleq$ Failure of the core heat pipe to transport core heat to the thermoelectric modules. 
The failure rates are defined as:

$k \stackrel{\Leftrightarrow}{=}$ Probasility of failure of launch vibration SPAR core isolation system resulting in vibration induced damage to core heat pipes.

$\lambda_{b} \triangleq$ Failure rate involving thermoelasticplastic stress in core heat pipe walls and weldments.

$c \stackrel{\wp}{=}$ Failure rate involving puncturing due to micrometeoroid penetration of exposed portion of core heat pipe.

$\gamma_{j} \stackrel{L}{=}$ Failure rate involving production of corrosive fluid impurities in core heat pipe fluid during operation.

${ }^{\prime} \stackrel{L}{=}$ Failure rate involving the molecular diffusion of non-fluid impuricies through core heat fipe wall to core heat pipe fluid.

${ }_{f} \stackrel{L}{=}$ Failure rate involving the separation of arteries from wick.

The core heat pipe failure initiator vector $\underline{u}(t)$ assumes all of the initiators to be statistically independent, so that we may write this vector as

$\underline{U}(t)=\left[\begin{array}{llllllllllll}F & F & F & F & F & F & F & F & F \\ a & b & c & d & e & f & b^{2} & c d & b c d e & d e^{3} & f^{2} & b^{3} c^{2} d^{3} e^{4} f\end{array}\right]^{\top}(8)$

where $F_{a}=1 . S_{o}(t), S_{o}(t)=\left\{\begin{array}{l}0, t<0 \\ 1, t \geq 0\end{array}\right\}$

and $F_{b}, F, \ldots, F_{b}{ }^{2} c d, F_{b c d e}, \cdots, F_{b}{ }^{3} c^{2} d^{3} e^{4} f^{2}$

are expected failure initiator distribution time nistories where the single subscripts imply the same kind of failure as described by the $\lambda$ 's, and the multiple subscripts imply failure initiator distributions for combinatorial failures of the initiators identified in the combination of subscripts, e.g.,

$F_{b^{2} c d}=1-e^{-\left(2 \lambda_{b}+\lambda_{c}+\lambda_{d}\right) t}$.
D. Sore Heat Pipe Development

A development progran is underway to produce core heat pipes for extracting energy from the reactor. Yet unanswered questions relate to the grade of materials, fabrication methods, types of wick structure, methods of bending, material transport and effects of impurities. The investigations now underway will lead to prototype units.

1. Heat Pipe Testing.

a. SPAR-1 Performance Testing (H. E.

Martinez, Q-13). Performance testing was completed on thr: SPAF-i heat pipe. The data is illustrated if. fig. 4. A wicking limit war defined as was an array of data points that describe a boiling limit. During the performance tests, it was determıned that after a dryout occurred rewetting could be accomplished in a few hours by running the heat pipe unloaded. Performance limits were, in general, higher after a relatively high-temperature, short time wet-in rather than a lower-temperature, long time wet-in. Because of the limited quantity of data generated, the rewetting time vs temperature characteristic could not be fully defined for the SPAR-i heat pipe.

In addition to the problem caused by the unsupported screen tube wick in the evaporator, as described below in the Core Heat Fipe Analysis section, it is believed that cxygen in the evaporator degraded the performance of the heat pipe. An attempt was made to hot trap the oxygen by concentrating the heat input very near the hafnium getter and ocerating the heat pipe at $1050 \mathrm{k}$ for 92 hours. The development of a hot spot in the evaporator prevented the use of a higher hot trapping temperature. It is somewhat doubtful that $1050 \mathrm{~K}$ was high enough to hot trap the oxygen effectively.

After the attempted hot trapping operation, the heat oipe was returned to its original configuration with a 300-ma evaporator. After running the heat pipe up to $1400 \mathrm{~K}$, helium was introduced into the calorimeter and it was found that the helium was leaking into the vacuun chamber. only $4 \mathrm{kN}$ of power could be extracted from the heat pipe before the pressure in the vacum chamber increased to a point were Rf arcing 


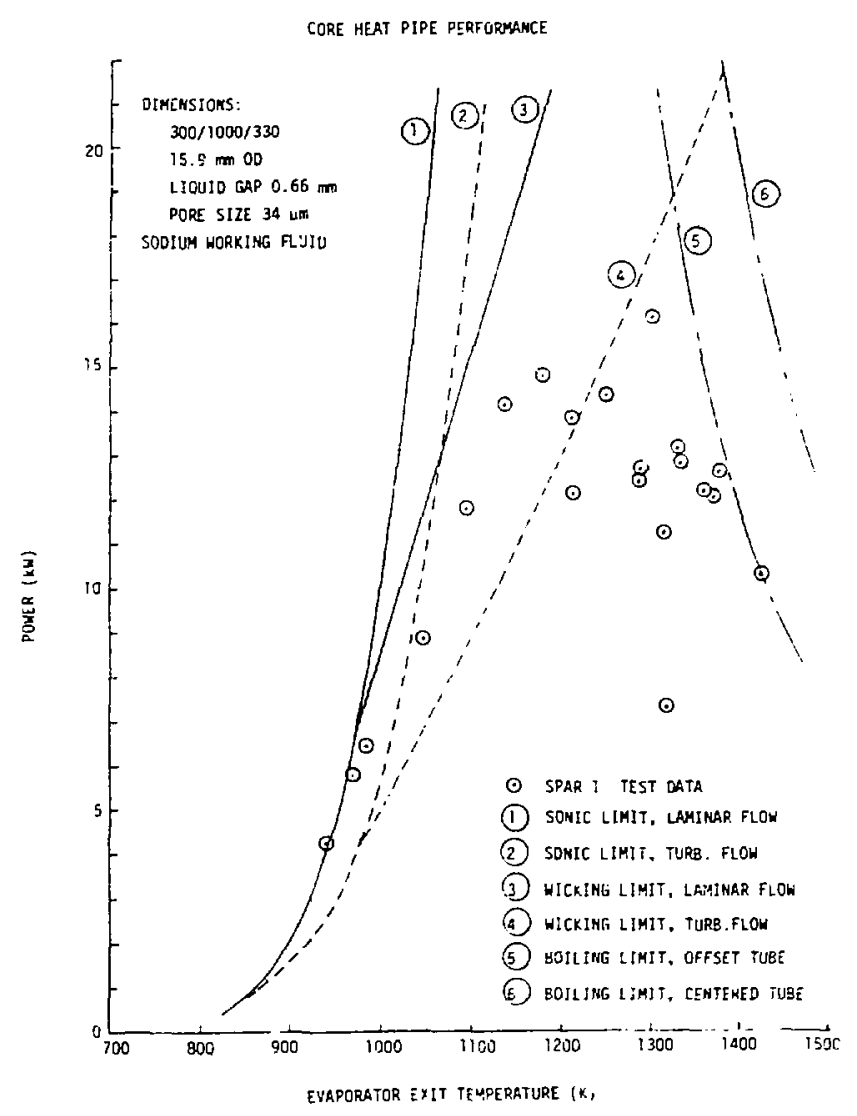

Fig. 4. Comparison between analysi.s and test for SPAR 1.

occurred. With the heat pipe at room temperature, the calorimeter was placed under 100 Torr of He pressure and it was deternined that there was no leak into the vacuum chamber; the leak occurred only at elevated temperature. Testing of SPAR-1 was suspended until the helium leak could be found and the problem corrected.

The heat pipe was removed from the vacuum changer arid the calorimeter removed from the heat pipe. Because of the close radial gap (.25 $\mathrm{mm}$ ), the heat pipe bonded to the calorimeter and during the disassembly the heat pipe galled and a small hole was gouged into the condenser. The heat pipe was then placed in a quartz tube, evacuated and heated with an RF power supply. It was found that the heat pipe was leaking sodium at the location of the gouge in the condenser section. The heat pipe was removed from the quartz tube, the cover tube and fill tube cut of $f$ and the pipe placed in a container tube and accumulition pot. The assembly was then placed in a furnace where the sodium was distilled out of the heat pipe.

$$
\text { b. SPAR-1 Post iest Diagnostics (H. E. }
$$

Martinez, L. Lundberg, L. Geoffrion, Q-13). SPAR-1 was damaged while it was being extracted from its calorimeter. During the high-temperature heat pipe tests it appears that a small area of diffusion bonding developed between the stainless steel calorimeter and the molybderum heat pipe. A small nodule of what was probably a mixture of molybdenum and stainless steel developed at this site. The initial bond between the heat pipe and calcrimeter was easily broken during the removal of the pipe from the calorimeter. However, the nodule stuck to the inside of the calorimeter and gouged the side of the heat pipe creating a longitudinal crack in the molybdenum containment tube. 
Upon reheating the heat pipe, sodium was observed leaking out of the crack.

After the tube failure was detected, the sodium was rerroved from the hrat pipe and the fiil end-cap was cut off. The screen tube was removed intact from the container tube, but inree longitudinal cracks were observed near the middle of the screen tube in the adiabatic section. Two of these cracks can be seen in Fig. 5. The cause of the cracks is unknown at this time but they appear to have been caused by an internal over-pressure because the area immediately surrounding the crack was expanded outward. A 60-mm-long dent that had previously been observed in radiographs was alsc Fourio in the screen tube about $80 \mathrm{~mm}$ from the fill-tube (condenser) end of the heat pipe. The cause or causes of thi: damage is not presently known. Butble-point porosity measurements on the screen tube revealed the presence of several longitudinal cracks. These measurements also revealed that the screen tube plug had lost its tight seal and had developed a leak determined to have a diameter of $120 \mu \mathrm{m}$. This $120 \mu \mathrm{m}$ leak was probably caused during disassembly. Analysis showed that such a large leak would have prevented the pipe from operating at the power levels achieved.

The containcr tube was split longitudinally, and no superficial evidence of attack by the hot sodium was found. The crack that caused the heat pipe to leak is clearly detectable inside the pipe. Metallographic and chemical analyses will be performed on all of the heac pipe components.

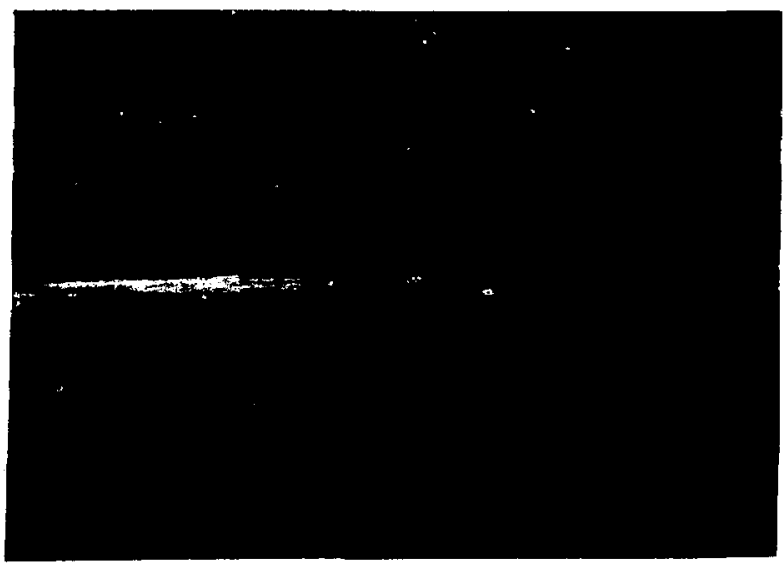

Fig. 5. Middle of SPAR-1 molybdenum screen tube.
2. Core Heat Pipe Analysis ( $F$. C. Prenger, Q-13). A comparison between the data obtained fron the SPAR-1 tests and the results of the performance analysis from the heat pipe computer code has been made. Figure 4 shows the performance limits obtained from the tests along with the predicted wicking, sonic, and boiling limits for both laminar and turbulent vapor flow. The predicted wicking limits are based on a wick pore size of $46 \mu \mathrm{m}$ as determined fiom a no-load tilt test of the heat pipe.

The decrease in measured performance at tenperatures above $1250 \mathrm{~K}$ is indicative of boiling at the heat pipe wall. The resulting vapor formation in the liquid return passage causes evaporator dryout. Curve 5 in Fig. 4 represents the boiling limit as a function of temperature and is based on the experimental data. Since SPAR-1 contains an unsupported screen wick, the liquid layer is thicker on one siuje of the wick. By centering the screen wick, the maximum liquid lay thickness can be reduced and the boiling limit raised. For the same size nucleation site, Curve 6 of Fig. 4 shows the boiling limit for the centered wick configuration. This technique has been used in the fabrication of the next molybderum core heat pipe, SPAR-1A.

The wicking limits observed below $1250 \mathrm{~K}$ are bracketed between the laminar and turbulent flow predictions. Additional analysis of these limits will await pore size measurements of the screen wick after disassembly of the heat pipe.

Use of an artery configuration is expected to elimina', the boiling limitation observed with the annular wick design. By collecting the liquid in discrete locations around the circunference of the heat pipe, large temperature drops across the liquid layer are avoided. Figure 6 shows a performance map of a two-artery heat pipe as a function ef temperature and screen thickness. The screen thickness for bath the arteries and the distribution wick are optimin at $0.5 \mathrm{~mm}(0.012$ in.). If the screen thickness is too large, the vapor flow area is reduced excessively; wherees, if the scr $\Rightarrow$ is too thin, the circumferential pressure drop in the distribution wick increases. Consideration of these two effects dictate an optimm screen thickness. 


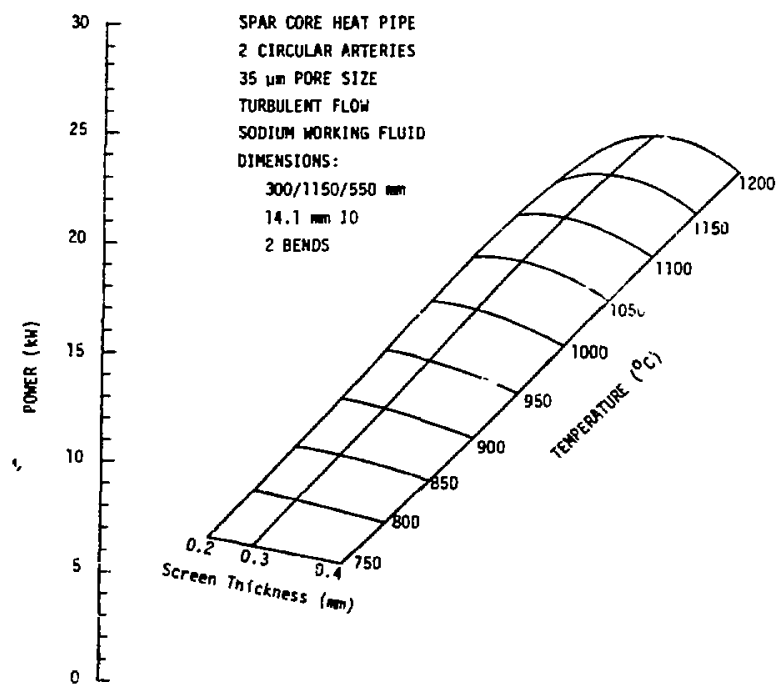

Fig. 6. Performance map of two-artery heat pipe for SPAR.

3. Heat Pipe Fabrication.

a. SPAR-la Fabrication and Assembly ( $L$. A. Geoffrion, H. E. Martinez, Q-13). SPAR-la was fabricated in an attempt to improve upon the performance limits of SPAR-1. SPAR-1 was limited by a relatively low boiling limit due to the screen tube wick not being centered in the evaporator. The screer, tube of SPAR-la was centered in the evaporator by spiral wrapping six turns of $0.3-$ ran- $\phi$ molybderum wire around the evaporator end of the screen tube. That the molybdenum wire produced a centered screen tube and a uniform sodium gap in the evaporator was verified by radiography.

After end cap welding, the heat pipe was outgassed at $675 \mathrm{~K}$ and loaded with an overfill of sodium. This was accomplished through the use of a calibrated loading pot that was filled with sodium from a canister driven by argon cover gas. The calibrated loading pot was drained into the heat pipe by a gravity head. A closure valve on the heat pipe fill tube was closed before all the sodium drained from the loading pot to make a sodium plug and prevent gas from entering the pipe.

The heat pipe was placed in a quartz tube, evacuated and heated with an RF power supply, thus distributing the sodium in the screen wick and filling the annulus of the heat pipe. After the quantity of sodium was measured on an analytical balance, most of the excess was removed by fitting a dump tank to the closure valve, evacuating the tank and allowing the excess to fill the tank. A small quantity of excess was left in the heat pipe so that it could be used on cold trapping the impurities and improve the performance of the heat pipe.

\section{b. Core Heat Pipe Bending Experiments}

(J. Runyan, N. Montoya. Q-1.3). It is advantageous from a fabrication stanopuint to make the two $90^{\circ}$ bends in a $2-m$ core heat pipe after it has been assembled. Two "bend test" heat pipes $16 \mathrm{~mm} \phi$ and $300 \mathrm{~mm}$ long with annular screen tube wicks were fabricated. They were completely filled with sodium and bent at $365 \mathrm{~K}$ so that the solid sodium could give support to the wick during bending. The $365 \mathrm{k}$ bend temperature was used because it allowed the maximum molybdenum ductility and yet kept the sodium soiid. The first "bend test" pipe had a stainless steel tube so that any possible problems that could arise from the bending of a molybdenum tube would be eliminated. Post test examination showed no change in porosity from the $31 \mu \mathrm{m}$ pretest value. Bending caused small buckles of uniform distribution to form along the compression (inner) side of the bend as seen in Fig. 7. Longitudinal ridges that originated during the swaging operation of wick fabrication were

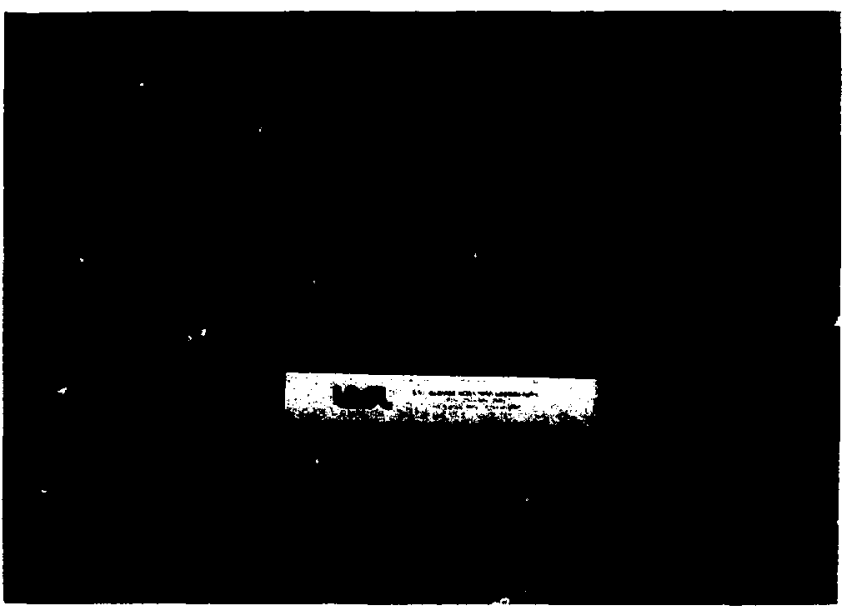

Fig. 7. Bent heat pipe stainless steel ervelope sectioned to reveal molybdem screen wick. 
amplified. Both the small buckles and the amplified longitudinal ridges are believed to be acceptable, although testing of a bent heat pipe is requirer before a final judgement can be made.

The second "bend test" heat pipe was identical to the first except that it used a molybdenum tube instead of a stainless steel tube. After bending, the screen tube wick was pushed out of the molybdenum tube. The buckles were relatively large and spaced about $50 \mathrm{~mm}$ apart. The porosity had ilicreased from $28 \mu \mathrm{m}$ before the bend to $49 \mu$ in after the benc. Microscapic examination of the surface of the screen tube at the point of maximum norosity showed that the screen tube was relatively smooth and polished in that region. This is indicative of excessive, localized rubbing contact betwe the wick and molybdenum tube. It appears that the small buckles, which occurred at about $5 \mathrm{~mm}$ intervals in the first bend test, caused relatively slight rubbing contact between wick and heat pipe tube at any given spot on the wick. During the second test, the buckles were re tively few and large, accurring in $50 \mathrm{~mm}$ intervals with excessive rubbing contact at these points. Increases in porosity occurred at nearly all of the points of excessive rubbing contact during the second test.

The cause of the excessive rubbing contact is not completely understood. Pre-bend radiographs showed that the screen tube wick was well centered in the stainless steel tube of the first test. The screen tube in the second test was in contact with the wall at one end before bending. Future bend tests will be directed toward ascertaining the importance of wick centering on detrimental rubbing contact and the attendant porosity increase.

c. Screen Tube Fabrication (L. B. Lundberg, L. A. Geoffrion, Q-13; J. Dickinson, $W$. Doty, S. Armstrong, (MB-6). Two 2-m-long screen tubes (MOST 9 and 10) were made of 150-mesh molybderum screen and swaged at CMB-6 in a two-jaw chuck swaging machine. After sintering, these screen tubes showed detrimental longitudinal cracks. In an effort to eliminate cracking, a small piece of MOST-11 was swaged at CMB-6 using two passes. The 21.3-mm- sheath and screen tube assembly was first swaged in a 20.6-mm die and then a 15.1-m die. The swaging was performed from both ends. After siatering, MOST-il also showed detrimental longitudinal cracks.

The remaining length of MOST-11 and MOST- 12 were sent to opk for swaging in a four-jaw chuck swaging machine. The four-jaw chuck projuces a more gentle and even swage. These screen tubes have been sintered. The porosity of MOST-12 is 33 $\mu \mathrm{m}$ overall. There is sufficient length at one end to allow the fabrication of a heat pipe with an evaporator of $20 \mu \mathrm{m}$ porosity.

\section{d. Production of Fine Molybdenum Screen}

(L. B. Lundberg, Q-13). An effort to produce a molybdenum screen that has a 325 mesh or finer for use in the development of an artery wick is continuing. A sample of the $25-\mu m$ low-carbon, arC-cast (LCAC) molybdenum wire we received last quarter has been evaluated by a wire mesh weaver to estimate the finest mesh into which it can be woven, and it has been concluded that there is a high probatility of success in the production of 325 mesh screen from this wire. An order has been placed for a few square meters of this screen.

4. Core Heat Pipe Artery Wick Development (K. L. Meier, Q-15; J.R. Runyan, Q-13). Tests performed on the screen-tube-wick core heat pipe SPAR-1 confirmed the existence of a boiling limit that prevents the pipe from reaching its design parameters of $15 \mathrm{kw}$ at $1400 \mathrm{k}$. The boiling limit can be increased substantially by using an artery wick. Several alternative wick designs were evaluated. They are shown in Fig. 8 . The self arteries require compound bending and simultaneous formation of both arteries and distribution wick. This type was considered more difficult to fabricate than the other types that allow separate fabrication of artery and distribution wick. Because these wicks must be bent, it was deemed wise to have the arteries only on the neutral bending axis to minimize tension and compression damage to the arteries. The design chosen for initial testing is number 5 and is shown in greater detail in Fig. 9. It consists of two 1.5-mm-i.d. alteries placed on the neutral bending axis. The arteries will be spot welded to the screen tube distribution wick. The molybdenum heat plpe tube is drawn down over the distribution 


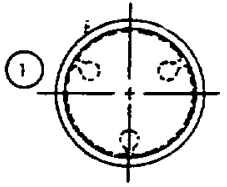

HICK HITH 3 SELF ARTERIES

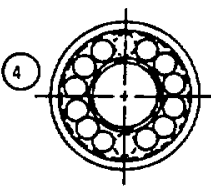

SPACER TUBES

ETCHEO OUT

AFTER SINTER]NG

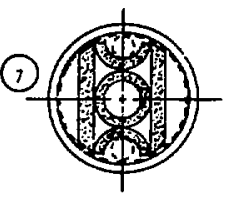

2 ARTERIES

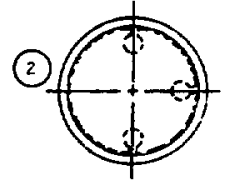

3 SELF ARTERIES,

2 ON NEUTRAL AXIS OF BEND, 3rd OH TENSIOH

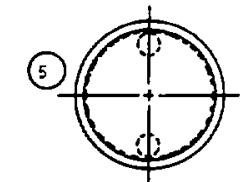

2 ARTERIES OH MEUTRAL AXIS OF DEND; $\mathrm{Al}_{2} \mathrm{O}_{3}$ TLFPORARY SPACERS FOR ASSEMELY

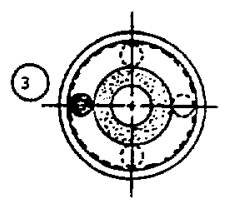

TWO A1 ${ }_{2} \mathrm{O}_{3}$ SPACER

FOR SIKTERING;

TERPORARY SPACES

FOR ASSEMBLY
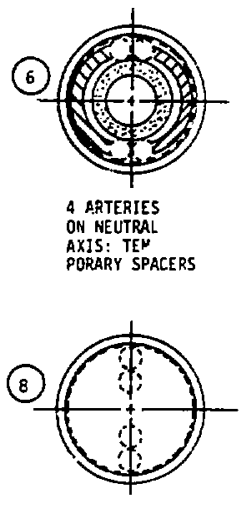

4 ARTERIES

Fig. 8. Possible artery configurations and positioning techniques.

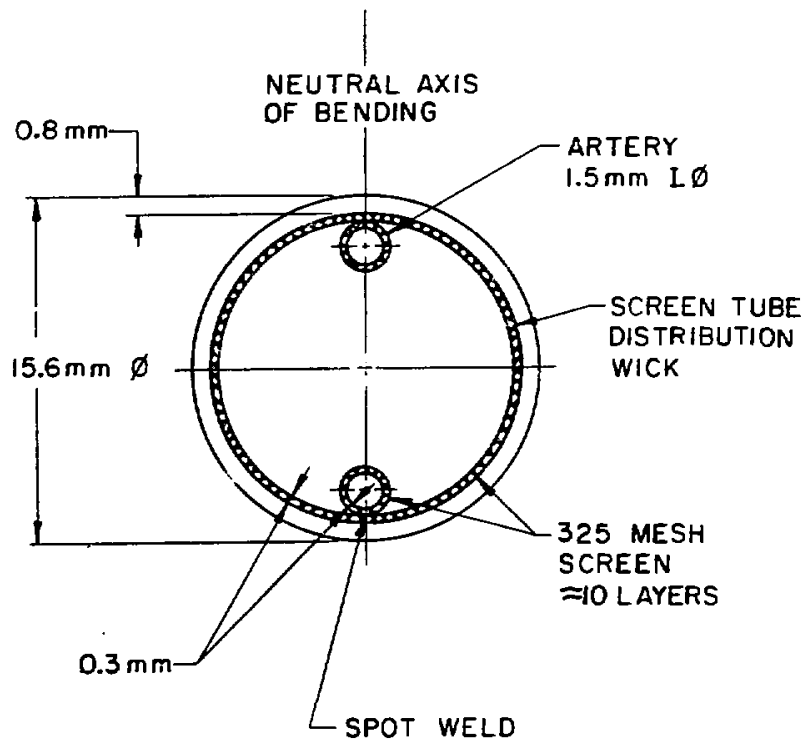

Fig. 9. Core artery heat pipe design. 
wick to make intimate contact. Both the arteries and distribution wick will be fabricated from 325 or 400 mesh molybdenum screen by wrapping several layers over a carbon steel mandrel. The wrapped screen will be inserted into a carbon steel sheath and the assembly drawn or swaged to compress the screen layers. The mandrel and sheath will be dissolved in HCl and the screen tubes sintereo. The arteries will be spot welded to the distribution wick, if the welds do not increase pore size. CVD is an alternate joining scheme if spot welding destroys the wick porosity. The arteries will be on the neutral axis of bending and will not he affected to any great extent by the two $90^{\circ}$ bends of the heat pipe.

Development of the artery wick has begun. Four layers of 150-mesh molybdenum screen (currently in stock) $40 \mathrm{~cm}$ long were hand-wrapped over a 1.5-mm- $\phi$ mandrel and inserted in a carbon steel sheath. Half of the assembly was drawn with an $0 . d$. reduction of $11 \%$. The other half was swaged to an o.d. reduction of 16\%. The sheath and mandrel were dissolved. Microscopic examination of the arteries showed that there was compaction of the screen and no apparent damage. Experiments with these arteries are currently proceeding to measure porosity and to develop sintering, and spot welding techniques. The following encouraging results are known at this time: (1) Arteries can be hand-wrapped without the need of a special machine. (2) Drawing and swaging do not damage the screen or the artery. (3) The $16 \%$ swage appears visually to be a good technique to fabricate a compact screen tube artery.

\section{Materials Technology.}

a. Molybdenum Corrosion Experiments ( $L$. B. Lundberg, L. A. Geoffrion, Q-13; D. Schell, A. Patterson, (CMB-6). Experiments designed to measure the compatibility of sodium or lithium with molybdenum and $\mathrm{TZM}$ in the presence of $\mathrm{UO}_{2}$ are being conducted. The compatibility capsules have $\mathrm{UO}_{2}$ rods of near stoichiometric composition sealed in a tube of the metal, molybdenum or TZM, surrounded by sodium or lithium in a molybdenum refluxing tube.

Uranium dioxide powder, which will sinter to a high density, has an average particle size of less than $1.5 \mu \mathrm{m}$. Unfortunately, if the oxygen content or the $\mathrm{UO}_{2}$ powder is near stoichiometry the powder is pyrophoric and difficult to handle. A super-sinterable-ceramic-grade stable urania powder with a stoichiometry of $\mathrm{UO}_{2.1}$ was obtained from CMB-8 for use as a starting material.

Rods were extruded irom this powder and sintered in hydrogen to produce high density $\mathrm{UD}_{2}$. The hydrogen sintering operation was expected to lower the oxygen content to provide rods of near $\mathrm{UO}_{2.0^{\circ}}$ Samples of the sintered rods have been submitted for cnemical analysis to determine the uranium-to-oxygen ratio.

The rods were ground so as to leave a 0.1-min clearance between their diameters and the diameters of the metal tubes being tested. The rods were placed in the molybdenum and TZM tubes with end caps electron bean welded to seal the tubes under vacuum. Thiese tubes were then placed in larger molybdenum tubes which were closed by electron beam welding leaving a small molybdenum tube extending from one end for use in filling the annulus with sodium or lithium. The fabrication and welding operations have been successfully completed and the assemblies are ready to fill.

$$
\text { b. Molybdenum Alloy Study (L. B. }
$$

Lundberg, Q-13). The evaluation of molybdenum and its alloys for use in the core heat pipes continued. The preliminary results of a study were presented to DOE with the recommendation that molybderium-rhenium alloy development commence. Some additional data has been found on the effect of strain rate on the ductile-brittle transition temperature (DBTT) for pure molybderum. ${ }^{1,2}$ These data are plotted in Fig. 10 on a log-log scale to illustrate the relatively good fit of the

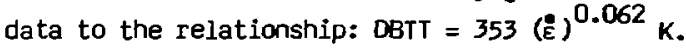
It should be noted that this relationship fits the data better than the fits proposed in either reference.

A more detailed examination of the published data on the effect of Ihenium content on the room temperature mechanical properties of molybderumrhenium alloys revealed a most surprising fact. The data from both electron beam and arc melted Mo-Re alloys plotted in Fig. 11 indicate the existence of a pronounced ductility peak between 10 and 15 wt\% rhenium. It is significant that this is precisely the rhenium content range for 


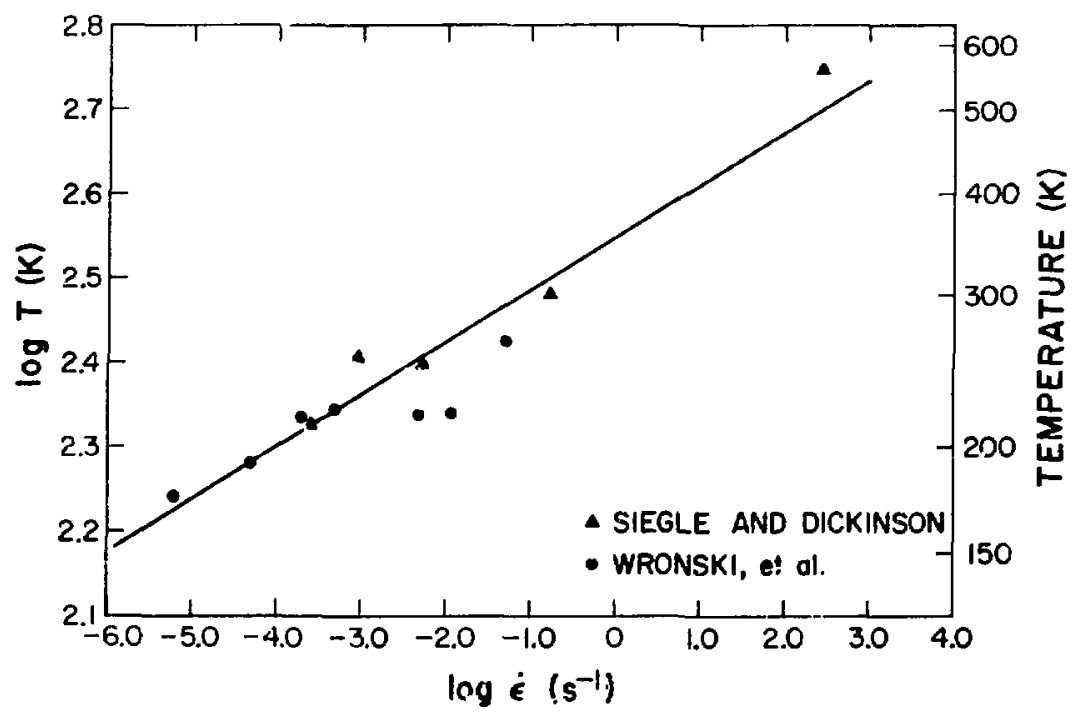

Fig. 10. Effect of strain rate on tensile DBTT of molybdenum.

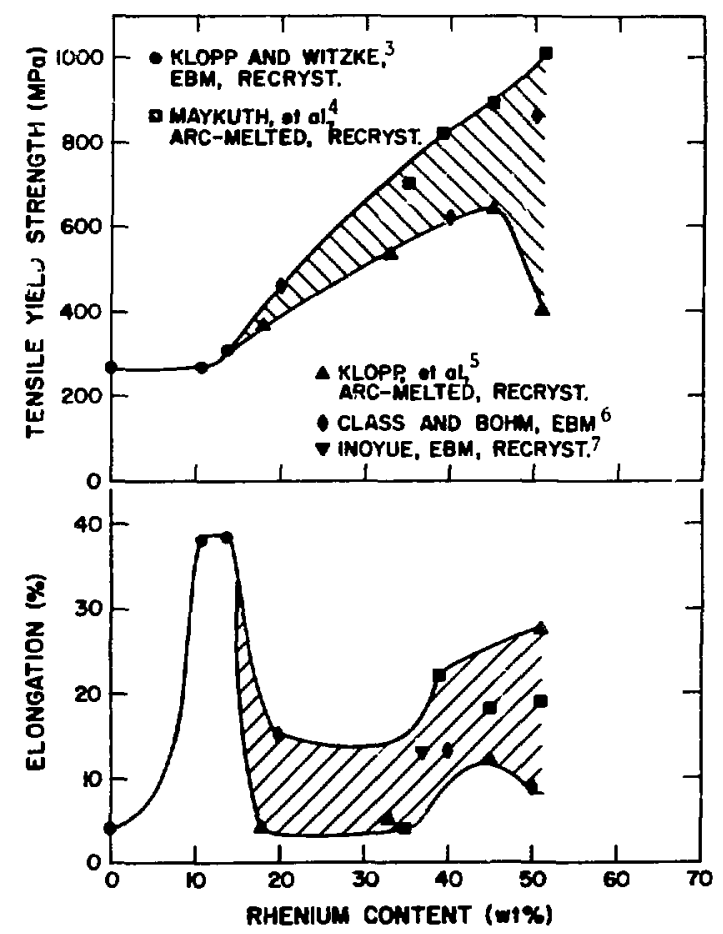

Fig. 11. Room temperature mechanical properties of melted Mo-Re alloys. maximum softening observed experimentaily 8 ano explained on the basis of alloy electron concentration. 9

A report of this evaluation has been drafted and will be published soon. Plars are being formulated to proceed with the p: Juction of wire, tubing, and rod from a Mo-13 wty Re alloy ingot prepared by electron beam melting.

E. Radiator Development

1. Materials.

a. Meteoroid Impact Studies (S. P. Girrens and L. B. Lundberg, Q-13; S. J. Bless, UDRI). Impact testing of radiator materials at the University of Dayton Research Institute (UORI) is complete and confirms ur choice of titanium for the radiator. Dr. Stechen Bless, the principal investigator, presented final results from the impact study at. ASL on July 25 anc: issued a draft of the final report for review. Hypervelocity penetration and perforation data were obtained for titanium and high purity beryllium at $293 \mathrm{~K}$ and $773 \mathrm{~K}$. Titanium targets investigated include Grade 2 titanium and alloys Ti-5Al-2.5Sn and Ti-6Al-2Sn-4ZI-2Mo. Inpacted target samples are currently undergoing metallographic examination at LASL. 
Data obtained from impacts on thick targets was used to substantiate the penetration relationship

$$
\rho=\left(\frac{81 \rho_{p} E}{4 \pi \mu_{t} S_{t}}\right)^{1 / 3} \text {, }
$$

where $E, \rho_{p}, o_{t}$ and $p$ are projectile energy, projectile density, target density and crater depth respectively. The crater volume data, summarized in Table I, spans two orders of magnitude in projectile energy and was used to determine the target material strength parameter, $\mathrm{S}_{\mathrm{t}}^{1 / 3}$. For Be at $293 \mathrm{~K}, \mathrm{Ti}$ and $\mathrm{S}_{\mathrm{t}}^{1 / 3}=$ 3.82 and 4.59 respectively; for $T 1$ and Be at 773 $\mathrm{K}, \mathrm{S}_{\mathrm{t}}^{1 / 3}=3.20$ and 3.64 respectively, where $\mathrm{s}_{\mathrm{t}}^{1 / 3}$ units are $\left(\mathrm{J} / \mathrm{mm}^{3}\right)^{1 / 3}$.

Perforation data at $773 \mathrm{~K}$, presented in Table $I$, established the validity of predicting the threshold penetration thickness (TPT) based on thick target response with the relation

$$
\mathrm{TPT}=1.5 \mathrm{P} \text {. }
$$

Impact cratering in titanium was ductile while cratering in beryllium was characterized by britrle fracture as evidence : by extensive surface spall and radial cracking. The two titanium alloys tested were both more resistant to hypervelocity penetration than was pure titanium.

The results of the experiments can be used to predict the TPT for meteoroid encounters. Typical damaging micrometeoroid energies are a few joules, which is at the low end of the range of energies investigated. For $773 \mathrm{~K}$ titanium, the TPT in $\mathrm{mm}$ foi a particle of mass ( $m$ in $\mathrm{mg}$ ) traveling at 20 $\mathrm{km} / \mathrm{s}$ is given by:

$$
\text { TPT }=2.44 \mathrm{~m}^{1 / 3}(\mathrm{Ti})
$$

For $773 \mathrm{~K}$ beryllium, the corresponding equation is:

$$
\text { TPT }=2.99 \mathrm{~m}^{1 / 3}(\mathrm{Be})
$$

Though the TPT relations for titanium and beryllium are comparable and the density of beryllium is much lower than the fensity of titanium, beryllium would be unsuitable for a hect pipe material because of its brittle behavior.

b. Emissivity Coating for Titanium (S. P. Girrens, Q-13). During recent discussions with representatives from $\mathrm{PL}$, another candidate nigh emissivity coating for titanium was suggested. The coating, RADIFRAX RC-356 (iron titanate), retains a totai hemispherical emittance greater than 0.85 at temperatures up to $1120 \mathrm{~K}$ in a vacuum equal to or better than $10^{-5}$ torr range. Two $\mathrm{CE}$ specifications cove $e_{\perp}$ in the formulation and application of RADIFRAX emissivity coating to íitanium have veen obtained. This coating will be applied to prototype radiator heat pipes for thermal ano adhesive performance testing.

c. Titanium-Potassium Compatibility ( $L$. B. Lundberg and J. A. Romero, Q-13). The experimental program to determine the compatibility of Grade 2 pure titanium with potassium continues. The heat pipe operating times and conditions are listed in Table III. No failures have been encountered.

2. Facilities (K. L. Meier, Q-15; H. E. Martinez, L. Vikdal, Q-13). All the parts for the test chamber to test the 5.5-m-long titanium heat pipe are at UHTREX. The assembly of the chamber is about one-third complete. Further assenbly work was suspended due to program realigrment. Resumption of chamber assembly and 5.5-m titanium heat pipe testing will be performed only on a time available basis.

The 6.1-m, 13-cm- $\phi$ processing furnace at UHTREX was fabricated. It has been tested successfully at temperatures up to $1100 \mathrm{~K}$. The furnace is now being used to fill a molybdenum heat pipe for the NEP program with Iithium. It will later be used to wet-in the NEP heat pipe, fill the 5.5-m titanium heat pipe, and wet-in the titanium pipe.

REFERENCES

1. L. L. Siegle and C. D. Dickinson, "Effect of Mechanical and Structural Variables on the Ductile-Brittle Transition in Refractory Metals," in Refractory Metals and Alloys II (Met. Soc. conferences, Vol. 17) M. Semcinyshen and I. Perlmutter, Eds., Interscie ce Publishers, New York (1963) p 65. 
TABLE I

SUMMARY OF CRATER VOLUME DATA

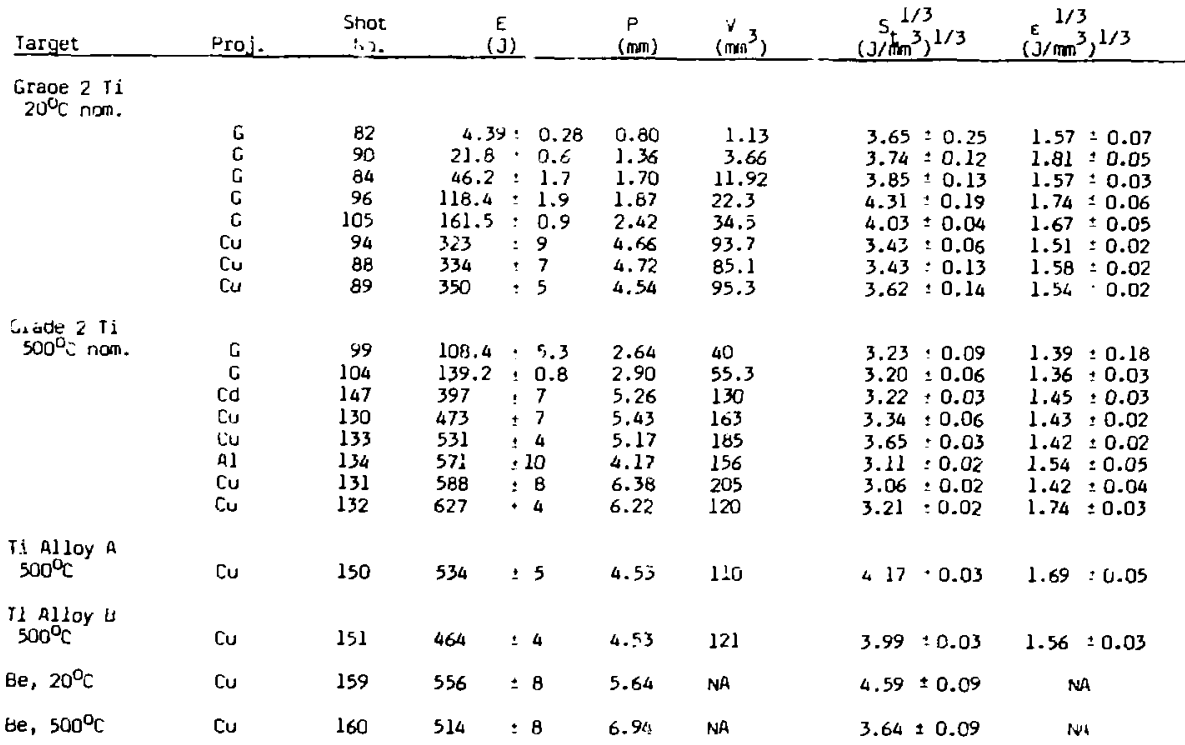

TABLE II

DATA FOR THIN TARGETS

\begin{tabular}{|c|c|c|c|c|c|c|}
\hline Target & $\underset{[\mathrm{mm})}{\mathrm{D}}$ & $\stackrel{T}{\left({ }^{\circ} \mathrm{C}\right)}$ & Shot & d* & $(\mathrm{km} / \mathrm{s})$ & Result \\
\hline Grade 2 Titanium & & 20 & 95 & 1.0 & 6.13 & pin hold perforation \\
\hline & 7.24 & 500 & 136 & 1.59 & 6.59 & perforation \\
\hline & 3.94 & 500 & 137 & 1.42 & 6.60 & spall, no perforation \\
\hline & 8.25 & 500 & 141 & 1.59 & 6.70 & perforation \\
\hline & 3.56 & 500 & 142 & 1.4 & 6.30 & no spall, no perforation \\
\hline $45^{\circ}$ & 3.94 & 500 & 143 & 1.4 & 6.80 & $\begin{array}{l}\text { penetration, symetric } \\
\text { crater }\end{array}$ \\
\hline & 3.56 & 500 & 144 & 1.4 & 7.12 & perforation t spall \\
\hline $\begin{array}{l}0.66 \mathrm{~mm} \text { shot blasted } T i \text {, bonded } \\
\text { to } 3.22 \mathrm{~mm} \text { grade } 2 \mathrm{Ti}\end{array}$ & 3.96 total & 500 & 152 & 1.4 & 6.0 & $\begin{array}{l}\text { spalled off surface plate } \\
\text { spalled rear of backplate }\end{array}$ \\
\hline $\begin{array}{l}\text { Zincorthotitanate coated Ti } \\
.55 \mathrm{~mm} \text {, bonded to } 9.5 \mathrm{~mm} \text { substrate }\end{array}$ & 10.2 total & 20 & 154 & 1.4 & 6.59 & $2.15 \mathrm{rm}$ total penetration \\
\hline $\begin{array}{l}\text { D-111 emissivity coating } T i, 56 \mathrm{~mm} \\
\text { bonded to Ti substrate } 9,5 \mathrm{~mm} \\
\text { shot blasted grade } 2 \mathrm{Ti}\end{array}$ & $\begin{array}{l}10.2 \text { total } \\
0.56\end{array}$ & $\begin{array}{l}20 \\
20\end{array}$ & $\begin{array}{l}156 \\
158\end{array}$ & $\begin{array}{l}1.5 \\
0.5\end{array}$ & $\begin{array}{l}6.60 \\
7.17\end{array}$ & $\begin{array}{l}p=2.29 \mathrm{~mm} \text { total } \\
\text { perforation } 1.5 \mathrm{~m} \text { dia. }\end{array}$ \\
\hline
\end{tabular}

"Proj. material 0.5, 1.0, 1.4-glass, 1.6 - copper. 
TABLE II I

TITANIUM/POTASSIUM CURROSION EXPERIMENTS

$$
\text { Sample No. }
$$

$\longrightarrow$

Tik-1

Tik=?

\begin{tabular}{l}
$\begin{array}{l}\text { Time } \\
\text { (h) }\end{array}$ \\
\hline 3800 \\
2500
\end{tabular}

2500
Temp

(K)

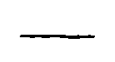

795

895

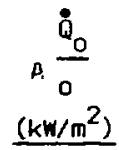

27

87

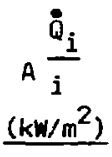

18

175

2. A. S. Wronski, A. C. Chilton and E. M. Capron, "The Ductile-Brittle Transition in Polycrystalline Molybdenum," Acta Met., 17 (1969) 751-55.

3. W. D. Klopp and W. R. Witzke, Mechanical Properties of Electron-Beam-Melted Molybdenum and Dilute Molybdenum-Rhenium Alloys," Lewis Research Center Report No. NASA TM X-2576 (June 1972).

4. D. J. Maykuth, F. C. Holden and R. I. Jaffee, "The Workability and Mechanical Properties of Tungsten-and-Molybdenum-Base Alloys Containir.g Rhenium," in Rhenium, B. W. Gosner, Ed., Elsvier Publishing Co., New York (1962) 114-125.

5. W. D. Klopp, F. G. Holden, and R. I. Jaffee, "Further Studies on Rhenium Alloying Effect in Molybdenum, Tungsten and Chromium," Battelle Memorial Inst: tute Report to Office of Naval Research on Contract $\mathrm{N}-1512(00)$ (July 12, I960).

6. $\hat{i}$. Von Class and G. Böhm, "Technical Properties and Durability of Some Technically Promising Molybdenum-Rhenium Alloys, "Planseeberichte für Pulvermetallurgie, 10, 3 (1962) 144-167.

7. H. Inouye, "Impact Behavior of Mo and Mo-Re Alloys," in Technical Highlights of Space and Terrestrial Systems Programs at 0ak Ridge National Laboratory for February 1980, from $A$. C. Schaffhauser to Distribution (April 18 , 1980) p 16.

8. J. R. Stephens and W. R. Witzke, "Alloy Softening in Group VIA Metals Alloyed with Rhenium," J. of Less Common Metals, 23 (1971) pp 325-342.

9. J. R. Stephens and W. R. Witzke, "Alloy Hardening and Softening in Binary Molybdenum Alloys as Related to Electron Concentration, J. of Less Common Metals, 29 (1972) pp 371-388.

\section{PLBLICATIONS}

D. Buden, "Assessment of the Need for Space Nuclear Electric Power," presented at the 15th Intersociety Energy Conversion Engineering Conference, Seattle, WA, August 18-22, 1980.

W. A. Ranken, "Experimental Results for Space Nuclear Power Plant Design," presented at the 15th Intersociety Energy Conversion Engineering Conference, Seattle, WA, August 18-22, 1980.

L. B. Luncherg and H. E. Martinez, "Fabrication of High-Temperature (1400-1700 K) Molybdenum Heat Pipes," presented at the 15th Intersociety Energy Conversion Engineering Conference, Seattle, WA, August 18-22, 1980 .

K. C. Cooper and R. G. Palmer, "System Trade offs in Space Reactor Design," presented at the 15th Intersociety Energy Conversion Engineering Conference, Seattle, WA, August 18-22, 1980.

K. L. Meier, S. P. Girrens, and J. M. Dickinson, "Titanium Heat Pipes for Space Power Systens," presented at the 15th Intersociety Energy Conversion Engineering Conference, Seattle, wA, August 18-22, 1980.

J. M. Dickinson, L. B. Lundberg, R. A. Patterson, and W. H. Zimmer, molybdenum Heat Pipes for a Space Power Source," presented at the 1980 TMS-AIME Fall Meeting, oct. 6-10, 1980, Pittsburgh, PA. 
II. REACTOR SAFETY: GAS-COOLED FAST REACTOR SAFETY EXPERIMENTS

A. Executive Summary (D. L. Harison, Q-13)

The Gas-Cooled Fast Roactor (GCFR) program in the US is phasing out. At LASL, work on the GCFR Low Power Safety Experiments (LPSE) is now concentrated on completion of the third 37-rod Full Length Suogroup test (FLS-3) prior to preparation of a înal report and program closeout in FY-81. This FLS- 3 test series is the first in which the rod bundle will be operated as a component of a large ( $10 \mathrm{~m}$ hiyl by $2 \mathrm{~m}$ wide) wiping circuit. This will provide the first out-of-pile simulation of the dispersion of decay heat in the GCFR structure by natural convection after a loss of coolant accident or during the refueling process.

Analyses have been performed on the FLS-3 systen to assess piping stresses, the distribution of temperatures throughout the circuit (and their influence on system pressure), and to size the flow metering orifice for the forced flow phase of the test series. Two new types of instruments, (extreme sensitivity differential pressure transducers and a laser doppler velocimeter) nave been received, checkej out, and installed, and the system has been successfully operated, both in vacuum and at high pressure, for bakeout purposes. B. Program Plaming (D. L. Manson, Q-13)

Because of ine decision to phase out the federally supported GCFR programs, all work (design, procurement, etc.) on the LPSE program in direct support of the Steel Melting and Relocation Tests (SMART) has stopped. However, because all procurement for the FLS-3 system is complete and the circuit fully assembled, these tests will be conducted. This will allow us to realize the full benefit of these unique tests without incurring any significant additional costs. The FLS- 3 test results will be included in the LPSE program final report.

C. Analysis (0. R. Benrett, Q-13)

FLS-3 piping loop stresses were found to be within the capabilities of the material used. The most critically stressed nember of the loop is the heat exchanger (Fig. 12). The stresses in this menber will be controlled by limiting loop pressure to $6.6 \mathrm{MPa}$, by providing auxiliary support for its external loads, and by limiting preloads

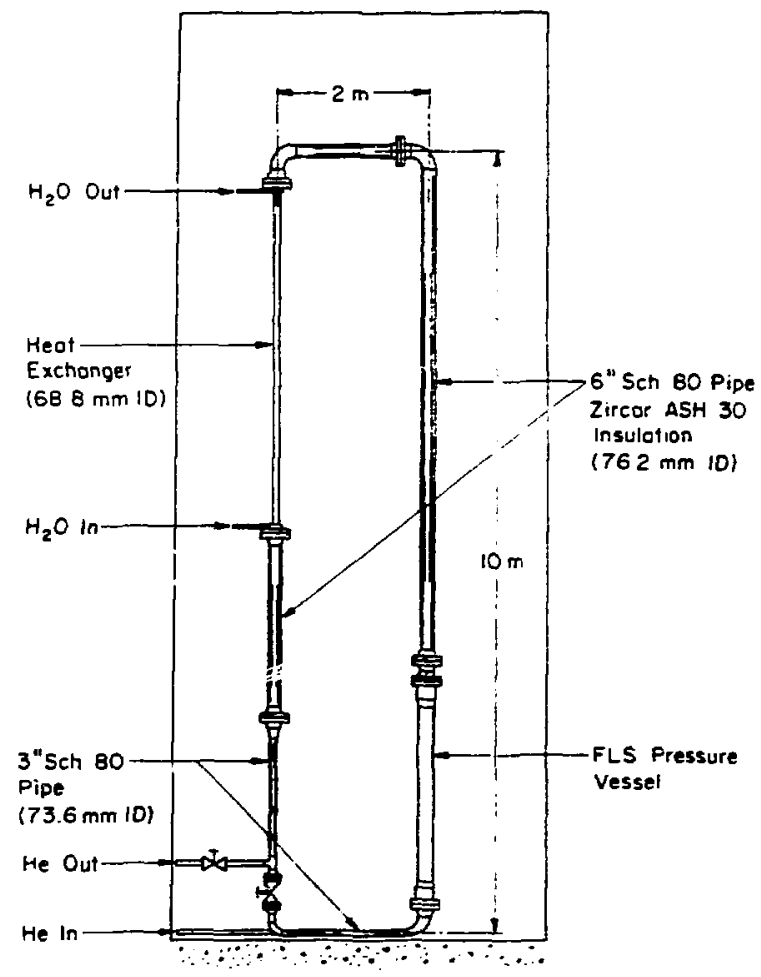

Fig. 12. FLS-3 test loop.

resulting from loop assembly. The Faulted Temperature Limit test and the Destruct Phases of FLS-3 require a constant mass flow on the order of 156 $\mathrm{kg} / \mathrm{h}(0.0092 \mathrm{lb} / \mathrm{s})$ of helium. Calculations made for this condition were influenced by the existence of a set of interchangeable choked-flow nozzles and instrumented orifice run. Assuming choked flow, a nozzle with throat diameter equal to $1.193 \mathrm{~mm}(0.047 \mathrm{in}$.) will be used with upstream pressure at $3.4 \mathrm{MPa}$ and back pressures ranging from 1.32 to $0.20 \mathrm{MPa}$.

volume-weighted temperature averages for the FLS-3 loop were used to determine initial pressurizations in the Natural Convection Test Phase. These temperatures were derived from analytical predictions of behavior of the FLS-3 system.

D. Procurement and Fabrication

1. FLS-3 (D. R. Bernett, J. Anderson, R. Ortega, C. Jeffifies, Q-13.)

a. Laser Dopoler Anemoneter. The 15-m helium-neon laser was received in mid August. Extensive work has been done to determine the 
effect of flow conditions on the output signal of this instrumert. Two fused-quartz windows (50 mm diam. by $13 \mathrm{~mm}$ iinick) have been inserted into specially-fabricated ports, Iesulting in a 25-mmdiam viewing area. The diametrically opposing ports have been welded to the 75-mm-diam leg of the FLS-? loop.

b. Differential Transducers. The MKS differential pressure transducers ordered in early January arrived in mio-September. The protracted delivery was due to difficulties in producing the two, 0-1 tor I range diaphragm transducers. Numerous failures of these transducers in the MKS calibration lab led to the delayed receipt of these high precision instruments.

E. Assembly, Installation, and Checkout 1. FLS-3 (D. R. Bennett, J. Anderson, R. Ortega, C. Jeffries, Q-13; J. Miller, E-2). a. FLS-3 Test Package. The FLS-3 37-rod bundle was instrumented and assembled with the hexagonal ZIRCAR (fibrous alumina, $480 \mathrm{~kg} / \mathrm{m}^{3}$ ) insulation. The test assembly was then installed into the inverted FLS pressure vessel that had been previously modified to allow for upflow convective conditions.

$$
\text { b. FLS-3 Piping Loop. The installation }
$$
of the test package in the FLS pressure vessel was followed by completion of the connecting FLS-3 piping. loop (Fig. 12). The loop had already been insulated where necessary with a less dense ZIRCAR insulation $\left(320 \mathrm{~kg} / \mathrm{m}^{3}\right)$. Initial problems with leakage at pipe joints upon pressurization were solved as indicated by the final leakage rate of the system (on the order of $0.4 \% / \mathrm{h}$ ). Plumbing and electrical connections were made with little difficulty.

The quartz viewing ports for the laser anemometer were installed on the 75-mm-diam leg of the loop, along with a support system for the laser and the transmitting/receiving optics. Component alignment is crucial to the successful use of the laser anemometer, and the support has theref: re been attached to the piping in an attempt to maintain this alignment during thermal expansion of the piping.

\section{c. FLS-3 Instrumentation. Checkout of} the FLS-3 instrumentation has progressed well. There are $58 \mathrm{CrAl}$ thermocouple locations around the FLS-3 loop and in the test insert (all checked out except for t.ue loss of one thermocouple in the test bundle).

In addition, there are saven pressure measurements, four differential pressure measurements, two water mass-flow and two helium mass-flow measurements, and four electricai measurements, including generator current and voltage. The $75-\mathrm{mm}$ ball valve open/close status is determined with limit switches.

The programs used to control and monitor the FLS-3 experiments were checked out using a watercooled dummy load hooked up to the 2.5-Mw gererator. Four different power profiles will be used during the testing sequences, and all required verification with the gensrator operating. As a result, the smallest control voltage output increment ( $5 \mathrm{mV}$ ) from the HP multiprogrammer, which normally produces a 12.5 amp step in generator current, was reduced by adding a voltage dividing circuit to the multiprogramer. This reduces the smallest control vo'tage output increment to approximately one-fifth of its original value. The smaller step allows finer control of the power input to the test bundle. The linearity between control voltage and generator current has not been affected significantly.

F. FLS Testing Sequence (D. Manson, D. R. Bennett, 0-13)

1. FLS-3 Test Matrix (J. Anderson, $R$. Ortega, Q-13). The sequence of tests and pertinent test parameters for FLS-3 are listed in Table IV.

2. FLS-3 Vacuum Bakeout I. The first Vacuum Bakeout of the FLS-3 systen was carried out on 9-28-80. The initial absolute pressure was 30 Pa. Power was applied on a half-period sinusoidal schedule with a 5000 s period. Maximn applied power was $448 \mathrm{~W}$ (103.4 amps) resulting in a maximum cladding temperature of $196^{\circ} \mathrm{C}$. Post test pressure levels were about $47 \mathrm{~Pa}$.

3. FLS-3 Heliun Bakezut. The purpose of the helium bakeout on 9-29-8n was to drive volatiles out of the external loop piping and insulation by neating due to convection, followed by evacuation. The power schedule was again a half-period sinusoid with a $5000 \mathrm{~s}$ period. The maximm applied power was $20.0 \mathrm{kw}$, resulting in a maxim 
TABLE IV

FLS-3 TEST SEQUENCE AND PARAMETERS

\begin{tabular}{cccc}
$\begin{array}{c}\text { System } \\
\text { Pressure } \\
\text { (MPa) }\end{array}$ & $\begin{array}{c}\text { Input } \\
\text { Power } \\
\text { (KW) }\end{array}$ & $\begin{array}{c}\text { Maximum } \\
\text { Cladding } \\
\text { Temp.(9C) }\end{array}$ & $\begin{array}{c}\text { Convective } \\
\text { Flow Mode }\end{array}$ \\
\hline
\end{tabular}

Bakeouts

vacuum Bakeout I

Helium Bakeout

vacuum Bakeout II

$\begin{array}{cccc}\text { vacuum } & 0.5 & 250 & \text { natural } \\ 4.48 & 20 & 250 & \text { natural } \\ \text { vacumn } & 0.5 & 250 & \text { natural }\end{array}$

Natural Convection Tests

Set 1: Test 1

Set 1: Test 2

Set 1: Test 3

Set 2: Test 4

Set 2: Test 5

Set 2: Test 6

Set 3: Test 7

Set 3: Test 8

3.54
6.58
1.01
1.00
3.04
0.50
1.01

$\begin{aligned} 10 & - \\ 30 & - \\ 45 & - \\ 10 & - \\ 30 & - \\ 5 & -\end{aligned}$

$\begin{array}{ll}- & \text { natural } \\ - & \text { natural } \\ - & \text { natural } \\ - & \text { natural } \\ - & \text { natural } \\ - & \text { natural } \\ - & \text { natural } \\ - & \text { natural }\end{array}$

Faulted Temperature Limit Tests

$\begin{array}{rrrr}\text { Test } 9 & 0.20 & 5 & 500 \\ \text { Test } 10 & 0.20 & 10 & 750 \\ \text { Test } 11 & 0.20 & 15 & 1000 \\ \text { Test } 12 & 0.20 & 20 & 1250\end{array}$

Destruct Test

Test 13

1.32

$37 *$

destruct

Forced

$15 \mathrm{~kg} / \mathrm{h}$

*r up to power level required to destruct $F$ LS-3 test insert.

clad temperature of $346^{\circ} \mathrm{C}$. Iritial helium pressure at ambient conditions was $4.53 \mathrm{MPa}$. However, at $70 \mathrm{~s}$, the unexpected opening of the emergency oump valve reduced th: pressure to 3.0 $\mathrm{MPa}$ in $195 \mathrm{~s}$. The problen wa's immediately corrected, but resulted in a loss of system helium. In order to compensate, helium was added to the loop to regain the original system pressure. This required an increase in the helium supply pressure at $952 \mathrm{~s}$ of elapsed time. At this point, the system was again isolated and the pressure allowed to change as a function of the system temperature. No other problems were encountered during the test sequence.
4. FLS-3 Rakeout Results. To date, results from the two bakeouts indicate that the system instrumentation is operating as expecteo, with only a few necessary corrections to programs and hardware. However, the helium bakeout data strongly indicates that the FLS-3 loop is running at a higher mean temperature than predicted. Two possible causes being analyzed are (1) the actual theimal conductivity of the piping insulation is less than the published conductivity, and (2) the gas-side heat transfer coefficients are significantly less than expected. Further analysis is being conducted on FLS-3 system performance prior to the second vacum bakeout and the testing sequence in Table $\Gamma$. 
111. STHUCTURAL INVESTIGRTION

A. Executive Summary (C. A. Anderson, Q-13)

The Lructural Margins to Failure Program has as its primary goal the quantification of tre failure load (i.e., compared with the design load) of certain nuclear plant structural components. The program has two parts. In the first part, Category I structures and structural systenis, exclusive of the cuntainment building, will be examined as far as their response to seismic, missile, and blast loacs. In the second part, the static and dynamic buckling of steel containments will be examined. Both programs are largely experimental. During the past quarter, our work on the first program ras been nighlighted by a meeting of the Peer Review Panel for this program, procurement of information on Category I structures from persunnel at the Tennessee valley Authority, and continued development of the experimental test plan where we are now focusing on a specific structural design. In the second program, a meeting of the Peer Review Panel was also held and is reported herein. Buckling experiments on thili-walled cylindrical shells with reinforced circular cutouts have been carried out in the past quarter and are also reported. In the HTCR Safety Program we are continuing our efforts to analyze the consequences of a Firewater Cooldown Accident as to thermal stresses developed in a Fort St. Vrain graphite core support block. Also, a creep analysis of a complex threedimensional concrete structure was carried out using the NONSAP-C finite element code. Finally, in our subsidence work, we have successfully reproduced, using the ADINA-T code, a published calculation of the steady-state free surface seepage through a porous rectangular dam.

B. Structural Mergins to Failure - Category I Structures Program (E. G. Endebrock, R. C. Dove, and $C$. A. Anderson, Q-13)

on July 8, 1980, R. C. Dove and E. G. Endebrock met with personnel of the Tennessee Valley Authority (TVA) at Knoxville, Tennessee. This meeting was held to obtain information about Category I structures located at nuclear power plants. Some results of the meeting follow.

In designing nuclear plant facilities, the thicknesses of interfor and exterior walls are dictated by penetrating missiles, radiation stielding, or pipe whip impact; and the steel reinforcement ratios are determined by the pressure or energy loadings. Slab designs are controlled by the vertical loading upon the particular slab. Because of the strength required to resist missile and entrgy loadings, TVA feels that seismic loadings on Cateyory I structures are not of major importance. TVA believes that the first distress due to seismic loading will accur in the piping and equipment supports. Piping and equipment support designs are stiff; hence, large loads are transmitted to the builoing walls and fioors. These large loads can lead to anchor fajlures.

TVA has sponsored considerable research on the behavior of anchor devices, base plates using stud anchors, and pipe whip phenamena associated with pipe ti downs. They have also tiested and evaluated ventilating duct supports and cable trays for selsmic load resistance. They have an ongoing program on the testing of anchors.

TVA uses fly ash in its concrete construction. The fly ash is used as an additive and as a cement replacement. The benefits are a much higher strength concrete but at the expense of a slower curing rate. Concrete designed for 5000 psi will reach strengths of 8000 psi or more when fly ash is used.

R. C. Dove and E. G. Endebrock attended the American Society of Civil Engineering meeting on "Civil Engineering and Nuclear Power" held in Knoxville, Tennessee. The Peer Review Panel moeting of the Structural Margins to failure Categor; I Structures Program was held in conjunction with this meeting, and we specifically elicited comments on our experimental plan. The size of the test structure received the most attention of the panel. The type of loading was also discu-sed. At this meeting, the panel did not contribute any suggestions that would warrant significant modifications of the proposed experimental plan. The panel agreed that damping, duration of motion, degradation of stiffness, and the establishment of the upper limit of allowable degradation were important items for consideration. We plan to contact the panel menbers again to determine if they have any further suggestions or comments. 
E. G. Endebrock attended a meet.ing with the NRC in washington, DC, on september 11, 1980. ?t this meeting, NRC presented its needs in a review of the adequacy of concrete masonry walls that form a part of Category I structures at nuclear power facilities. Also attending this meeting, was a potential contractor qualified to provide NRC with assistance in the evaluation of masonry walis. LASL is to negotiate with this party for its services to the NRC. These negotiations are presently in progress.

The development of the Exporimental test plan continues. The effort is nuw focusing upon the test. structure design. The wajor design restraints on the test structure are:

1. The major structural element is a shear wall.

2. The ultimate capacity must be controlled by sinear and not by flexure.

3. The ultimate capacity must be less than the capacity of a particular test facility.

4. The vibration mode of prime interest is sidesway and its corresponding natural frequency should be the lowest natural frequency of the test structure.

The test facility for which the test structure is being designed is located at the white Sands Missile Range (WSMR). The maximum frequency of WSMR' : dynamic test equipment is $100 \mathrm{~Hz}$ and its maximum force capacity is about 40,000 $10:$.

A shear fallure is ensured by adjusting the height to length ratio of the shear wall. The most difficult restraint is in designing the test structure such that the lowest natural frequency is less than $100 \mathrm{~Hz}$ and the mode shape of the lowest frequency is the desired vibration mode. These are a function of the test structure geometry and weight distribution. Mass must be added to decrease the natural frequency to the desired value.

An example of a test structure design is shown in Fig. 13. This design does not meet restraint 4. The vibration mode of interest is the third natural frequency of the structure. The first four vibration modes are shown in Fig. 14.
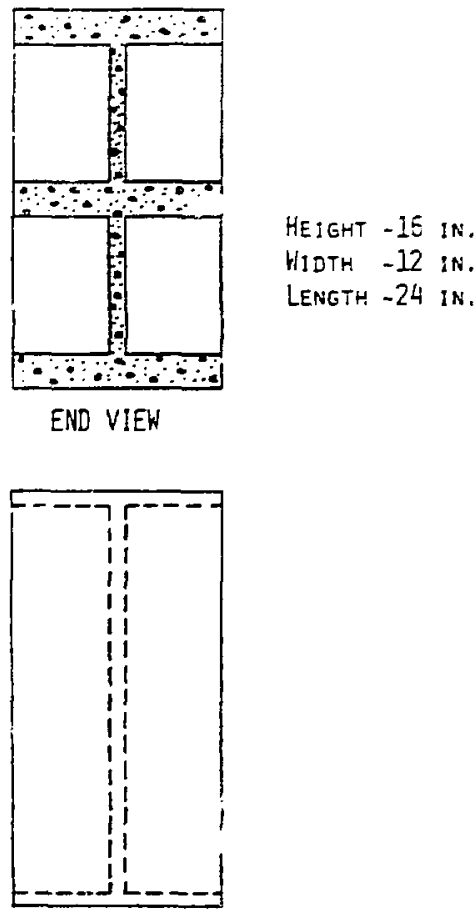

TOP VIEW

Fig. 13. Shear wall test struciure.

We are continuing the investigation of various test structure configurations and testing arrangements.

C. Structural Margins to Failure - Containment Buckling (J. G. Bennett, T. A. Butler, R. C. Dove, and J. Romero, Q-13)

The first Peer Review Panel for thi: progiam met at the University of California, Berkeley, on Aluust 15, 1980. The pariel reviewed three conponents of this program which will also be discussed here.

1. ASME ARM Verification Experiments. As was reported last quarter, experiments are being carried c.t on steel cylinders to verify the results reported for Mylar cylinders in Ref. 1. The issue is the area replacement method (ARM) for reinforcement around circular penetrations in shells. The Peer Review Panel received our plans for this portion of the program. Ouring the discussions by the panel of the ASME APM verification experiments, a number of points were brought out. Apparently, the requirements for conpactress of the reinforcenent in the ASME Boiler and Pressure 


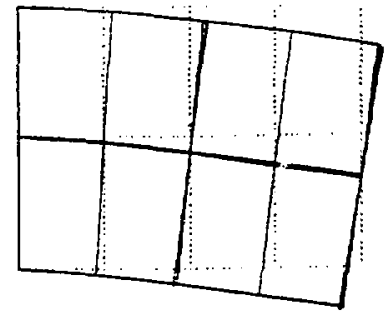

Side sway mode.

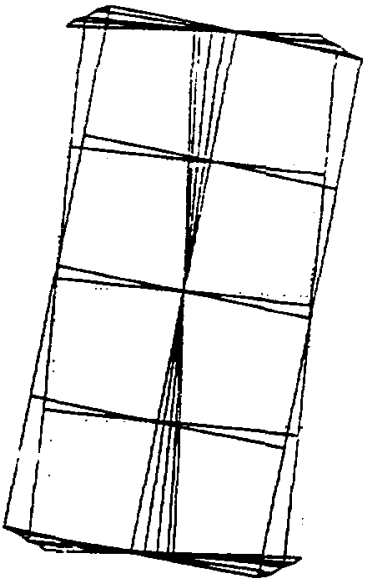

Torsiona1 mode.

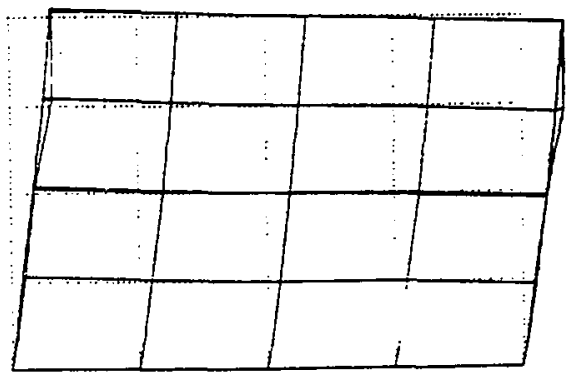

Shearing mode.

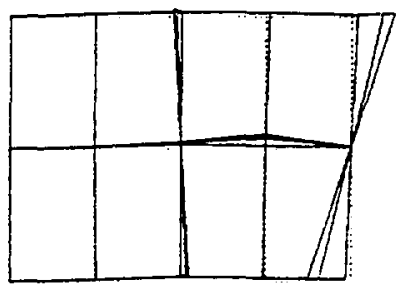

Roof rocking mode.

Fig, 14. Vibrational modes of shear wall test structures.

Vessel code, Div. 1, Sec. III, NE 3332, that specifies the limits within which reinforcement around a circular cut-out in a cylinder be located were put into the code for stress concentration purposes and may not be as well suited for buckling purposes. Experiments by C. D. Miller of Chicago Bridge and Iron have confirmed that the reinforcement is more effective against buckling for larger penetrations if it is spread further away from the penetration in the plane of the cylinder than is allowed in the ASME code. Further discussion indicated that this is probably because the stress concentration around a hole in a curved shell has a much wider range of influence than it does in a flat plate. Clarjfication of these points should be of interest to NRC in some future research, but this program is not directed at answering these questions. The ARM experiments were presented as being confirmatory in nature and as an effort to get the program moving experimentally, but not the main thrust of the Containment Buckling Program. The panel seemed to accept this work as being a useful contribution to the buckling literature.

The literature indicates that "fabricated" shell behavior for elastic buckling may be significantly different than for shells designed in accordance with specified imperfection limits. ${ }^{2,3,4}$ Fabricated cylindrical shells are those made from welding together cold or hot formed structural steel with "normal" specifications on tolerances. Germetrical imperfection limits are not spesified in the design and large imperfections are the rule rather than the exception. Obviously, the magnitude and form of the 
imperfections and the residual stresses are influenced to some extent by the method used to manufacture the shell. For shells that buckle elastically, however, the literature indicates that the geometric imperfections have great influence, while residual stresses have very little influence. In this program, we are restricting our investigation to "fabricated" shells since steel containments are very definitely in this category.

Experiments on the cylinders that were being constructed during the last quarter are underway. Although some preliminary results are available, no definitive conclusions have been drawn as yet. The results to date, however, do tend to verify the results reported in Ref. 1.

Figure 15 shows a typical rolled and seam welded cylinder in a buckled state that has no penetration. The radius to thickness ratio $(R / t)$ for this cylinder is 460 , corresponding to dimensions typical of the cylindrical section of the condensor steel containment. The classical buckling load $\left(\mathrm{P}_{\mathrm{Cl}}\right)$ for this cylinder under a uniform axial load is $201 \mathrm{kN}$ (45 $240 \mathrm{lb}$ ). The three test average of collapse load for the cylinders tested to date text is $49.8 \mathrm{kN}(11,195 \mathrm{lb})$. The capacity reduction factor (knockdown factor) $\alpha_{\mathrm{QL}}=$ $P_{\text {test }} / P_{C L}$ for fabricated cylinders is given by proposed ASME coode case N284 according to the equation

$$
\begin{aligned}
& \alpha_{Q L}=1.52-0.473 \log _{10}(R / t) \\
& (R / t<600, \text { elastic buckling). }
\end{aligned}
$$

For this cylinder, this equation gives $\alpha_{\mathrm{QL}}=$ 0.26 and from the three experiments, $\alpha_{\mathrm{QL}}=$ $P_{\text {test }} / P_{C L}=0.25$. The purpose of these tests is to verify the initial capacity reductions for the cylinder without penetrations. The cylinders containing circular openings will experience a further capacity reduction and the ratio of the buckling value of the cylinders with cut-outs $\left(P_{\text {nco }}\right)$ to those without $\left(P_{\text {wco }}\right)$ will be used to examine the effect of the area replacement method.

C. D. Miller, Director of Structural Research, Chicago Bridge and Iron, has been extremely helpful in bringing us up to speed in this program by supplying reference material including a computerized literature survey on the buckling of sylindrica? shells (stiffened or unstiffened, any loadings), and materials related to proposed ASME code case $N 284$ and its commentary.

2. Computer Code Benchmark Experiments. The purpose of this portion of the program is to have available experiments designed to check the predictive capability of commonly used buckling analysis codes. Lockheed Palo Alto Research has begun work on a contract with the NRC Structural Engineering Branch to demonstrate the solution to a series of buckling problems using the computer codes B SOR 4, B SOR 5, and STAGS Cl. Benchmark experiments of mutually agreed upon geometry and loadings will be planned and carried out during the coming fiscal year.

Several points were generally agreed upon by the Peer Review Panel regarding the experiments that will be used as computer code benchmarks. First, there are already many good experiments in the open literature on axially-loaded cylindrical shells. Little would be gained in repeating such an experiment. However, good experimental data on cylinders under more complicated loadings is difficult to find and would be far more usefui for computer code verification. An example suggested is a cylinder loaded by one Fourier harmonic in pressure circumferentially, and under an axial load. Such an experiment, if it could be devised, would be useful in checking the nonaxisymmetric loading analysis capability of axisymnetric computer codes.

Second, it was generally agreed that the chosen experiment or ryperiments should be in the radius to thickness ratio $(R / t)$ range of containment shells and should be of materials that have behavior similar to prototypical containment materials.

Third, the hope was expressed that several repeats of the same experiment would be possible in order to have some indication of the accuracy and sensitivity involved. It was further pointed out that these experiments must be very carefully carried out with as much data as feasible taken on the geometry, geometrical imperfections, and behavior under load. 


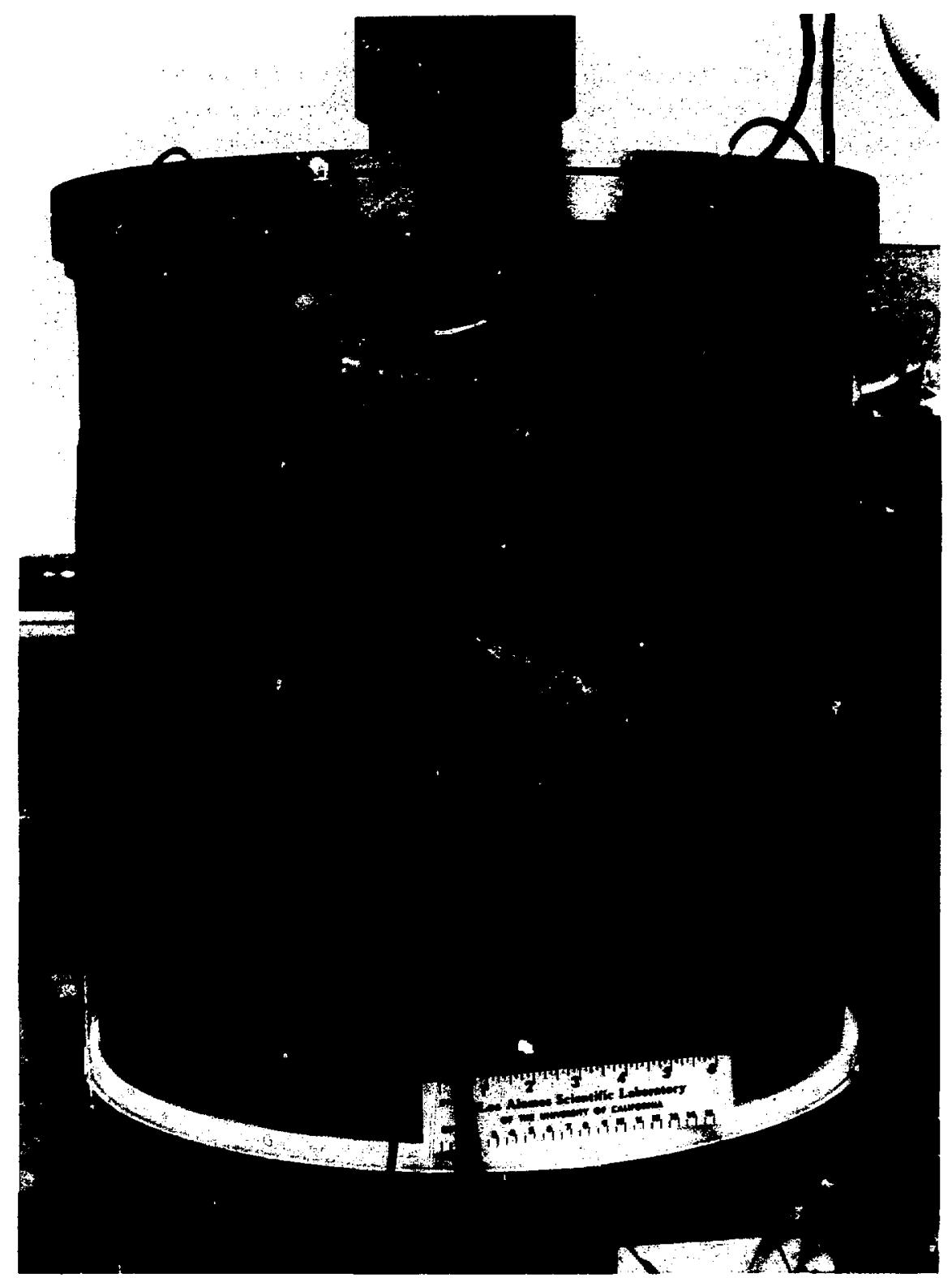

Fig. 15. Buckled cylinder in ASME arm verification experiments.

Further contacts with the Lockheed Palo Alto Research Laboratory will be made to establish the details of tinis phase of the prosram.

3. Dynan ic Testing of Model Containments. The dynamic test program on containment models was enthusiastically received by the Peer Review Panel. The lack of good experimental data for buckling of containment-like shells under dynamic loadings was pointed out. The special problens and loading situations related to the offshore
Power Systems design were discussed. The panel agreed that the dynamic loadings chosen should be relatively simpler in nature and that we should not try combined loadings until the simpler ones were well understood. The Loss of Coolant Accident (LOCA) loading and seismic loadings and the current design practices for these were discussed briefly. The greatest contribution the progran could make in this area is to show that 
the equivalent static load method used currently for buckling analyses is adequate for dynamic loadings. The consensus of the panel was that this method probably is adequate, but experimental verification would be a significant contribution from this program.

D. HTCR Structural Investigation

1. NDNSAP-C Code Verification (C. A. Anderson, L. M. Carruthers, C. R. Wiig, Q-13). Figure 16 represents a crusi-sectional view of a typical pressurized water reactor containment building that uses a post-tensioning system to keep the concrete in compression during operational and design basis accident loadings. This problem was chosen as a creep analysis test problem for the NONSAP-C code since it possesses stringent geometrical, data storage, and data output requirements.

The creep analysis of this problem is rendered three dimensional because of the post-tensioning system on the dome of the containment building. Typically, the tendons are arranged on a triangula: grid inside of a hexagon with center on the same axis of symmetry, as shwwn in Fig. 17. This provides a $60^{\circ}$ symetry in the stress state in the dome. The dome tendons then attach to the vertical sidewall tendons as shown, ano circumferential tendons are used to prestress the cylincrical portion of the containment building. The containment building is lined on the inside with a relatively thin steel membrane, which serves to contain fission product gases in the event of an accident.*

Eight-node bricks, 4-node membranes, and multinode tendons were chosen to represent the concrete, steel liner, and post-tensioning cables, respectively. A typical finite element is shown in Fig. 18. To generate the nodes and elements for the fin:te element model of a $60^{\circ}$ section of

*The model simplifies considerably certain features of an actual containment builring. Thus, there are many more tendons in the actual Duiluing than shown in Fig. 17 and an equivalent tendon stiffness was generated by lumping the tendon cross-sectional area; the actual building is higher than indicated by the model; and, there are buttresses at 60 degrees to anchor the circumferential tendons.

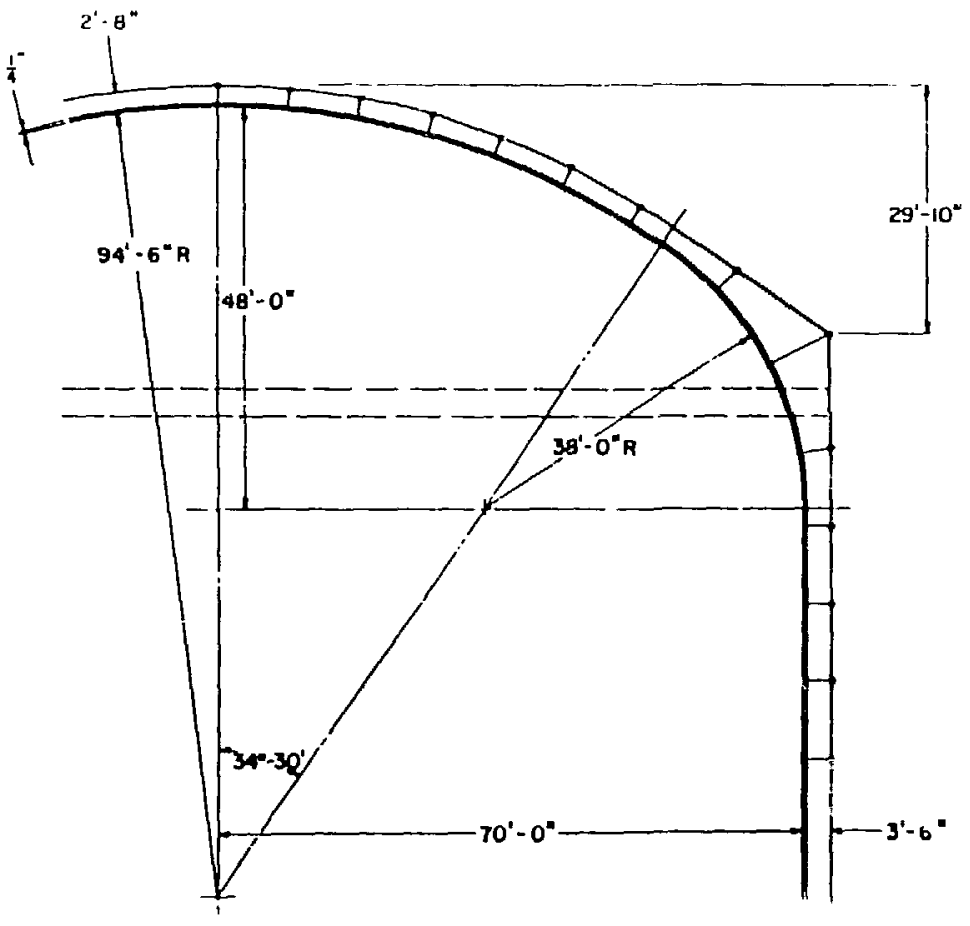

Fig. i6. Containment building schematic. 


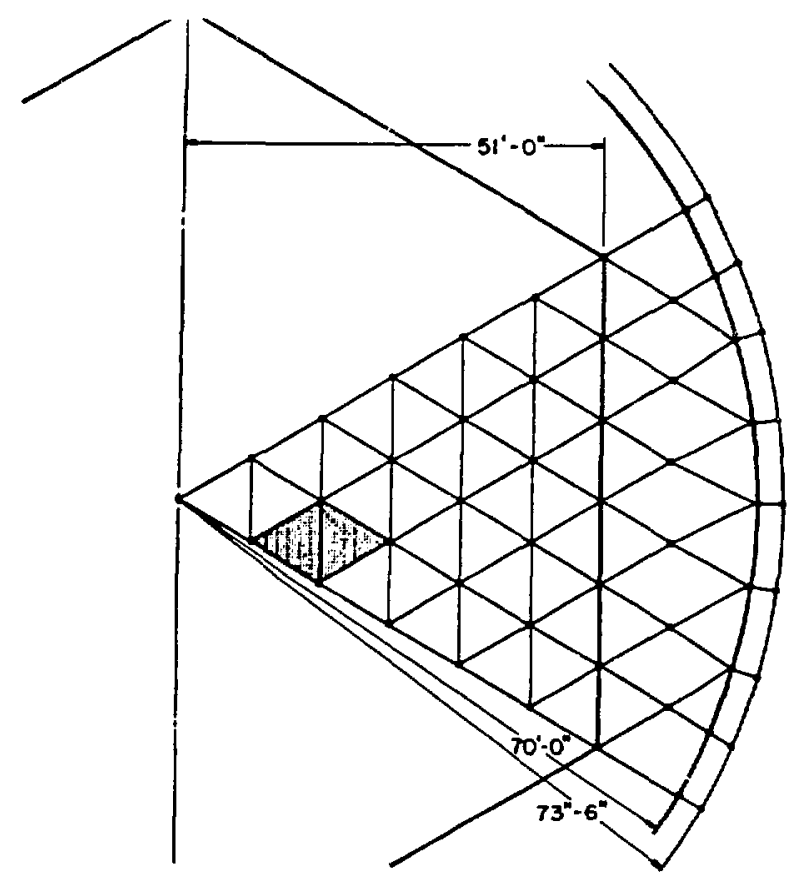

Fig. 17. Tendon arrangement on thie dame of the containment building.

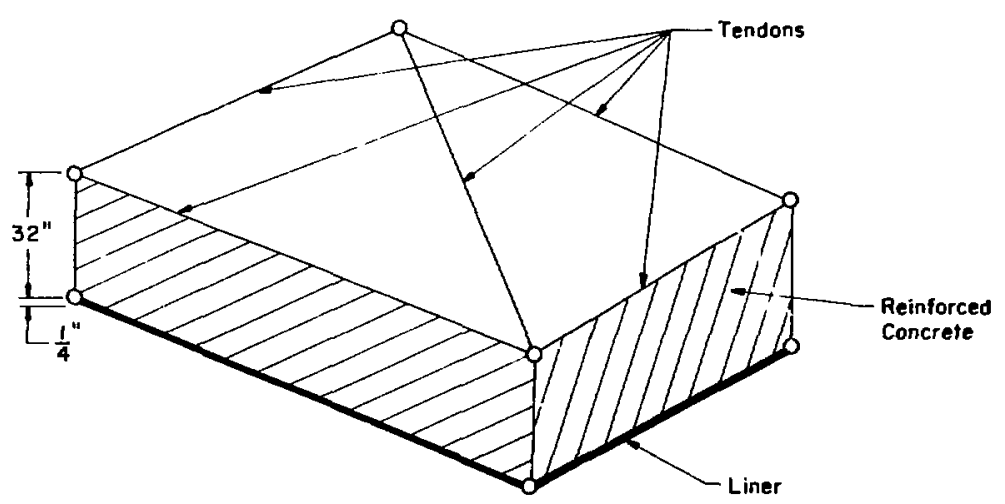

Fig. 18. Typical finite element ir: the dome.

the containment building, the mesh generator code INGEN was used. Figure 19 illustrates three views of the resulting finite element mesh as well as the logical mesh used to descrioe the brick element connectivity (the tendon connectivity is not shown).

Although the number of nodes (276) and elements (117 each concrete and membrane, 41 tendon) were modest, the connectivity of the tendons produces a fairly large stiffness matrix with 118994 entries, 744 equations, and a half-band width of 716. Using a three-term Dirichlet series for representing the creep compliance function, three separate blocks of concrete elements were required for storage of the stress, strain, and hidden 


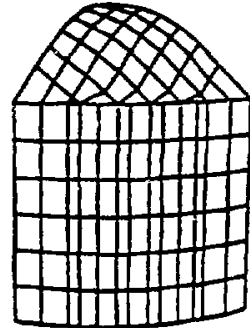

BACK VIEW

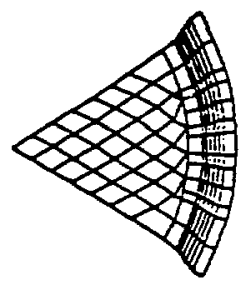

BotTOM VIEW

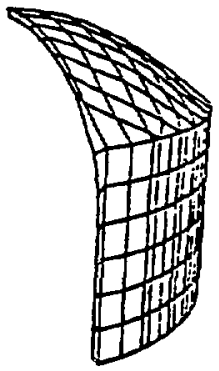

SIDE VIEW

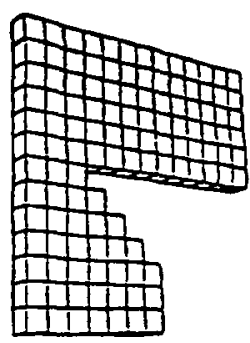

Logical Mesh
Fig. 19. Views of the finite element mesh for the containment building.

variable arrays for the COC-7600 computer. Thus, the problem provides a good test of a computer code and computing facility to handle realistic structural creep problems.

For this problem, a three-term viscoelastic aging function elastic behavior of the concrete and of the membrane and tendons was assumed. The tendons were post-tensioned to 0.0005 strain at 90 $d$ from concrete casting. The ensuing creep was calculated using 15 time steps with an initial time step of $1 \mathrm{c}$. Figure 20 illustrates two color-toned plots of the deformed shape of the dome model after load application. (The deflections have been scaled up by 500.) The dome vertical deflection (measured at the apex) as a function of time is shown in Fig. 21. To execute this problem required $52 \mathrm{~m}$ on the $C D C-7600$. On the CRAY computer, where only one block of concrete elements is required instead of three and where the equations are solved in-core, the corresponding running time was $21 \mathrm{~m}$.
2. Core Support Block Thermal Stress Analys (T. A. Butler and C. R. Wilg, Q-13). Several detailed steady-state analyses of the response of the Fort St. Vrain core support block (CSB) were performed using the three-dimensional finite element model described in Ref. 5. Input to the model was obtained from calculations performed at the Oak Ridge National Laboratory (ORNL) using the ORECA computer code to simulate core response during firewater cooldown ( $F W C D$ ) after a loss of forced circulation (LOFC) acciderit.

Because of size restrictions, we could not calculate details of stresses ntar the keyway of the CSB with our three-dimensional model. Therefore, we introduced a substructuring technique where data from the three-dimensional model was used to determine boundary conditions for a detailed two-dimensional model of the keyway area. Figure 22 shows the resulting stress field near the keyway. Although stresses throughe at most of the CSB remain well below the minimum tensile strength of PGX graphite, the stresses near the corner of the keyway exceed this minimum strength (approximately 1200 psi).

At a meeting held at the LASL on August 25, 1980 , we discussed our results with representatives of the Nuclear Regulatory Commission (NRC), General Atomic Corporation (GAC), Public Service Company of Colorado (PSC), and ORN. Based on action directives from this meeting, ORN recalculated core response for a $72 \%$ power case using a refined ORECA model. We used the ORECA output to load our three-dimensional model. Steady-state results indicate that the stresses are significantly lower, but near the corner of the keyway they still exceed the minimum tensile strength of PGX graphite. However, comparison of our calculated average CSB temperature with ORECA predictions indicated that a steady-state analysis of the CSB may not be sufficient for accurate stress predictions. Subsequently, we have performed some preliminary transient calculations. These calculations indicate that the CSB stresses are significantly lower (perhaps as much as a factor of two) than the steady-state predictions.

The scale of the experiment and problems associated with it were discussed briefly and it was pointed out that if the same material is used 

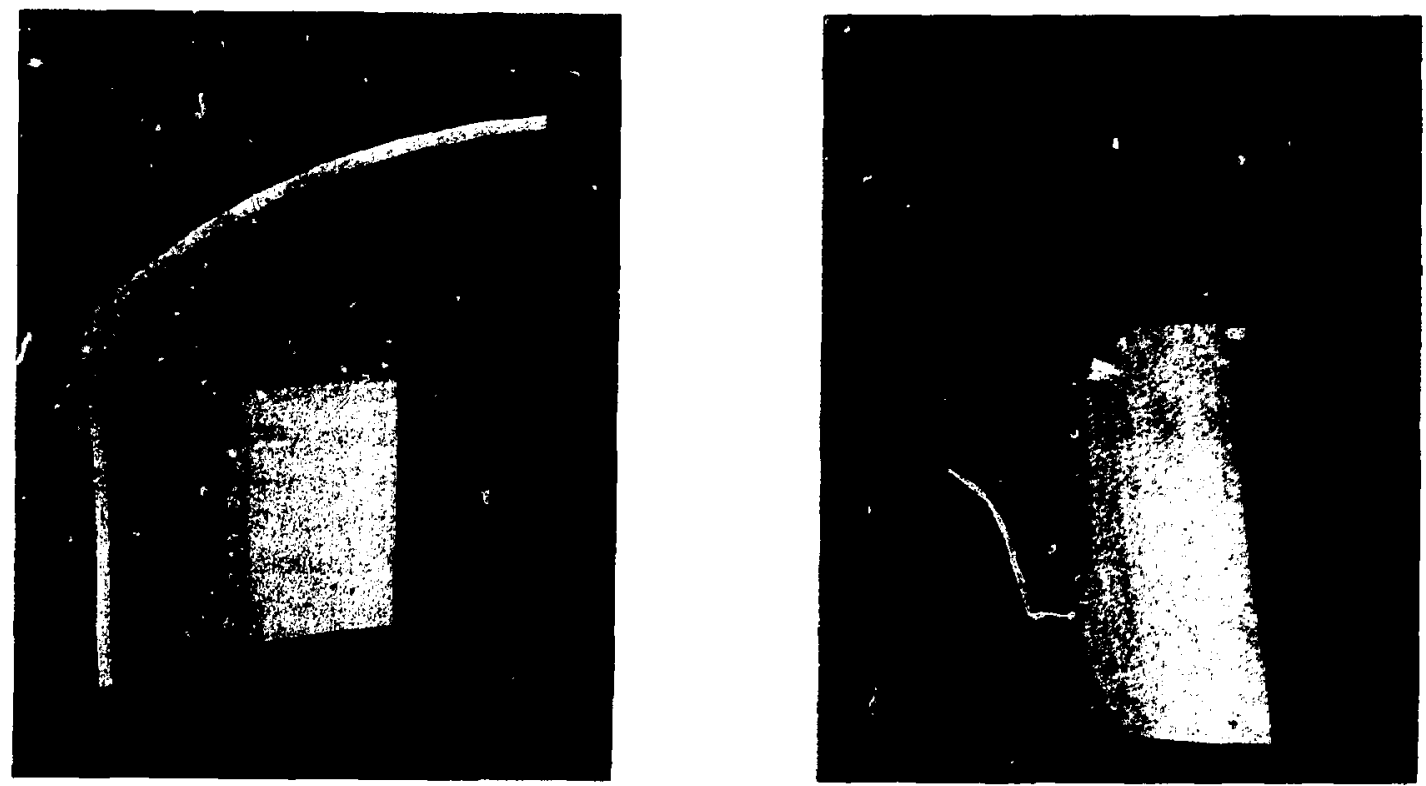

Fig. 20. Color preview of deformed shape of dome after post-tensioning.

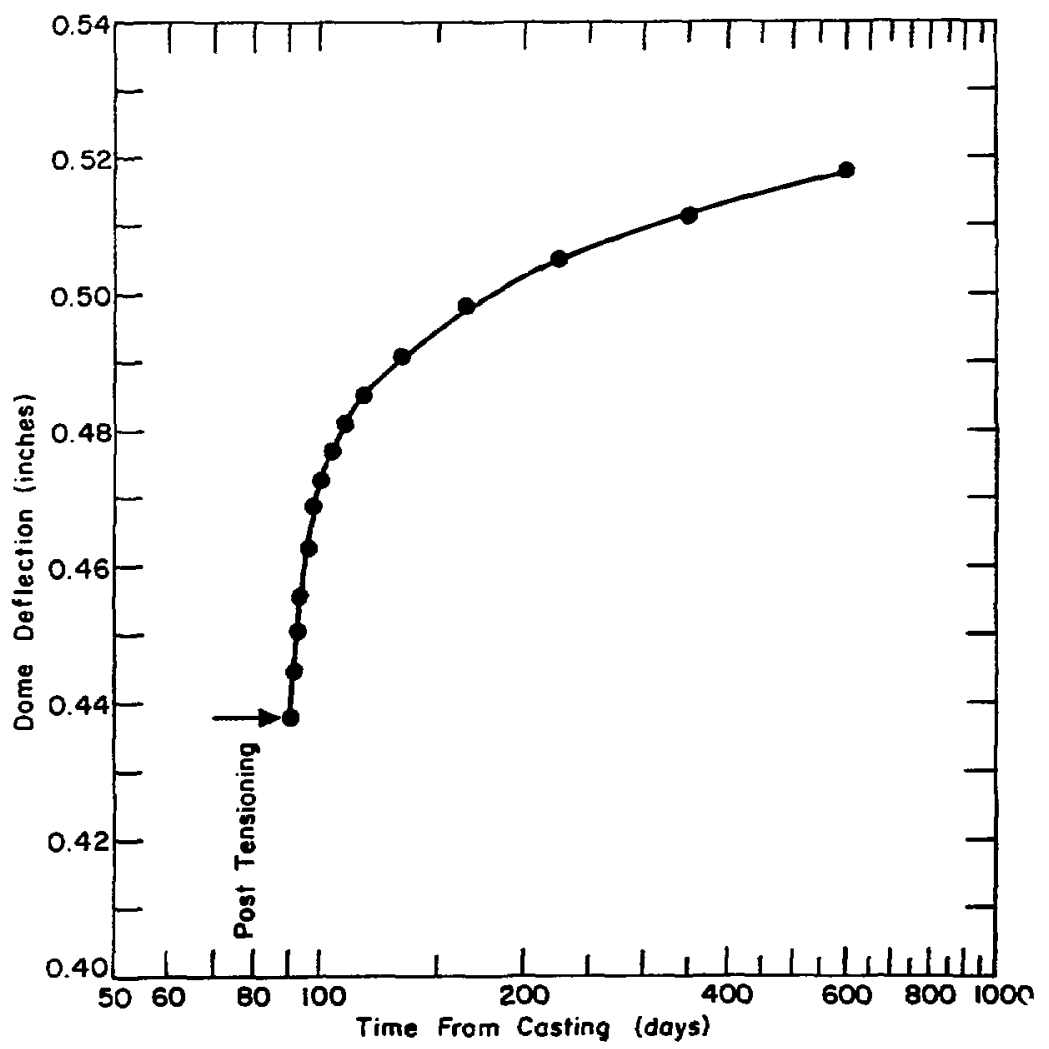

Fig. 21. Dome deflection as a function of time. 


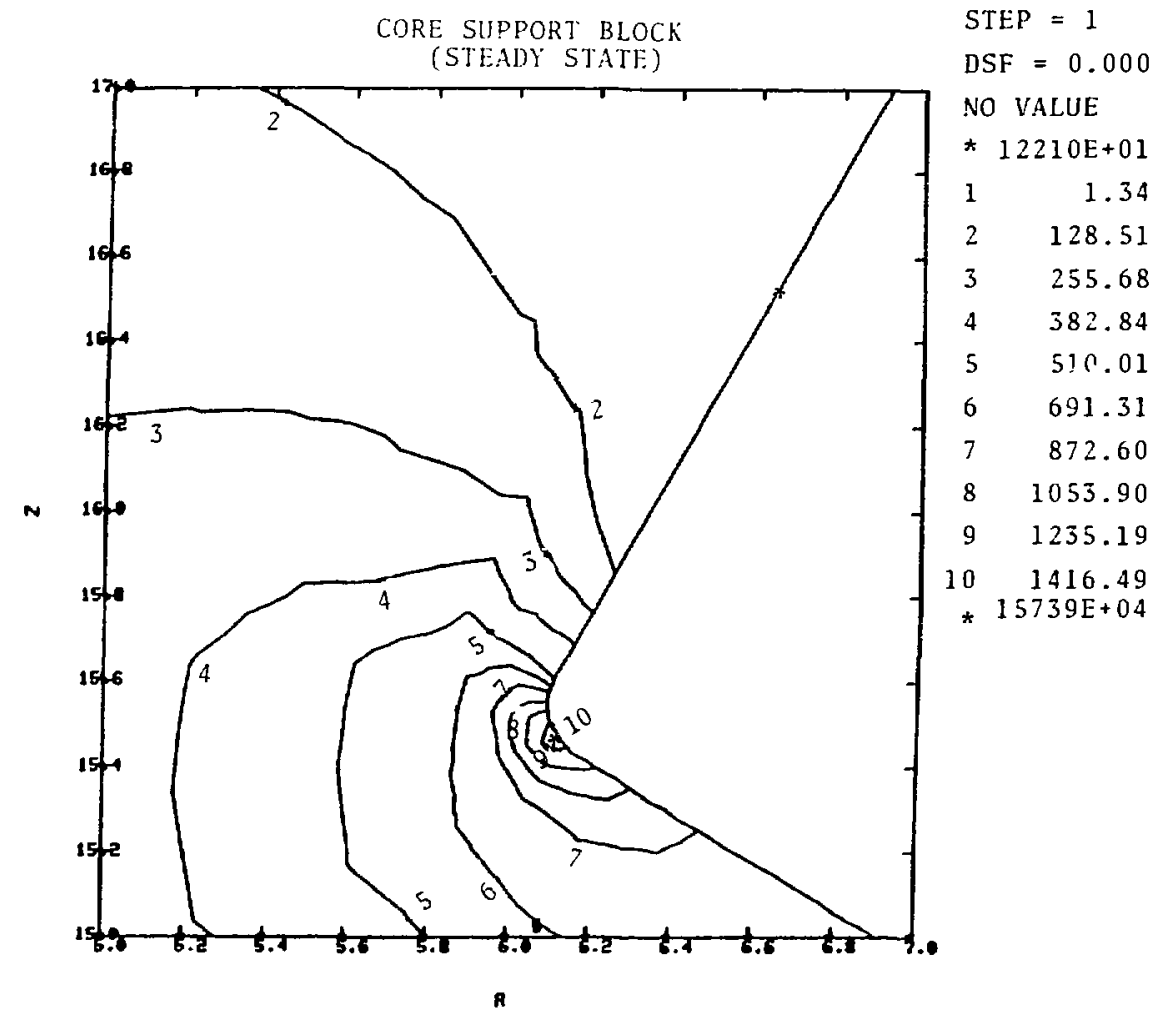

Fig. 22. Maximum principal stresses near keyway corner for steady state analysis (100\% power).

in a containment model that the scale rill probably be unreasonable. A distorted model of the same geometry can be constructed, however, and will be useful in verifying computational results. E. Ground Water Flow (S. P. Girrens, Q-13)

The purpose of this program is to develop a versatile finite element computer code for the prediction of ground water motion. The code will be utilized to study the dislocation of surface water (e.g., streans, lakes, etc.), water tables, and aquifiers after subsidence caused by underground mining. Analytical capabilities will include determination of the free surface and the interface between saturated and unsaturated Iegions for varcy and non-Darcy flows, and calculations for pressure gradients, velocity profiles, and engineering flow quantities through both porous and fissured media.
Effort this past quarter coricentrated on the problem of predicting free surface seepage without mesh iteration for Darcy flow. Using PDINAT as a baseline code, the reproduction of a previously published calculation ${ }^{6}$ for the steady-state free surface seepage through a porous Iectangular dam was investigated. A description of the problem and the finite element mesh are illustrated in Fig. 23. The solution employs a nonlinear permeability model of the porous media to avoid finite element mesh distortion near the free surface. Incorporating the necessary coding changes into ADINAT resulted in the successful prediction of the seepage free surface shown in Fig. 24.

Work next quarter will be directed toward the tasks of expanding the free surface capability to three-dimensional problems and including a nonDarcy flow capability into the free surface computations. 


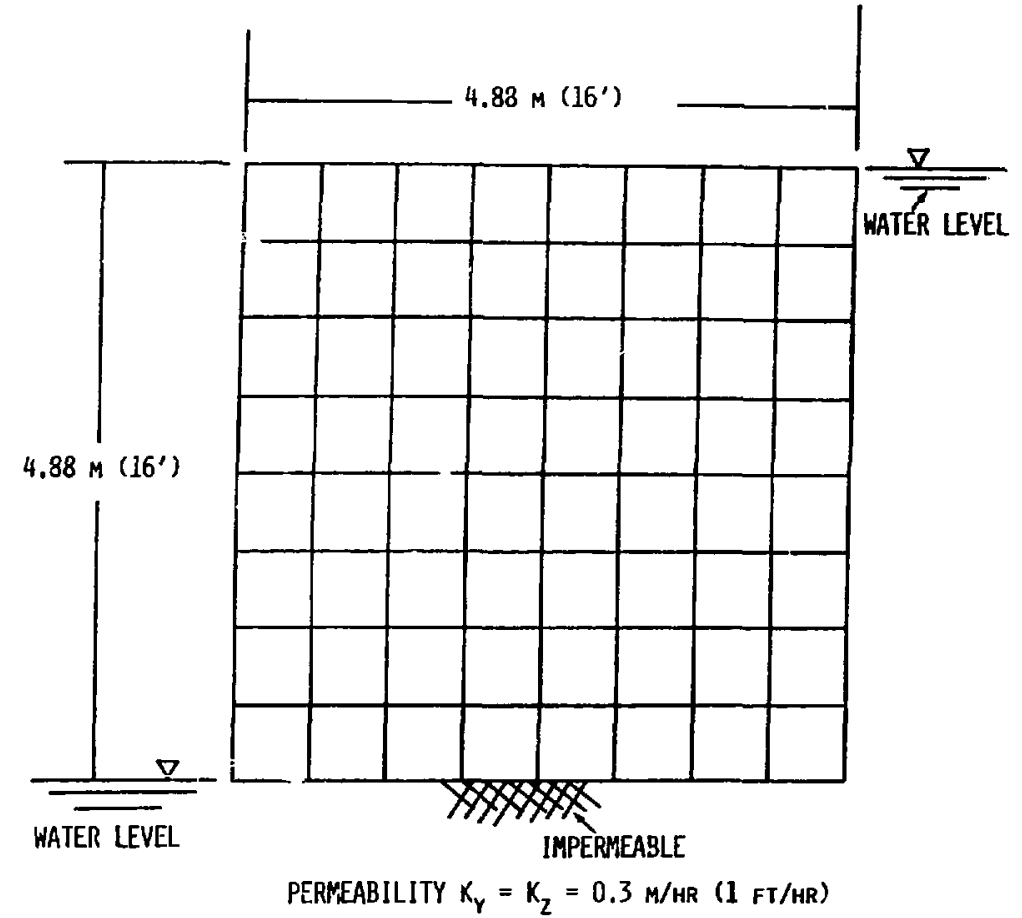

Fig. 23. Finite element mesh for flow through rectangular dam.

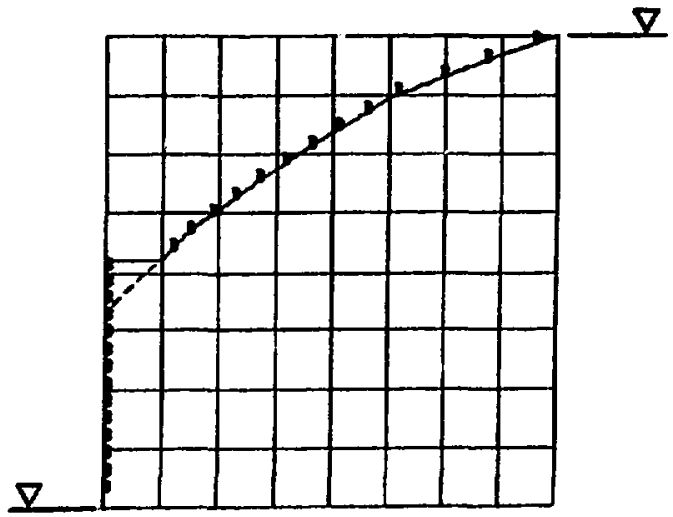

Fig. 24. Free surface contour for steady-state unconfined flow through a porous block medium.

\section{REFERENCES}

1. C. D. Miller and R. B. Grove, "Buckling of Cylindrical Shells with Reinforced Circular Dpenings Under Axial Compression," Chicago Bridge and Iron Report, March 14, 1980.

2. C. D. Miller, "Fabricated Cylindrical Shells Under Combined Axial Compressive Load and External Pressure," Chicago Bridge and Iron Report, February 1979.

3. ASHE Code Case N284, mketal Contaimment Shell Buckling Design Methods," Section III, Class $M C$ in preparation $7 / 2 / 80$.

4. C. D. Miller, "Buckling of Axially Compressed Cylinders," Journal of the Structural Division, American Society of Civil Engineers, March 1977, pp 695-721.

5. J. F. Jackson and M. G. Stevenson, muclear Reactor Safety Quarterly Progress Report for October 1-Decenber 31, 1979, LA-8299-PR, May 1980, pp 118-123.

6. K. J. Bathe and M. R. Khoshgoftar, MFinite Element Free Surface Seepage Analysis without Mesh Iteration," Int. 3. for Muerical and Analytical Methods in Geomechanics, Vol. 3 , No. 1, 13-22 (1979). 
IV. HEAT PIPE TECHNOLDGY DEVELOPMENT

A. Executive Summary (M. Merrigan, Q-13)

Work in heat pipe technology development during this quarter has included continuation of materials investigations and operation of a molybdenum-core SiC heat pipe on the ceramic heat pipe program. Entrainment limits have been the subject of investigation under the gravityassisted heat pipe studies in heat pipe engineering. Feasibility investigations of two heat pipe configurations having potential application to energy conservation fields have been started as part of the heat pipe engineering effort.

In-house materials investigations have been concentrated on the evaluation of sealing materials for SiC-to-SiC joints ary on the development of coating techniques for tungsten deposition as ceramic tube liners. The glass seals will be used in the investigation of alternative ceramiccompatible working fluids. Initial samples of tungsten coating appear promising and are now undergoing metallurgical examination.

A molybdenum-core, Sic-coated heat pipe utilizing all welded assembly has been operated in air at temperatures over $1100 \mathrm{~K}$ and a power level of $815 \mathrm{~W} / \mathrm{cm}^{2}$. A second pipe of this configuration is in fabrication with continued testing of the two planned for higher temseratures.

The investigation of cravity-assisted heat pipe operating limits has continued with the major effort in this period expended on the determination of entrainment limits for mercury working fluid as a function of fluid volume, tilt angle, and temperature. The measurements were taken using a 3.6-m steel heat pipe employing an internal thread wick. Future tests are planned with knurled heat pipes using both sodium and mercury as working fluids.

The Kanthal A-l heat pipe under evaluation for application in lower temperature stages of ceramic heat pipe recuperators has been temperature conditioned and is being performance tested.

Initial air lift pump efficiency is being evaluated as part of feasibility testing of the upside-down heat pipe concept. Tests to date have indicated the possibility of achieving liquid vapor ratios in the lift colum that are compatible with 20 foot lift capacity.
Feasibility evaluation is being conducted on a heat-pipe solar collector concept involving the use of the heat pipe wick as a direct solar collection surface. Tests to date have demonstrated a collector efficiency over $60 \%$ with limits established by the liquid-side thermal resistance in the condenser. Modifications are planned to reduce this resistance.

B. Ceramic Heat Pipe Technology Development Program (M. A. Merrigan, E. S. Keddy, W. E. Dunwoody, and $L$. B. Lundberg, Q-13)

1. Introduction. The ceramic heat pipe program is directed to the development of highcemperature heat pipes fabricated of ceramic materials for use in high-temperature heat exchangers. The ultimate goal of the program is the demonstration of these units in industrial processing furnaces.

Recuperation of heat from high-temperature furnaces is 1 inited by temperature-dependent material characteristics. Metallic recuperators are limited to about $1000 \mathrm{~K}$ by loss of strength and oxidation. Ceramic materials used in conventional brickwork heat exchanger configurations have been limited by joint leakage problems. Ceramic tube designs reduce sealing problems but still require sliding joints or compliant tube end seals. Ceramic heat pipe based recuperator designs offer high corrosion and abrasion resistance, high temperature capabi:ity, reduced leakage, element redundancy, and simplified replacement and cleaning.

The development of ceramic heat pipe recuperator elements involves the selection and test of materials and fabrication technicises having productive potential, evaluation of technology in subscale tests, design and test of components for full-scale recuperator applications, and demonstration of heat pipes in subscale and full-scale recuperator installation.

work on the program has involved the selection of candidate pipe envelope materials, working fluids, and protective envelope liner materials based on temperature limits and compatibility considerations. Alumina-niobium-lithium and silicon carbide-tungsten-sodium combinations were selected for initial tests. Tungsten-lined CVD silicon carbide heat pipes using sodium as a 
working fluid have been fabricated and operated in vacuum, air, and combustion gases at temperatures to $1200 \mathrm{~K}$. Current hardware investigat.ions are directed toward achieving more reliable assembly techniques, improving huat pipe performance, and increasing the Jemonstrated operating temperatures of the devices.

2. Program Planning. On September 11, 1980, a continuation of prior discussions was conducted with the ExxON Research and Engineering Staff concerning possible ceramic heat pipe applications in EXXON process plants. EXXON appears interested in a joint effori leading to a full-size ceramic heat pipe heat exchanger demonstration in one of their facilities. At the close of the discussions, Mr. Richard Boorman, the Division Manager of the Engineering Technology Department, said that his people were impressed with the technological base available at LASL and that he would like to explore the possibility of funding a program with us. Boorman then made the following proposals:

1. EXXON will select some specific applications areas for ceramic heat pipe technology within their interests in coal liquification and synthetic fuels conversion.

2. Hard information will be developed by EXXON with regard to the operating environment for such a recuperator device.

3. EXXON will try to identify a specific facility for installation of a ceramic heat pipe recuperator and if a facility can be identified they will plan on installing the final device and evaluating it in actual operation.

They plan to complete this effort in six to eight weeks and contact us with their results.

The molybdenum core heat pipes to be CNTO SiC coated by Chemetal Corporation have been conpleted, vacuum tested, delivered to chemetal and the first returned with coating completed. The second is being held until initial evaluation is complete. Inspection of the delivered pipe showed sone variation in coating thickness but the unit was corisivered operable. Tests have since been conducted at operating temperatures to $1200 \mathrm{~K}$ in air. As the molybdenum core approach appears promising, plans are to fabricate a similar heat pipe using lithium as a working fluid for testing at higher temperatures, and to continue development with Chemetal on increased size devices. Edward Britt, Technical Director of Rasor Associates, Inc., has requested information on our development work on these heat pipes. Rasor is apparently considering funding a subcontract effort by chemetal to develop coating capability for larger tubes for use in Rasors thermionic diodes. The effort would consist of a development subcontract from Rasor for a program administered through NASA, Lewis Laboratory. Period of the effort would be one year and cost about \$60,000. The possibility of jointly funded support for this effort in order to reduce costs to the individual programs and share the technology produced will be investigated. On July 15, 1980, a technical paper sumarizing work on the program was presented at the AIAA 15th Thermophysics Conference in Snowmass, Colorado. 1

3. Prototype Heat Pipe Development. a. Materials Investipated. LASL $\mathrm{CHB}-6$ development of equiaxed CVD tungsten coating for Sic heat pipe tubes has contimued during the report period.

- $0 \mathrm{SiC}$ tubes $7.62 \mathrm{~cm}$ long by $1.9 \mathrm{~cm}$ by 0.157 $\mathrm{cm}$ wall, closed on one end, were immersed vertically in a fluid bed of $100 \mathrm{~cm}^{3}$ of lightly coated 300-um-diam hollow spheres and coated with tungsten for $25 \mathrm{i}$. Coatings in excess of 0.025-cm wall thickness tungsten were produced on the outside surface of the tubes. Typical coating conditions were:

$$
\begin{aligned}
& T=708 \mathrm{~K} \\
& \text { Pressure }=50 \text { Torr } \\
& W_{6}=40 \mathrm{~cm}^{3} / \mathrm{min} \\
& \mathrm{H}_{2}=500 \mathrm{~cm}^{3} / \mathrm{min} \\
& \text { Time }=25 \mathrm{~h}
\end{aligned}
$$

The surfaces produced by these coatings were very smooth, highly reflective and should exhibit a refined grain structure typical of fluid-bed tungsten deposits.

One SiC tube $0.38 \mathrm{~m}$ long by $2.22 \mathrm{~cm} 0 . d$ by $0.31 \mathrm{~cm}$ wall closed on one end was mounted horizontally and filled approximately one-third full with $10 \mathrm{~cm}^{3}$ of heavily tungsten coated spheres $500 \mathrm{wm}$ in dianeter. The SiC tube was rotated at 
8 rpm so that the tungsten coated spneres were free to tumble and scrub the inside surface and duplicate the action and grain refinement of a conventional fluid bed. Gas inlet tubes for the introduction of $\mathrm{WF}_{6}$ and $\mathrm{H}_{2}$ were placed down the center of the SiC tube so that no interference between the tubes and tumbling particles was possible. Two different inlet tıbes were designed and fabricated. The first was a coaxial design with WF ${ }_{6}$ admitted at even intervals along the tube with the $\mathrm{H}_{2}$ flowing only out of the erid of the inner coaxial tube. This design produced tungsten throughout the inside surface of the twe; however, radiography indicated a heavier tungsten coating in the vicinity of each WF $_{6}$ entrance nole.

The second inlet tube consisted of two parallel tuoes welded together, one used for $\mathrm{WF}_{6}$ and $\mathrm{H}_{2}$. Out let holes were provided along each tube. This design did not result in completely uniform distribution of the gases. A third design is now being considered. Typical coating conditions were:

$\tau=723 \mathrm{~K}$

Pressure $=100$ Torr

$\mathrm{WF}_{6}=50 \mathrm{~cm}^{3} / \mathrm{min}$

$\mathrm{H}_{2}=600 \mathrm{~cm}^{3} / \mathrm{min}$

Time $=32 \mathrm{~h}$

After 32 hours of coating, the Sic tube incurred a radial fracture at approximately the center. This fracture revealed a tungsten coating of $0.064 \mathrm{~cm}$. Metallography is pending to detemine the tungsten structure.

Two of the CVD SiC tubes furnished to San Fernando Laboratories (Chemetal) for tungsten coating were broken in handling at the vengors plant after coating was completed. As replacements, San Fernando Laboratories has offered to fabricate equivalent cubes by deposition of tungsten on mandrels, removal and overcoating with CVD silicon carbide. As this sequence of operations has been reported to produce better tungstensilicon-carbide bonds than deposition of tungsten over SiC, their offer was accepted and the fabrication has been started with delivery scheduled for october. The broken tubes have been returned and are being used in electron beam weld braze closure experiments.
A leak was discovered in the kanthal A-l heat pipe after cover twbe attachment. This was probably caused by microcracking in the weld-affected zone. A thicker recralloy end plate was fabricated and the pipe reassembled, using TIG welding for tne cover tube attachment. The re-assembled pipe has been conditioned at $1323 \mathrm{k}$ in order to develop a uniform oxide layer and is now ready for performance tests in air.

The alumina neat pipe fabricated for $z$ inc compatibility studies was completed using a recrystallizing glass seal for pipe ciosure. Filling and sealing of the pipe was successful, ruwever, the alumina tube cracked during wet-in in a muffle furnace. Cause of the envelope failure appears to have been thermal stress resulting from nonuriform distribution of the working fluid within the pipe. It had been hoped that the alumina tubes would survive furnace exposure at constant temperature for the compatibility experiments. As this is apparently not true, further compatibility tests will be conducted with silicon carbide tubes. An investigation of sealing techniques for normetallized silicon caroide tubes has been started with an initial temperature objective of $1273 \mathrm{~K}$. A series of seal specimens were prepared by hutt sealing Iight cylinders of silicon-bonded silicon carbide having a $3.17 \mathrm{~mm}$ wall with high temperature glasses and leak checking the joints. The glasses evaluated in this preliminary investigation are summarized in Table $V$. All the glass seals were fired in air.

Failure to obtain nermetic seals with these glasses prompted the evaluation of silicon suggested by the Norton Company. A butt joint specimen sealed with silicon at $1733 \mathrm{~K}$ in hydrogen was vacuum tight and has achieved $100 \mathrm{~h}$ of testing at $1273 \mathrm{~K}$ in aiI without developing a helium leak. An attempt was made to duplicate the successful silicon joint in the heat pipe vacum assembly facility. Two joints were attempted, a butt joint and a taper joint. Neither was successful. It appears that the high vapor pressure of the silicon at the braze temperature $(1683 \mathrm{~K}$ ) causes bubbling and loss of material when no background gas is present. In general, butt joints are difficult seals to fabricate, especially when the physical properties of the sealant are not ideally matched 
TAELE $V$

GLASSES EVALUATED IN PPELIMINARY INVESIIGATION

$\underline{\text { Glass }}$

(1) $34 \mathrm{Al}_{2} \mathrm{O}_{3}-15 \mathrm{MgO}-50 \mathrm{SiO}_{2}$

(2) $37.5 \mathrm{Ca}-06.5 \mathrm{MgO}-56 \mathrm{SiO}_{2}$

(3) 91 Feldspar K-8 Kaolin-1 Gentanite

(4) Trioxide $\left(\mathrm{Al}_{2} \mathrm{O}_{3}-\mathrm{SiO}_{2}-\mathrm{MnO}\right)$

(5) Honeywell \#7372

*units are $\mathrm{cm}^{3}(\mathrm{STP}) / \mathrm{s}$. with tnose of the sibstrate. The choice of uutt joints for seal evaluation was expediert and specimens with lap joints, a more forgiving design, are being machined from the Si-Sic material for re-evaiuation with glasses (1), (2), and (5) of tne taple.

D. Subscale Heat Pipe Fabrication. The first of the two low-carbon, arc-cast molybdenum core heat pipes has been received from chemetal folluwing their coating of the tube with CNTO sic. Prior to shipment of the pipes to cherretal for coating they were operated in a vacuum at temperatures of approximately $1275 \mathrm{~K}$ in order to verify oreration. The initial tube returned by Chemetal has been inspected and found to be coated well enough for operation in air. This heat pipe has been operated using an electrical furnace as a heat source with the condenser region radiating to the laboratory environment. Following this successful demonstration, a gas-gap calorimeter was installed and performance data taken for the pipe up to the limits of the furnace input. Data from these tests is presented in Fig. 25. Peak axial power density achieved in these tests was 815 $w / c m$. A gas-fired heat source is now in work for use in tests of the heat pipe at higher temperatures. Plans are to proceed with coating of the second test pipe following evaluation of the present tests.

A solid CVD SiC, tungsten-metallized tube was assembled into a sodium heat pipe using a cylinorical, tungsten coated, closure plug and palladium cobalt braze. The braze closure was made at $1510 \mathrm{~K}$. The heat pipe was operated in a vacuum envelope with slowly increasing temperature. Sone

\begin{tabular}{ll} 
Temperature & He Leak Rate* \\
\cline { 2 - 2 } 1673 & $\sim 10^{-j}$ \\
1673 & $\sim 10^{-5}$ \\
1673 & gross \\
1573 & $\sim 10^{-5}$ (reaction) \\
1533 & $\sim 10^{-5}$
\end{tabular}

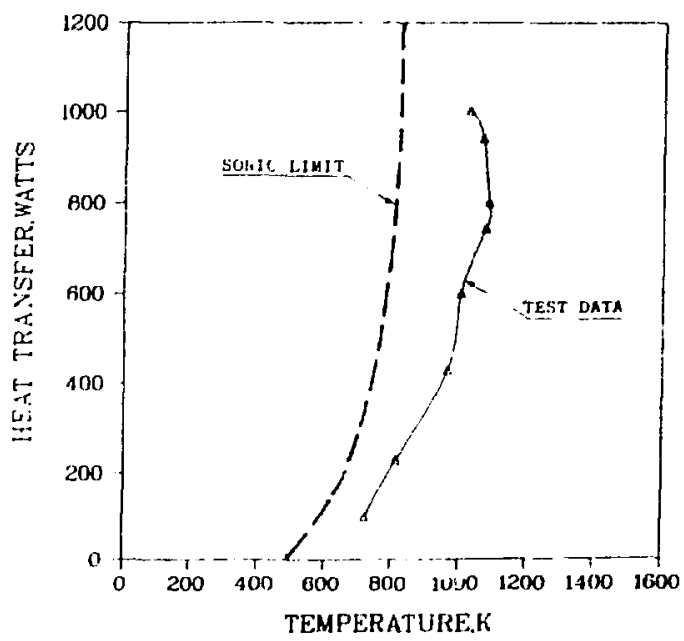

Fig. 25. SiC-W-Mo heat pipe performance.

noncondensible gas appeared to be present in the pipe, indicated by a cool area at the end of the pipe with a fluctuating zone of large temperature gradient at the gas-vapor interface. After approximately $2 \mathrm{~h}$ of operation the pipe fractured in the region of the gas-vapor interface. Post test inspection did not reveal any obvious cause for the failure other than the high thermal stresses induced by the fluctuating gas-vapor interface. Fill procedure is being reviewed in hopes of improving the degassing of the pipe material prior to closure.

The solid, alpha-phase silicon cartioe pipes ordered from Carborundun Corporation have not yet been received. Delivery originally scheduled for early September is now promised for mid-october. 
c. Test Facility Development. Fabricat on of the fluidized-bed heat rejection portion of the subscale test facility has been completed. work is continuing or, the furnace part of the facili iy.

4. Design and Thermal Analysis Activities. The promising results achievad to date with the molybdenum core heat pipes have prompted an investigation of the economics of such a configuration under the conditions used in Ceramic Heat Pipe Hecuperator Study conducted for LASL by Girrett Corporation. The major unknown in the extension of the analysis to these neat pipes is the cost of the core tubing when procured in quo.tity. vendor quotations of unit costs are being requested under the rules for delivery and quantity that were used in the prior study. Paybuck periods will be determined using this cost data for the steel re-heat furnace case.

\section{c. Heat Pipe Engineering}

1. Gravity-Assist heat Pipes (F. C. Frenger, Q-13). Recent emphasis on energy conservation has resulted in widespread interest. in thermal recovery units, particularly in medium and high temperature applications. The superior perfnrmance characteristics of heat pipes car be used to advantage in these systems if fabrication costs are kept low. Gravity-assis heat pipes with simple wick structures are promising candidates for these systems and are consequently a current focus of the heat pipe engineering program.

Performance tests have been completed on a 3.6m steel heat pipe using mercury as the working fluid. The heat pipe diameter was $38 \mathrm{~mm}$ with a wall thickness of $2.3 \mathrm{~mm}$. Internal threads were cut to a depth of $0.38 \mathrm{~mm}$ with a peak-to-peak

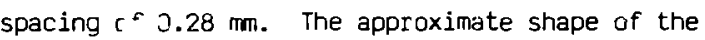
grooves formed by the threads was triangular although plastic deformation of the material during cutting created a "lip" of metal at the apex of each groove. The triangular shape of the grooves allows an infinitely adjustable radius of curvature of the vapor-liquid interface preventing interruption of the ciscumferential distribution of working fluid. However, the small pitch of the threads creates a tortuous path for the returning liquid. This requires that the heat pipe be overfilled, i.e., provided with enough excess liquid to form a suarle or trough of liquid inside the heat pipe. The grooves are then only used to distribute the iiquid circumferentially and the iquid pudale provices the axial transport of the liquid to the evaporator.

The heat pipe was tested at tilt angles of $10^{\circ}, 27.5^{\circ}$, and $90^{\circ}$ measured from the hor $i-$ zontal. A work $\perp$ f fluid reservoir was located at the condenser end of thie heat pipe and through the 's of a calibrated manifold, a knowil. .lume of working fluid was introduced in-. tu inco the heat pipe. This arrangeme.it proved satisfactory although working fluid could only be added using this technique. Kemoval of working tiuid requirec disassembling the test fixture and inverting the heat pipe. The volume of the internal threads was approximately $66 \mathrm{~cm}^{3}$ and this was tne initial sharge of mercury placed in the heat pipe. An additional $330 \mathrm{~cm}^{3}$ of mercury was containeo in the reservoir.

The reat pipe was fittej with a 1.8-m gas--5ap calorimeter. ${ }^{1}$ Heat was supplied with an induction coil. The coil length was varied between 0.63 and $0.81 \mathrm{~m}$ leaving an adiabatic section of approximately $0.64 \mathrm{~m}$ in length. The heat pipe could not be started with less than $103 \mathrm{~cm}^{3}$ of excess working fluid; however, this was with the maximum length evaporator $(0.81 \mathrm{~m})$. Other tests showed the heat pipe was easier to start with the shorter coil; therefore, the $103 \mathrm{~cm}^{3}$ volume may not represent the minimuri volume for operating the neat pipe.

Data obtained at working fluid volumes of 103 , 298, and $330 \mathrm{~cm}^{3}$ are shown in Fig. 26 . The performance limit is a strong function of operating cemperature but is weakly influenced by tilt angle and working fluid inventory. The entrainment limit curve in Fig. 26 represents a best fit of the experimental data. The sonic limit was calculated using the heat pipe computer code HTPIPE $^{2}$ and is shown fDI comparison.

The performance limits were characterized by overheating at the beginning of the evaporator which was the extreme lower end of the heat pipe. This is indicative of an entrainment limit since the liquid is being held at the condenser end ty the vapor shear forces. In certain instances a hamering or thumping could be detected. This was 
associated with boiiing in the liquid pool and results when a slug or liquid was elevated by a vapor bubble with the hamering noise occuring when the liquid slug dropped back into the pool. This unstable operating region was observed when temperature differences between the pool and the heat pipe wall exceeded $100^{\circ} \mathrm{C}$. This effect could be minimized by a slow startup of the heat pipe.

The data obtained with the mercury heat pipe will be used with data from the toluene, water, and methanol heat pipes to provide a data base for an entrainment model for gravity-assist heat pipes. Future tests are planned with krurled heat pipes using sodium and mercury as the working fluids.

2. The Upside Down Heat Pipe (Dan Koenio, Q-13). The goal of this new effort is to demonstrate experimentally the proof of principle of a new heat pipe concept. In conventional heat pipe designs capillary action limits the range of operation to less than a meter; the aim of the

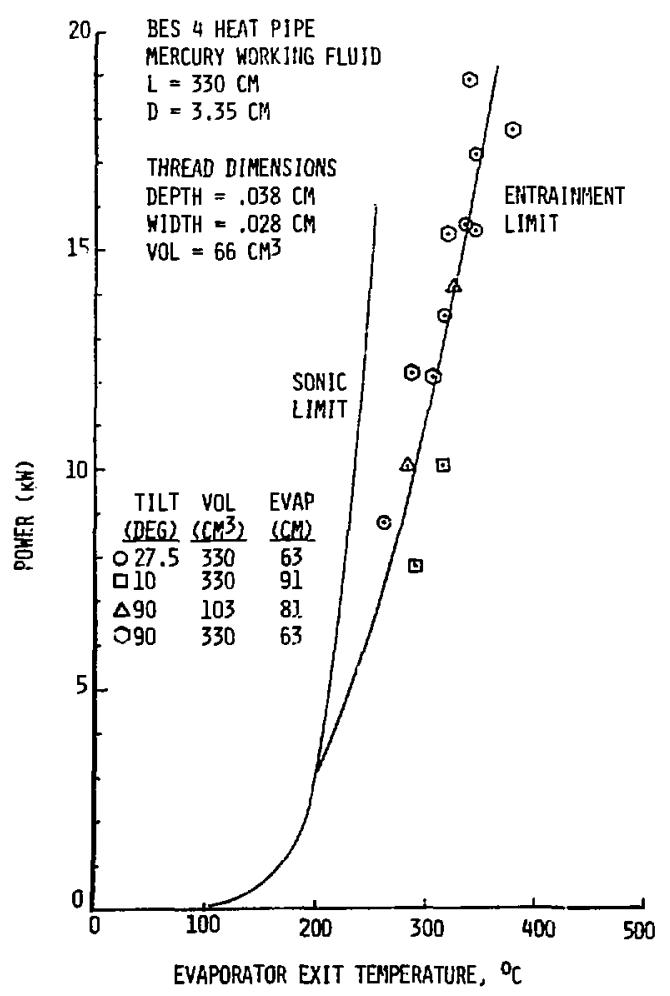

Fig. 26. Performance limits of gravity-assist, mercury heat pipe. proposed heat pipe concept is to extend the range of pumping height to several meters for application in space heating and domestic water heating by solar energy. The concept is illustrated schematically in Fig. 27. The vapor in traveling toward the condenser creates a low pressure in the throat of the venturi. The vapor sweeps the roncondensable gas toward the bottom of the pipe. The gas, which is now at a higher pressure, travels up the return tube and reenters the vapor stream through the ejector. Condensed liquid will plug the end of the return tube and be entrained by the recirculating, noncondensible gas. At the top of the return tube the liquid will be separated from the gas and collect in a reservoir. The average density of the gas-liquid mixture in the return tube will be less than that of a fully liquid colum allowing the circulating fluid to be pumped to greater heights than with a fully liquid return. Present efforts are directed to determination of the efficiency of the vapor lift pumping process and measurement of the average density of the gas-liquid mixtures in the return tube. These experiments will provide a basis for evaluation of the concept. Early tests results show that about $1 \mathrm{ml}$ per second of water can be pumped a height of about $7 \mathrm{~m}$ in a $6 \mathrm{~mm}$ i.d. tube with a pressure head under $100 \mathrm{~mm} \mathrm{Hg}$ in a flow regime that was partly slug flow, partly drop flow. This amount of flow would correspond to a heat transfer rate in a heat pipe of about $2 \mathrm{kw}$. Experiments will be conducted at different heights and with tubes of different diameters. An effort will be made to see if still lower pressure heads can be achieved in a more drop-mist type of flow.

3. An Atmospheric Heat Pipe for Solar Collectors (M. Merrigan, Q-13). A new heat pipe concept having potential application in flat plate solar collectors for hot water of space heating is being evaluated. The concept involves operation of a heat pipe at constant pressure with a high percentage of noncondensible gas in order to permit the enclosure to be designed without regard to pressure induced stresses, a necessity if large flat structures are to be built economically. Operation of the heat pipe in the presence of a high peroentage of noncondensible gas is accomplished by providing a separate circulation path 


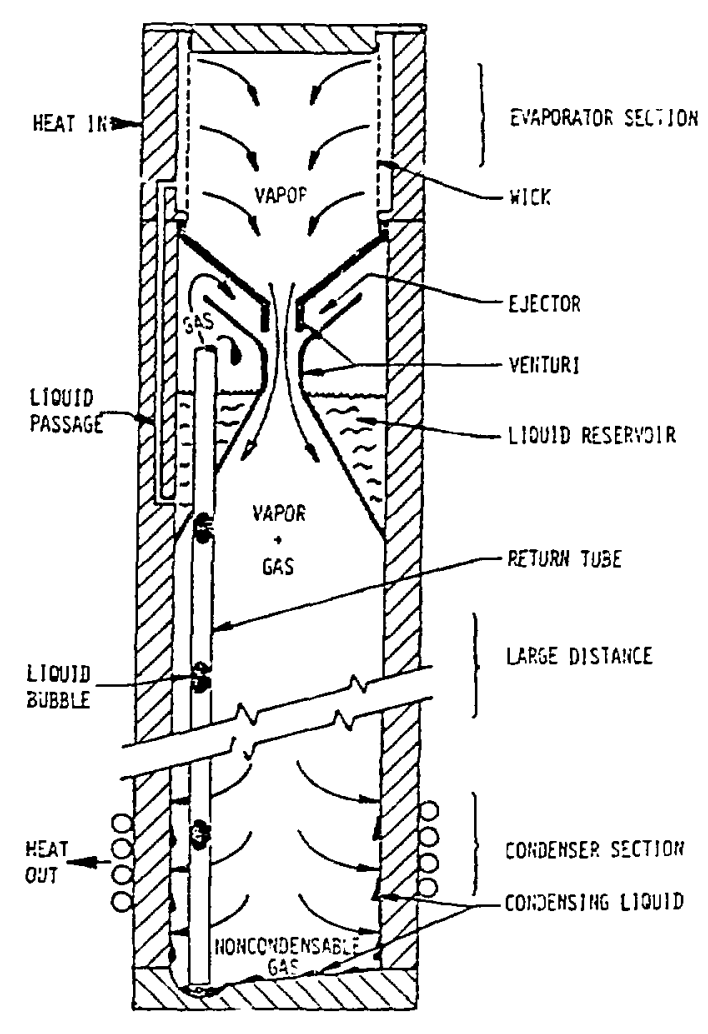

Fig. 27. Venturi gas-ejector vertical heat pipe.

for the gas and by maintaining adequate gas velocity over the coridenser surface. Unlike a conventional heat pipe where the potential difference required to operate the phase change loop is provided by the change in saturation pressure of the liquid corresponding to the temperature difference between the evaporator and condenser, the primary forces involved in the operation of this device

are convective, resulting fiom the change in molecular weight of the gas-vapor mixture due to evaporation and condensation of the working fluid. The essential features of the heat pipe are shown in Fig. 28. Because the heat pipe operation in the hody of the collector serves to concentrate the solar heat input over a comparatively small area in the condenser, high heat transfer coefficients are required in the secondary flow loop if good collector efficiency is to be achieved. This may be accomplished by the use of internal extended surface in the condenser tube, high secondary flow loop velocities, or by the use of a second, conventional heat pipe for condenser heat transfer to other storage. Evaluation of the concept has been conducted with a pumped secondary loop at comparatively low flow velocity. The test data from a recent run summarized in Table VI indicates that the present limitation of the collector is the secondary flow heat transfer mentioned above. Modifications are planned to eliminate this restriction.

TABLE VI

ATMOSPHERIC HEAT PIPE COLLECTOR TEST

Collector area:

Solar Insolation:

(per Eppley Black and White

Pyremometer Model 8-48)

Secondary loop flow rate

Secondary flow $\Delta T$

Secondary flow temperature

Collector surface temperature

Collected energy

Collector efficiency
$0.186 \mathrm{~m}^{2}$

$938.3 w / m^{2}$

$0.0315 \mathrm{Kg} / \mathrm{s}$

$0.80 \mathrm{~K}$

$301 \mathrm{~K}$

$335 \mathrm{~K}$

107.2 W

$61.3 \%$ 


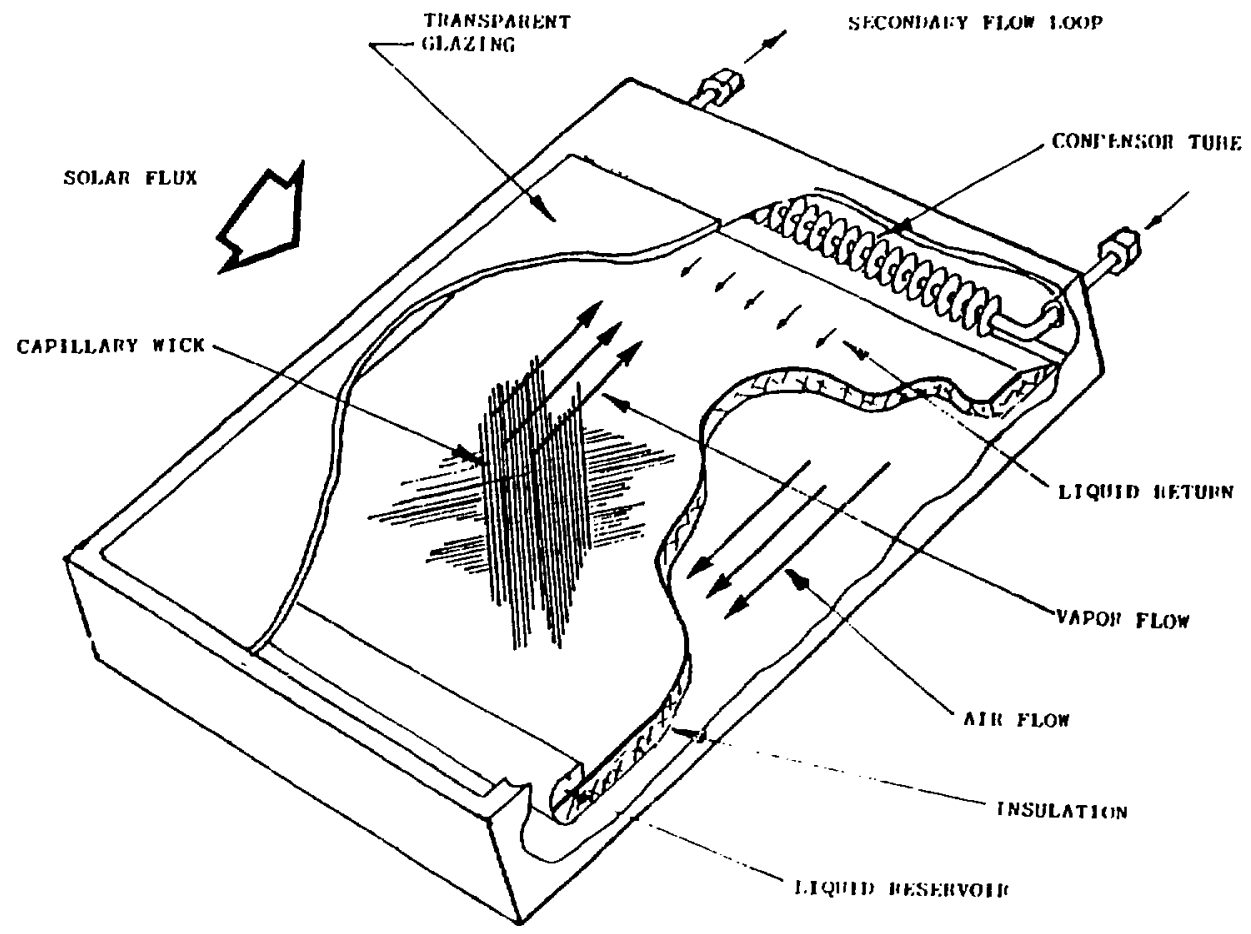

Fig. 28. Heat pipe solar collector. 
V. NUCLEAR CRITICALITY EXPERIMENTS AND SAFETY

A. Executive Summary (E. A. Plassmann, Q-14)

The construction of our new solution critical assembly, SHEBA, was completed, first criticality obtained, and over 100 irradiations already provided for evaluation of criticality accident alarm detectors and personnel dosimetry. Participants in the experimental program included personnel from several DOE contractors as well as vendors who came to test their radiation detection equipment. SHEBA was operated at powers up to $5 \mathrm{~kW}$ with detectors placed at various locations both with and without intervening attenuation shields.

A "dry run" to coordinate a Codiva IV neutron burst with the firing of a test shot at PHERMEX has been successfully completed. For this first run, the test assembly contained depleted uranium. We will ultimately attempt to measure neutron multiplication in a dynamic subcritical plutonium system. In the present experiment, four different neutron detectors were evaluated, and baseline detection levels established. Results show that we must eliminate stray electromagnetic radiation and refine collimation of the Godiva neutron beam and the detector geometry.

In order to analyze the InRad measurements on the device for the NTS verdello event, the backscatter of radiation in the room had to be accounted for. As expected, because of the massive concrete construction, large neutron and gamma-ray correction factors are required. The results indicate that dose-rate values with sufficient reliability can be obtained for simple symmetric systems. However, for more complicated devices, a further extensive characterization of the vault is required.

A prototype, double-canned, $10-\mathrm{kg}$ blend of mixed plutonium and depleted-uranium oxides has been fabricated for eventual use in the Honeycomb assembly machine. The finished container, dimensioned to fit into the Honeycomb matrix, is presently being monitored for temperature and pressure buildup to assure safe handling during the proposed experiments.

Work is continuing on the construction of a ${ }^{3}$ He neutron scintillation spectrometer for use at the Brookhaven TRISTAN mass separator. Since quartz windows cannot withstand the required pressure, we have reverted to our original design using a glass window and wavelength shifter coupled to a visible-light-sensitive photomultiplier.

The Seforad ${ }^{3} \mathrm{He}$ ion chamber was employed in an attempt to measure the leakage neutrons in the energy range from 100 to $1500 \mathrm{keV}$ at the LASL weapons Neutron Facility. Although there was insufficient data to obtain the spectrum, we were able to specify a neutron flux in this range.

B. SiHEBA

Accident Simulation for Criticality Alarm Detectors (H. M. Forehand, R. E. Malenfant, E. A. Plassmann, G. E. Hansen, M. B. Diaz, B. Pena, Q-14). First critical was achieved with our new solution assembly, SHEBA, on September 6, 1980. This was just four and one-half months after we received funding approval for the program. Dur purpose was to provide a radiation source similar to what might be encountered in proposed centrifuge processing plants to benchmark calculations and to evaluate criticality accioent alarm detectors and personnel dosimetry. A series of experiments, which included steady-state and ramp operation, were completed for Goodyear Atomic Corporation and Dak Ridge Gaseous Diffusion Plant personnel who were here at Pajarito Site to test their equipment. In addition, seven detector vendors participated in evaluations of their products and Lawrence Livermore National Laboratory was involved with spectrum and dosimeter measurements.

A schematic diagram was presented in the last quarterly report. Figure 29 is a photograph of the completed critical assembly inside the thin metal building near Kiva I. SHEBA is a bare assembly fueled with a solution of $\approx 5 \%$ enriched uranyl fluoride initially stored in two horizontal 25.4-cm-diam x 1.5-m-long "safe" stainless-steel tanks. The solution is transferred to the reactor cavity, a 56-cm-diam $\times 1.3-m-h i g h$ stainless-steel tank with 0.64-cm-thick walls, by evacuating the cavity wile applying helium pressure to the storage tanks. A completely clean geometry is provided in this simple cylindrical system since reactivity control is effected by varying solution level. A "safety rod" may be inserted in a central thimble to provide fast shutdown. 


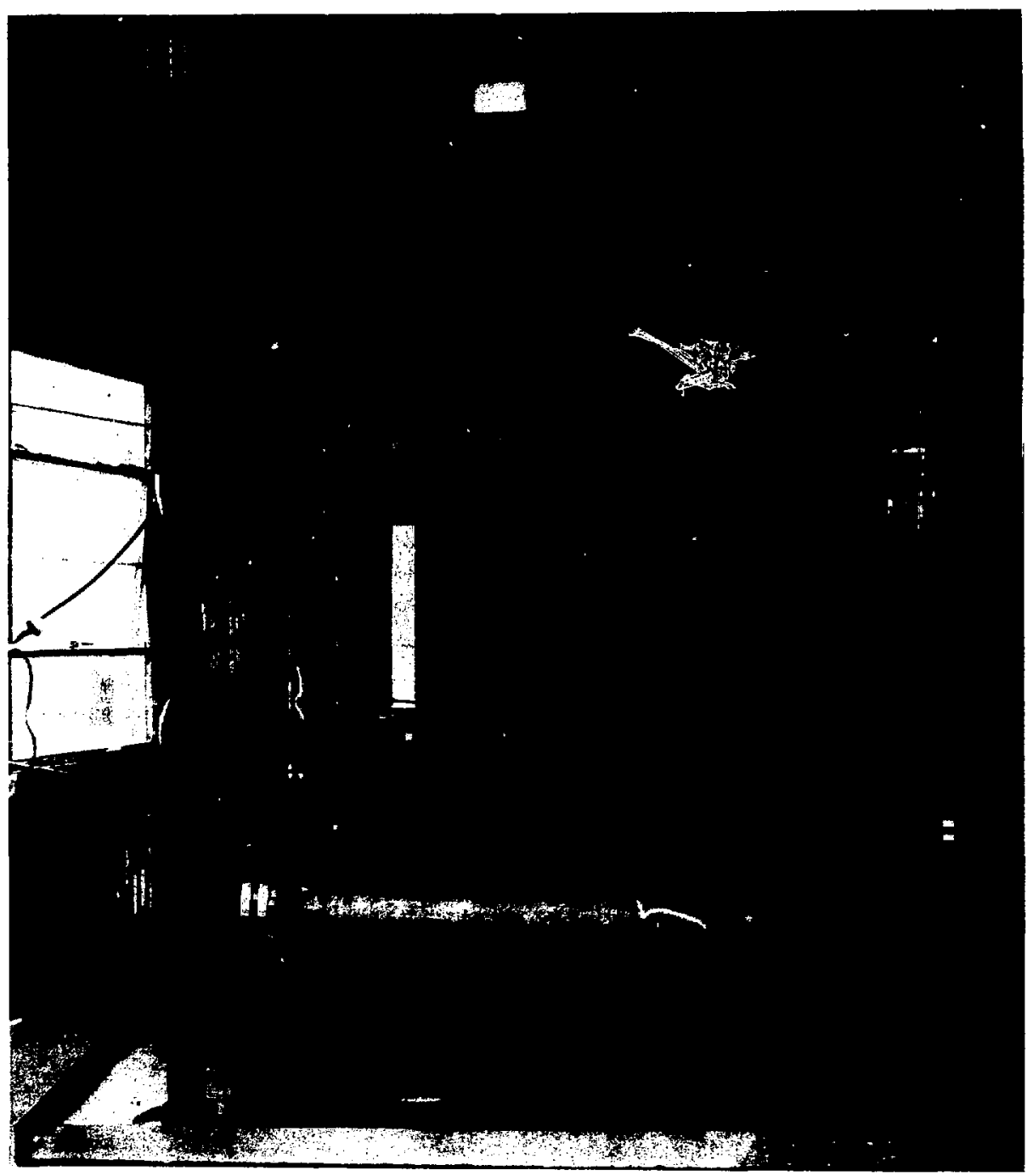

Fig. 29. SHEBA, a $U(5) \mathrm{O}_{2} \mathrm{~F}_{2}$ solution critical assembly.

The critical solution height was found to be $36.5 \mathrm{~cm}$ at $25^{\circ} \mathrm{C}$. This corresponds to $85.5 \mathrm{l}$ of solution in the cavity since the specific volume for the system is $2.342 \mathrm{l} / \mathrm{cm}$. With subsequent measurements we found the variation in critical height as a function of solution temperature. This is plotted in Fig. 30 and yields $\Delta h / \Delta T=$ $0.0602 \mathrm{~cm}{ }^{\circ} \mathrm{C}$. The scatter in the experimental points is attributed to the resolution that could be achieved in reading the solution height in the cavity sight glass as viewed on a television screen. As critical height was not an important parameter of the experiment, the resolution is adequate.

The observed reactivity added to the system corresponding to changes in solution height is shown in Fig. 31 . The same scatter is seen in the operator readings of the solution height. The curve is drawn to reflect evaluation of previous experiments on solution assemblies. ${ }^{1}$ After this plot was established, we decided to limit reactor periods to no shorter than $20 \mathrm{~s}$. This conservative 


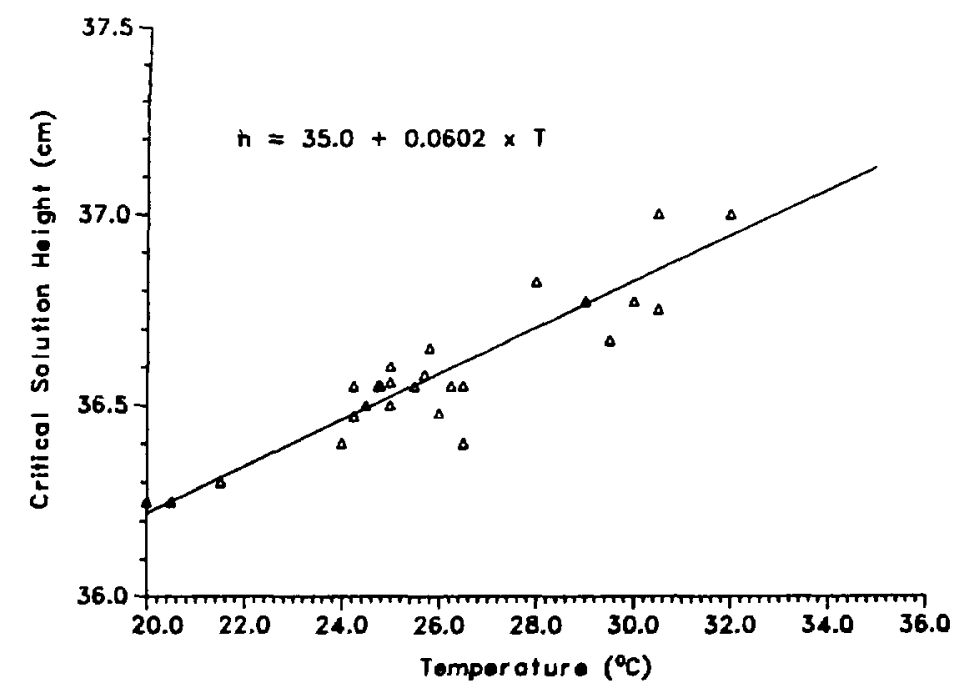

Fig. 30. SHEBA solution critical height as a function of temperature.

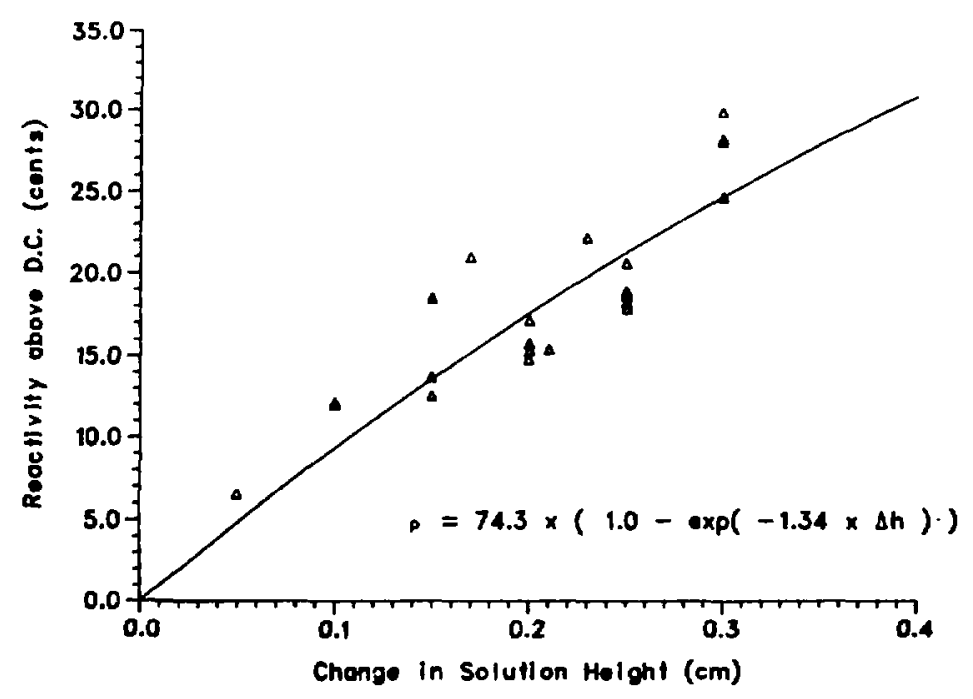

Fig. 31. SHEBA reactivity addition for solution height changes.

mode of operation was dictated by the inherent sluggishness of the control and safety systems. We plan to make the system more responsive with simple modifications.

An attempt was made to evaluate the relationship between power level and neutron leakage as measured by a Keithley amplifier readout of current generated in our standard moderated $\mathrm{BF}_{3}$ ionization chamber system. This was done by a Group CNC-1l radio-chemical analysis for ${ }^{99}$ Mo of a solution sample after a high power run. Preliminary indications are that $1 \mu \mathrm{A}$ corresponds to a power level of $1.09 \mathrm{~kW}$ after correction for the zero-offset on the Kiethley. The resulting power calibration curve is drawn in Fig. 32. Further experiments are required to establish a more precise power relationship.

For the just completed Goodyear Atomic and vendor irradiations, we operated SHEBA at power ranging up to $50 \mathrm{~kW}$. Detectors were positioned at 


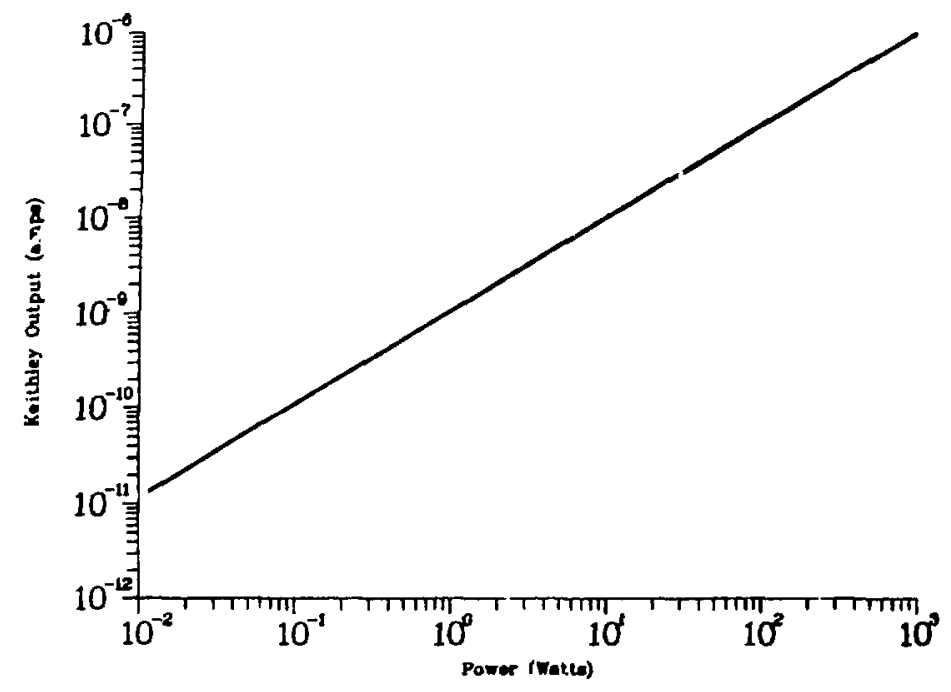

Fig. 32. SHEBA power calibration.

various locations from 2 to $275 \mathrm{~m}$ from the assembly. Attenuating shields, used either singly or in combination, included $20-\mathrm{cm}$ concrete, $10-\mathrm{cm}$ lucite, and up to 28-cm-thick steel. Evaluations of the experimental results will be made available to us when they are completed.

c. Godiva IV

1. Machine Modifications for Operation at TA-15 (T. F. Wimett, R. A. Pederson, J. Sterbentz, A. Martinez, $K$. Nereson, Q-14). During this reporting period, development of the concept of using Godiva bursts to measure neutron multiplication in dynamic subcritical assemblies was advanced to the field-test phase at PHERMEX. In order to prepare the Godiva IV Burst Assembly for its move to the PHERMEX Facility we had to disconnect the control wiring between the assembly and Kiva III terminal boxes. Then, multiconductor cable connectors were mounted on the assembly and new control cables, $150 \mathrm{~m}$ in length, were made. These were checked-out by moving the control console to Kiva III and plugging in the new cables (on their reels) between the console and machine. With the $U(93)$ fuel removed, all assembly operations were exercised and performed satisfactorily.

The control console, radiation scram circuits, strip chart recorders for fuel temperature and power levels, startup scalars for neutron counters, oscilloscopes, and other instrumentation for burst operation were then assembled in the trailer we would use as a portable control room.

After transport to PHERMEX, the fuel was mounted on the assembly machine and enclosed in a cadmium shroud. The reactor was then lowered into position in the partially completed concrete block house using a truck crane. Large concrete blocks were added to close up the roof of the shield chamber.

The control trailer was positioned mext to the PHERMEX detection building and all wiring was completed between the reactor, the control trailer, and a second remote control panel in the detection building. After radiation scram circuits and signal cables were installed, Godiva Iv was assembled to critical with a neutron source nearby. Burst operation was then undertaken in a stepwise manner, starting from prompt critical, to calibrate the neutron reflection effects in the block house. We observed that the additional reflection from the walls and low ceiling added about $10 \mu \mathrm{s}$ in "standard" burst duration over the enclosed corner operation previously performed in Kiva III.

During our operation at TA-15, a total of 16 bursts were generated with an integrated $y$ ield of $5.6 \times 10^{17}$ fissions. Six of these, each with a yield of about $6 \times 10^{16}$ fissions, used pulsed source initiation to establish timing of the power 
level trigger and the burst peak. Reproducibility of "standard" bursts was within $\pm 6 \%$ without correction for nan-ambient fuel temperature. Because alpha contamination within the block house was negligible at the conclusion of the experiments, we are assured that aluminum plating on the fuel has not lost its integrity.

Godiva IV will be returned to Pajarito Site where we will prepare for another PHERMEX experiment scheduled early in November, 1980.

2. Subcritical Measurements at PHERMEX ( $A$. E. Evans, R. E. Malenfant, T. F. Wimett, R. A. Pederson, Q-14). For this first experiment at PHERMEX, the test assembly had depleted uranium substituted for its fissile core and was fired in a containment vessel. Diagnostics applied to the shct included a PHERMEX x-ray radiograph, pin-dome nieasurements, and our attempt to measure the time dependence of simulated neutron output from the dynamic system during irradiation by a Godiva burst.

This "dry-run" experiment was intended to (1) study problems associated with the synchronization of Godiva, PHERMEX, and the test shot, (2) measure radiation doses associated with Godiva at the site, (3) assure the safety of the technique before attempting it with a shot containing fissile material, and (4) determine the baseline detection levels so that a meaningful measurement can be made.

The geometry of the experiment is shown in Fig. 33. The test shot is contained inside a 1.3-m-diam, 2.5-cm-thick steel spherical container. This vessel, filled with glass balls to mitigate the shock wave from the explosion, is placed in the center of a 3-m-diam, 8-cm-thick safety vessel that is maintained under vacuum during the shot. To close the safety vessel there is an additional 7.5-cm-thick, 35-cm-wide steel ring around its diameter. This "belly band" is situated at an angle to the horizontal plane so that it is centered approximately $1 \mathrm{~m}$ above the ground on the side away from and $2 \mathrm{~m}$ from the ground on the side closest to the PHERMEX target, thereby permitting the PHERMEX $x$-ray beam to pass through the test object without passing through the belly band.
Godiva was located in a 1.3-m-thick shield house made from high-density concret = blocks. The wall closest to the experiment has a 0.6-m-square opening containing a 15-cm-diam aluminum collimator tube set in sandbags and concrete block.

Neutron detectors were placed at about 45 degrees to the axis of the PHERMEX $x$-ray beam and 120 degrees to the axis of the Godiva beam to minimize the effect of direct irradiation from these two sources.

The detectors we used were:

Detector 1. A 12.5-cm-diam x 1.25-cm-thick Hornyak button mounted on an RCA-type 8055 photomultiplier, operated at 1200 volts.

Detector 2. A 2.5-cm-diam x 1.25-cm-thick Hornyak button mounted on an Amperex-type XP1180 photomultiplier, operated at 1200 volts.

catector 3. A 2-mm-thick NE102 plastic scintillator mounted on an Amperex-type 2020 photomultiplier, operated at 2000 volts.

Detector 4. A $1-g^{238} \cup$ spiral fission chamber, pressurized at $0.26 \mathrm{MPa}$ (38 psig) and operated at a bias of 300 volts, battery supplied.

Detector No. 1 was placed in a lead and borated-polyetnylene collimator centered 5.3 meters from the test shot and elevated about 3 meters above the ground plane so as to look through the top half of the safety vessel. Detectors 2 and 3 were placed on the floor of the test building, centered $3.2 \mathrm{~m}$ from the shot, looking up through the lower half of the safety vessel. These detectors were wrapped in cadnium and placed in 4-cm-thick lead shields. Detector 4, also wrapped in cadmium, was placed inside near the bottom of the safety vessel, a distance of 1.3 meters from the test shot. Signals from all detectors were fed through 50-ohm calles properly terminated to the PHEPMEX detection chamber. Signals were recorded using Tektronix-type 7912 transient digitizers.

To generate a fission burst with precise timing, pulsed neutron source injection must be used to initiate the fission chain reaction in Godiva. 


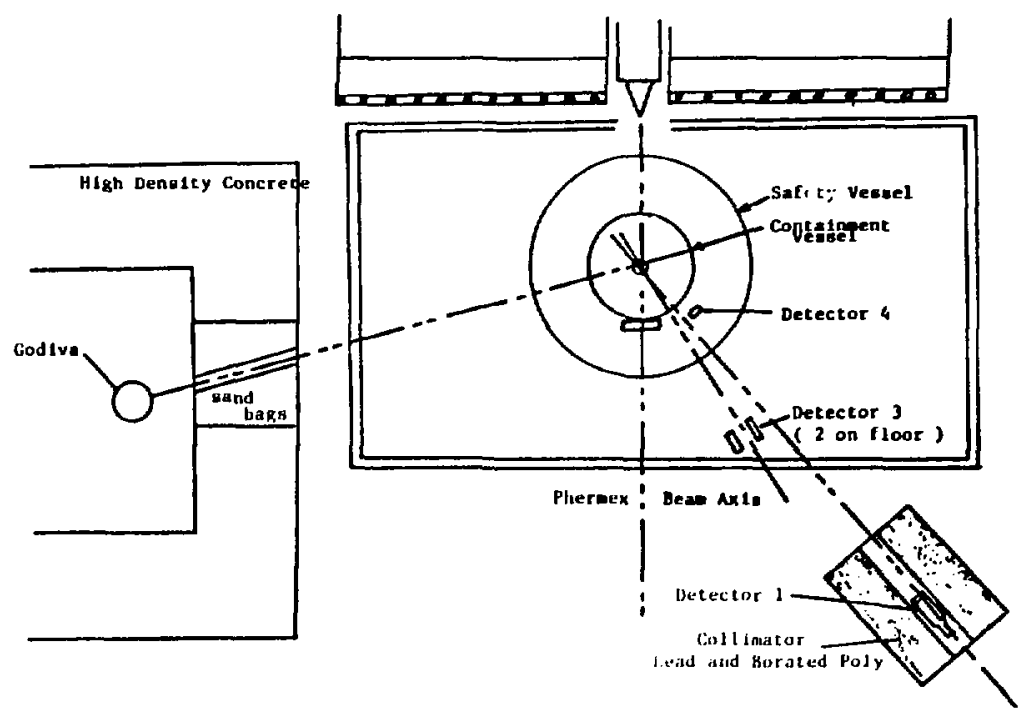

Fig. 33. Schematic of Codiva-PHERMEX experiment at TA-15.

Because the reactor must be in a super-promptcritical state before pulsed neutron injection, there is always a finite probability that background neutrons will initiate the burst before injection of the neutron pulse. To minimize the time (where preinitiation could accur) between attainment of superprompt criticality by burst rod insertion and neutron pulsing, a signal generated by the burst rod in-limit switch was employed to automatically initiate the entire sequence of events. This signal activated the PHERHEX capacitor charging circuit. As soon as PHERMEX was ready for pulsing, a signal was generated to fire the neutron pulser and initiate the exponential fission growth in Godiva. A typical e-folding period in this case is about $13.5 \mu \mathrm{s}$. When Godiva power reached a preset threshold ( $\approx 4 \mathrm{MW}$ ) on the buildup to the full neutron burst, a trigger signal was generated fron, a radiation detector and was sent back to PHERMEX control which accepted it within a time gate and appropriately delayed it for initiating both the PHERMEX pulse and the explosive charges. The advantage of using this Godiva power level trigger for synchronizing the other two events is that it acts as an abort signal. For example, if Godiva preinitiates or the pulsed neutron source fails to initiate a burst, the trigger pulse does not occur within the PHERMEX time gate, and everything is aborted except for the Godiva burst. The following time sequence shows the order of events that affect Godiva.

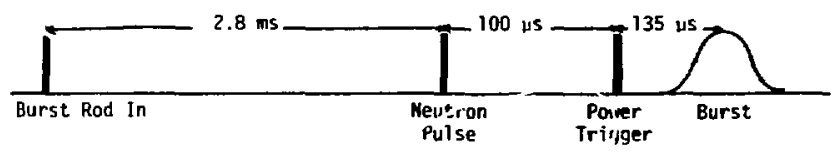

For this first experiment, a burst magnitude of about $4.5 \times 10^{16}$ fissions was arbitrarily selected because its time duration, measured at half maximum power, would be about 10 times the lifetime of the multiplying fission assembly. with such a burst, timing errors of up to $20 \mu \mathrm{s}$ could be tolerated without serious reduction of neutron flux on the target. Experience gained in generating 10 such bursts, many under poorly controlled reactor temperatures, indicated that $t i m-$ ing reproducibility was at least twice as good as expected and the synchronization error was $\pm 5 \mu \mathrm{s}$. we now conclude that a burst of $6 \times 10^{16}$ fissions, which would effectively double the target flux but produce a burst duration of $30 \mu \mathrm{s}$, would be near-optimum.

Neutron detector data were recorded from 13 Godiva bursts. The first 10 of these were background runs made without the test assembly and with the upper half of the safely vessel removed. 
Run No. 11 was synchronized with a PHERMEX burst and operation of detonators inside the empty containment vessel. Also, the complete safety vessel was in place. Run No, 12 was a static exposure of the test assembly with Codiva and PHERMEX, and Run No. 13 was the actual firing of the test shot.

Pertineni results are summarized in Table VII. During burst No. 6 , the beam hole to Godiva was plugged with $15 \mathrm{~cm}$ of iron and $10 \mathrm{~cm}$ of polyethylene. Comparison of data from this burst with bursts 5 and 7 show that $60 \%$ of the radiation from Godiva as seen by the detectors is apparently due to streaming through the Godiva shielding. Comparison of bursts 7 and 11 on Detector 1 suggests that most of the signal comes from scattering of the Godiva beam by the walls of the inner containment vessel, and that the outer safety vessel attenuates this radiation by a factor of 4 to 5 . The reduction in signal levels in Detectors 1 and 2 for bursts 12 and 13 over levels observed in $\mathrm{pi}_{\text {ivi }}$ i.jrsts is attributed to attenuation of the Godiva beam by the containment vessel and the upper half of the safety vessel, which was in place for the three final runs. The Godiva beam axis was just below the belly band, on the lower half of the safety vessel, but some part of this collimated oeam, plus a streaming component, would have irradiated the containment vessel directly when the top of the safety vessel was absent. The results indicate the need for better collimation of both the codiva beam and the detectors in order to reduce backgrounds.

Experience with the dry run indicates that several changes would increase the probability of a successful measurement.

1. The digitized signals from the PHERMEX highspeed oscilloscopes shows too much detail. It is possible that by simply monitoring detector output current a better diagnostic signal than the digitized data may be obtained. X-rays from PHERMEX create a negative pulse and an ensuing $6 \mathrm{MHz}$ oscillation was found to be inherent in the data acquisition system. It was present even when the cable from the detector was disconnected at the input to the R7912 waveform digitizer. This oscillation was found to be associated with the PHERMEX injector gun pulse, and might be due to an inadvertent connection of PHERMEX and detection-chamber grounding systems, possibly through the power supplied to Godiva controls which are in a bunker located outside of the detection trailer. Since the multiplication event we are looking for is expected to occur about 4-5 $\mu \mathrm{s}$ after the PHERMEX pulse, we must try to eliminate this interference before the proof experiment is attempted.

2. Better collimation of the Godiva beam should reduce background. Time constraints in the dry run precluded evaluation of different materials to define the collimator. Combinations of concrete, polyethylene, lead, and steel may be more effective than the sand bags that were used.

3. Cracks in the shield house could be covered with an additional layer of 20-30 cm of concrete. This could be done oy stacking blocks.

As a result of the dry run:

1. We have demonstrated that the PHERMEX pulse, initiation of an implosion, and a Godiva burst can be synchronized in a safe manner. Several apparent conflicts in operating philosophy were resolved before the live operation.

2. We have demonstrated that the collimated radiation from Godiva will not seriously effect the PHERMEX detection films.

3. We have demonstrated that the radiation doses in the portable control room at PHERMEX are $1 / 10$ to $1 / 100$ of those experienced in the control room at Pajarito Site as predicted in the safety evaluation.

4. We have demonstrated the feasibility of relocating Godiva Iv from Pajarito Site, safe operation in the remote location, and return to Pajarito Site with a minimum of personnel exposure.

5. We have measured the baseline radiation levels (albeit with some difficulty) and thereby demonstrated the utility of the removable shield house at PHERMEX. In addition, we have demonstrated the capability to make measurements in the severe nuclear and electromagnetic radiation enviroments present at PHERMEX. 
TAGLE VII

SUMMARY OF OETECTOR OATA FROM SODIVA BURSTS AT PHERMEX

\begin{tabular}{|c|c|c|c|c|c|c|c|}
\hline Burst No. & $\begin{array}{l}\text { Godiva } \\
\text { Burst, } 4 T(" \mathrm{C})\end{array}$ & $\begin{array}{r}\text { Detect } \\
\text { Det }](a)\end{array}$ & $\frac{\text { Signal Ma }}{\text { Uet } ?^{(b)}}$ & $\begin{array}{l}\text { irium, mv, } 5 \\
\text { bet } z^{(c)}\end{array}$ & $\therefore$ lead & $\begin{array}{l}\text { Safely } \\
\text { Vessel Iop. }\end{array}$ & Notes \\
\hline 4 & 189 & 150 & 180 & h०O & * & of 1 & Backgrouno \\
\hline 4 & 245 & 200 & $2 B(j$ & 1000 & 3.5 & off & Background \\
\hline$r_{1}$ & 264 & 75 & 110 & 400 & $\ddot{2.0}$ & uff $f$ & Godivg por thote plugged \\
\hline$y$ & 263 & 270 & 300 & 1000 & 4.0 & off & Background \\
\hline 11 & 236 & 50 & * & * & * & ont & Uttonators on $y$ \\
\hline 17 & $? 30$ & 35 & 200 & 810 & 3 & an & Static witn test device \\
\hline 13 & 243 & 37 & 210 & 8370 & 10 & un & Dynamic with cest devica \\
\hline
\end{tabular}

Notes:

* liata unavailable.

(a) 17.5-cm-d jam Hornyak bution, in collinator $5.33 \mathrm{~m}$ from test device.

(b) $2.5-c m-d i a m$ Hornyak button, 13 in from test device.

(c) 5-Cm-dian $\times 0.3-c m$ NE $102,3.2 \mathrm{~m}$ from test device.

(d) 238 fission chamber 3.2 in from device for bursts $4.7,1.2$ in from device (inside safety vessel) for bursts $11-13$.

6. We have demonstrated the integrity and safety of initiators on conventional high explosive when subject to the radiation environment from Godiva.

Before the next "live" experiment:

1. We must eliminate or finesse stray electromagnetic radiation that confuses the desired measurements.

2. We must attempt to refine collimation, both at the source and at the detectors, and reduce nuclear radiation background.

3. We must calibrate the detectors by means of static measurements on known multiplying systems (e.g., the 6.3-kg Pu-alloy Flattop Core, the 9.7-kg Pu-alloy Thor Core, the $38-\mathrm{kg}$ U(93) Multiplying Assembly).

4. We must attempt to raise or lower Godiva so that the collimation axis will not intersect the massive clamp band on the safety vessel. In conclusion, with the mechanical success of the "dry run," we can nuw concentrate on the details of this difficult, but important, experiment. We are very satisfied with the results to date.
D. Comet Universal Assembly Machine

1. Demonstrations for Nuclear Criticality Safety Classes (E. A. Plassmann, T. P. McLaughlin, D. R. Smith, Q-14; C. C. Byers, Consultant). During the past quarter, the Comet machine was used in conjunction with three separate two-day sessions of the Nuclear Criticality Safety class to provide hand stacking and remote subcritical neutron multiplication measurements of an assembly containing alternating lucite plates and $U(93)$ foils. These demonstrations have been given many times in the past several years as part of a continuing criticality safety program for laboratory personnel who handle fissile materials. We operated comet for these classes on July 9-10, August 13-14, and September 10-11, 1980.

2. Criticality Safety of Water-Flooded w79, W82, and w86 Systems (T. P. McLaughlin, E. A. Plassmam, Q-14). Experiments are being designed to provide data to check calculational methods employed in weapons criticality safety analyses. In particular, confirmation of the expected subcriticality of the W79, w82, and w86 systems, if immersed in water, is an immediate objective. The 
w79 and w82 are Lawrence Livermore National Ladorztory (LLNL) warhead designs for artillery projectiles, and the WB6 is the LASL wainead for the Persning missile. All three designs present special criticality safety considerations that are outside of the existing data base for analytic predictions. LLNL is providing both financial and manpower support since the results are oirectly applicable to their programs.

Both subcritical and critical configurations will DE assembled with the universal Comet machine. A preliminary series of neutron transport, ONETRAN, caiculations have been made to specify the nominal dimensions of aterials necessary for the experiments.

Plutonium parts are currently being fabricated by Group CMB-11. Some of these are already completed. When they have canned the finished pieces, we will be able to obtain precise dimensions for the fabrication of beryllium and polyethylene reflectors. We are making all the parts with spherical symmetry for simple and accurate calculational verification of the experimental results. The polyethylene will be used to simulate water flooding and we will use it to obtain criticality by varying its thickness as a reflector. Both low- and high-density polyethylene will be used to extend the range and versatility of the measurements.

\section{E. Flatiop}

Demonstrations for Nuclear Criticality Safety Classes (E. A. Plassmann, B. Pena, T. P. MCLaughlin, Q-14; C. C. Byers, Consultant). As part of the laboratory Nuclear Criticality Safety Course, we ran the flattop machine to demonstrate our critical assembly operating procedures. In this way, participants have a chance to see and work with the nickel-coated, 5.9-kg Pu-alloy cort, load the assembly, and run it remoteiy at delayed critical and on positive reactor periods. During this quarter, Flattop was operated for three sessions of the class on July 10, August 14, and September 11.

\section{F. HONEYCOMB}

Mixed Oxide Criticality Experiments (R. E. Malenfant, Q-14). Group CMB-11 completed the fabrication of a double-canned $10-\mathrm{kg}$ blend of $60 \%$ $\mathrm{PuO}_{2}-40 \% \mathrm{u}(0.2) \mathrm{O}_{2}$ (depleted uranium axide) using rign purity $\mathrm{PuO}_{2}$. The can is configured for planned experiments in the Honeycomb assembly machine and will be evaluated for thermal characteristics, uniformity of moisture content, pressure builoup, and nandling prior to comitment to full-scale manufacture.

Materials were dry tiendeo, sampled for analysis and, then, over a period of several nours, 600 ine of distilled water was adreo while tlending in a lucite "v" blender. The resulting "damp" blend was d free flowing nowder.

i $750 \mathrm{~g}$ charge was then pressed to 50 toric using a Greenaro press with stearic acid as the dit lubricant. The resulting compact was structurally sound although some slight tear-away from the punch faces had occurreo. The compact measured $6.4 \mathrm{~cm}$ square by $3.2 \mathrm{~cm}$ thick and nad a derisity of $5.51 \mathrm{~g} / \mathrm{cc}$.

This compact was weighed and stored overnight in a zip-lock poly bao. The following morning it was evident that water had been expelled fom the compact and condensed on the inside of the bag. Subsequent $750 \mathrm{~g}$ compacts were pressed to 40,30 , and 20 tons until the blend was consumed. Surprisingly, the lower forces resulted in similar final densities. Two compacts were held for loss-on-iznition determination. The remainder were placed in a $38.7-\mathrm{cm}-10 \mathrm{ng}, 6.83-\mathrm{cm}$-square, outside dimension can, made of 0.32-cm-thick aluminum. A lid having a centered $0.64-\mathrm{cm}$-diam hole was epoxied to the top of the can. Finally, a thin layer of Apeazon temporarily sealed the hole, through which a thermocouple would later be inserted. The filled can was cleared, weighed, and put into a clean secondary aluminum can for seal-welding. The assembly was then returned to a hood where the thermocouple (attached to a recorder), pressure relief valve, and pressure gauge were attached.

Initial temperature and pressure readings were $35^{\circ} \mathrm{C}$ and about $40 \mathrm{kPa}(56 \mathrm{psig})$. The central temperature is substantially higher and the pressure valve may be relieving. The filled can will be monitored for some time to assure safety before it is transferred to us for future diagnostic measurements. 
G. $P C A$

Preparation for Static UF ${ }_{6}$ Experiments $(H$.

M. Forehand, Q-14; R. G. Hnite, Consultant).

Although the Plasma Core Critical Assembly, PCA, was shut down after rompletion of the $U_{6}$ vortex confinement experimental series, ${ }^{2}$ the electromechanical control system was recently activated, exercised, and declared operational in preparation for experiments on a confined $u_{6}$ system. This will be a graduate student program done in conjunction with the Nuclear Engineering Uepartment at the University of Florida. A new $U_{f}{ }_{6}$ core cannister is now being fabricated with modifications as requested by the florida participants. The new design allows static operation with up to $3 \mathrm{~kg}$ of $\mathrm{Uf}_{6}$ at $0.41 \mathrm{MPd}(60 \mathrm{psig})$. Provision has been made inr thermocouple, flux wire, and foil string penetrations.

H. Cockcroft-walton Accelerator

1. Maintenance (A. E. Evans, Q-14). Oil was changed in all vacuum-system forepumps and roughing pumps, belts were inspected and changed where necessary, and three leaking shaft seals were replaced. All vacuum gauges were checked, recalibrated, and overhauled as necessary. A continuing proulen of high forepressure on pumping system No. 2 indicates possible breakdown or contamination of the diffusion-pump oil, which may necessitate complete disassembly and cleaning of the system.

After consideralie review and revision, an updated standard operating procedure for the facility was approved and adopted.

The liquid-nitrogen feed system for the highvacuum cold traps is now revised to include automatic transfer of liquid nitrogen from the outside storage trailer to a 100 - intermediate dewar Located in the experimental bay. This dewar, which had been used before, was moved closer to the cold traps to reduce liquid nitrogen losses when they are filled. With the automatic transfer to the dewar, less frequent refilling is required which saves liquid nitrogen. Also, it allows unattended operation of the vacuum system for unlimited periods of time. Annual usage of liquid nitrogen for this purpose is $72 \mathrm{kl}$ at a cost of $\$ 5,800$.
2. Accelerator Pulsing (A. E. Evans, M. B. Qiaz, Q-14). The ability to observe nanosecond beam pulses at the accelerator target has been hampered by If interference from the $140-\pi \mathrm{Hz}$ osciliator which drives the accelerator ion source. This If interference would also effect the use of high-sensitivity, high-impedance instrumentation planned for later experiments. in an attempt to correct the problem, we have built a perforated-brass cage around the ion source and its ascillator, and provided if choking for all electrical leads into the cage. This successruliy suppressed the interference, nowever, in the process, we lost about $80 \%$ of our available beam current. The reason for this is not evident and more work will be necessary to restore the accelerator to its full current capability.

1. "INRAO" Measurements of LASL Weapons

Measurements on the Device for the Verdello Event (E. A. Plassmann, R. A. Pederson, Q-14). Since the device for the verdello event was complete with high explosive, INRAD measurements on it had to be made in a secure location. The location was chosen because of safety, security, and safeguard considerations. This room is small, $5.43 \mathrm{~m}$ on each side, with 41-cm-thick steel reinforced concrete walls, thick concrete floor, and heavy steel vault doors. Obviously, the reflection of radiation from the walls and floor is a major complication to the measurements and an assessment of this effect had to be made.

We know that the intensity of radiation from a point source in free space decreases as the reciprocal of the square of the distance, $r$, from the source. Measured deviations from the $1 / r^{2}$ dependence are caused by detector response, background radiation and, particularly in our case, by rom return. It is essential that the magnitude of this room return correction is determined in order to analyze the INRAD data taken in the vault.

Because of the concrete walls and floor, we expect a large neutron room scattering effect. To measure this, a ${ }^{252} \mathrm{Cf}$ source $\left(Q=1.57 \times 10^{7}\right.$ neutrons/s on June 10,1980) was positioned in the center of the vault, $107 \mathrm{~cm}$ above the floor, and counting rates recorded as a function of distance toward the open vault doors with our Iracerlab NP-1 (Snoopy) detector. A representative set of 
neutron counting data is listed in Table VII. At all positions, more than $2 \times 10^{4}$ counts were recorded, so the statistical deviation in the counting rates is less than $1 \%$. The average background measured at this time was 0.41 counts/min. From previous work with this source, the NP-1 Snoopy detector was found to have a calibration resporise of 165.5 (counts/min)/(mrem/h) so free space counting rates to be expected as a function of distance from the source can be calculated. The difference between the recorded counting rate (less background) and that expected at the several detector distances of Table VIII is a measure of the neutrons being reflected back to the detector from the walls and floor of the room. We have plotted the ratio, $F_{\Gamma}(r)$, of room return neutrons to the total counting rate (less background) in Fig. 34. This is the correction factor which must be applied to data taken on an INRAD device.

For comparison, also plotted in Fig. 34 is the room return ratio measured in the experimental bay where we have been dcing our INRAD experiments for the past few years. The dasheu curve denotes a constant room return over the entire range of measurements. The fact that the experimental points closely follow this curve assures us that

TABLE VIII

NEUTRON COUNTING WITH ${ }^{252}$ Cf SOURCE IN NEW ACCOMMODATIONS

Distance to Source ${ }^{(a)}$ Recorded Couriting Rate ${ }^{(b)}$

(m)

(counts/min)

$\begin{array}{lc}0.249 & 41567 \\ 0.499 & 11021 \\ 0.753 & 5035 \\ 0.977 & 3112 \\ 1.247 & 2039 \\ 1.747 & 1175 \\ 2.247 & 795.1 \\ 2.747 & 568.8 \\ 3.247 & 425.4 \\ 3.747 & 321.1\end{array}$

(a) ${ }^{252} \mathrm{Cf}$ source $\left(Q=1.57 \times 10^{7}\right.$ neutrons/s on June 10, 1980).

(b) Statistical deviation is less than $1 \Delta$ background is 0.41 counts/min. in this room we can safely make the essumption of constant room scatter within a $3.5 \mathrm{~m}$ radius of the source origin. The much higher and non-unifo:m room scatter in the present facility is attributed to its massive concrete construction.

A representative set of data to characterize measurements in the vault with respect to gamma radiation is listed in Table IX. The countingrate data shown are for the detector we call $G M(H)$ and a ${ }^{137} \mathrm{Cs}$ source which had a strength of 0.971 $\mathrm{mCi}$ on June 11,1980 . The average gamma-ray background was found to be 32.06 counts/min ano the dead time correction was 0.17 mis. Knowing the source strength and the detector resoonse of 1206 (counts/min)/(mR/h), the room return can be dctermined at each experimental source-to-detector Jistance. In Fig. 35 we have plotted the room return correction factors for both the vault and the usually used experimental bay for the same detector $G M(H)$. The curves drawn are for constant room returns, different for each room, and the experimental points show that this approximation is valid for each room. However, the room return for gamma rays in the vault is some two and one-half times greater.

TABLE IX

GAMMA-RAY COUNTING DATA WITH ${ }^{137}$ CS SULRCE IN NEW ACCCMOD.ATIONS.

Distance to Source $^{(a)}$ Recorded Counting Rate $^{(b)}$ (m) (counts/min)

$\begin{array}{lc}0.321 & 3462 \\ 0.575 & 1154 \\ 0.799 & 621.6 \\ 1.069 & 371.5 \\ 1.569 & 195.1 \\ 2.069 & 130.1 \\ 2.569 & 97.62 \\ 3.069 & 81.84 \\ 3.569 & 69.87 \\ 4.069 & 64.20\end{array}$

(a) ${ }^{137} \mathrm{Cs}$ source $(0.971 \mathrm{mCi}$ on June 11, 1980)

(b) Statistical deviation is about 1\%; background is 32.06 counts/min. 


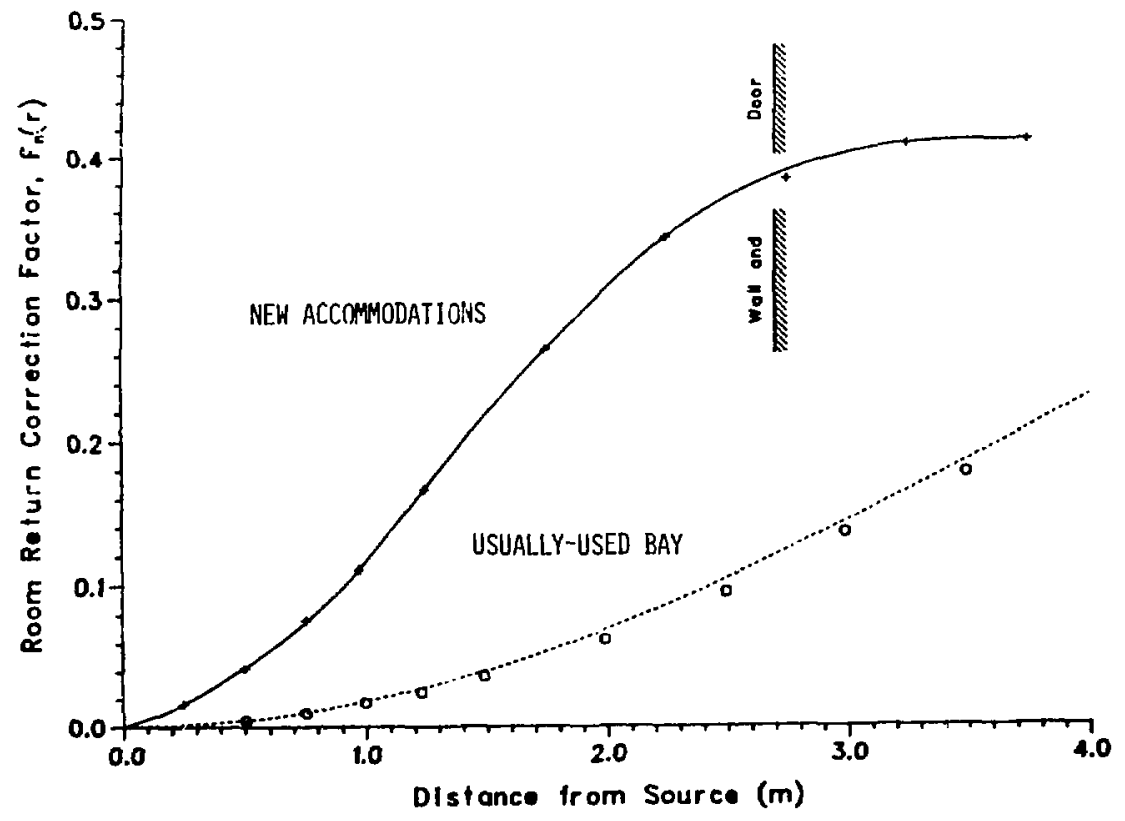

Fig. 34. Neutron room return correction factor.

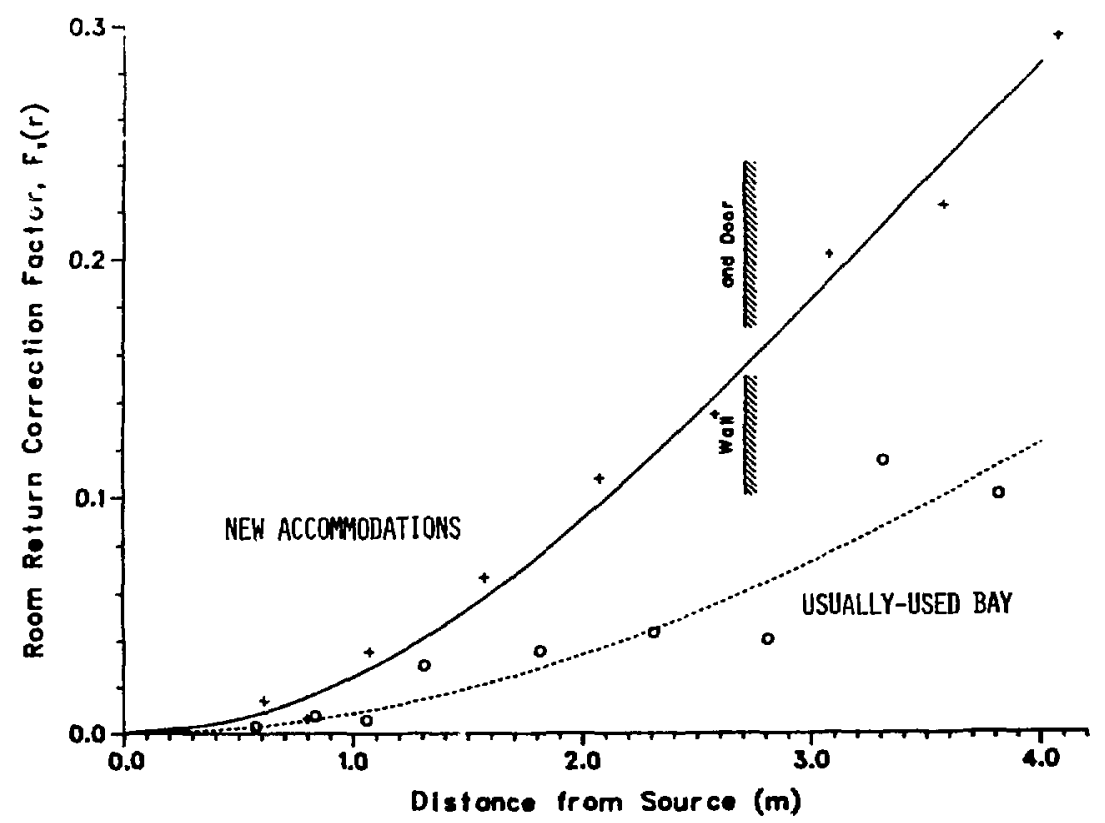

Fig. 35. Gamma-ray room return correction factor. 
These neutron and gamma-ray roon-return correction factors were employed in the analysis of counting data measured on the device for the verdello event. The results indicate that even though there are considerable difficulties in making INRAD measurements in the new accommodations, results with sufficient reliability can be obtained on simple symetric devices such as this one. The uncertainties will become greater if more complicated systems are attempted. At the conclusion of this reporting period, efforts were underway to undectake more sophisticated evaluations of room effects. Initial results show promise of significantly increasing the understanding (decreasing the uncertainty) in measurements, particularly when coupled with calculations.

3. High-pressure HE-3 Neutron Spectrometer Development of $a^{3}$ He Gas Scintillator (A.

E. Evans, Q-14). Construction of a ${ }^{3} \mathrm{He}$ gas scintillator for $n-\gamma$ coincidence spectrometry of delayed-neutron enitters at the Brookhaven TRISTAN facility is continuing. In addition to its use in this research program, for wich the development is funded, the detector should be valuable for INRAD measurements of neutron spectra. This is particularly true for work at remote sites since the detection efficiency is expected to be a factor of 30 greater than the presently used ${ }^{3} \mathrm{He}$ ionization chamber.

In order to avoid the use of a wavelength shifter inside the scintillator, we had originally planned to build this detector with a quartz window and use an ultraviolet-sensitive photomultiplier. It was felt that direct conversion of the ultraviolet output from a ${ }^{3} \mathrm{He}-\mathrm{Xe}$ mixture would give better neutron-energy resolution than a system using visible light produced in the wavelength shifter and transmitted through a glass window to a visible-light-sensitive photomultiplier. The effort to build an ultraviolet-transmitting cell was thwarted, however, when we found that quartz windows could not withstand the $13.8 \mathrm{MPz}$ (2000 psi) intended gas pressure in our detector design. Accordingly, we returned our efforts to develop the glass window and wavelength shifter.
Obtaining good results with the wavelength shifter requires vapor deposition of the diphenylstilbene in a carefully controlled distribution of thicknesses to compensate for geonetrical factors of reflection from various parts of the cell wall.

During this reporting period, an $\mathrm{Al}_{2} \mathrm{O}_{3}$ casting intended to serve as a light reflector inside the cell was vacuum coated with aluminum and overcoated with a thin layer of $\mathrm{MgF}_{2}$ as a reflector of ultraviolet light which would otherwise escape by transmission through the $\mathrm{Al}_{2} \mathrm{O}_{3}$. The evaporations were completed by Group P-3 and the cell was assembled and then tested at $17.3 \mathrm{MPa}$ by Group wX-5. A manifold has been const:ucted to evacuate the cell and fill it with a ${ }^{4} \mathrm{He}-\mathrm{Xe}$ mixture. Adequate light output and leak integrity of the cell will be established before filling with ${ }^{3} \mathrm{He}$.

K. Leakage Neutron Spectrum at WNR

Measurement of Neutron Energies up to $1.5 \mathrm{MeV}$ with Seforad Detector (A. E. Evans, Q-14). Together with Groups $P-3$ and $H-1$, we participated in a measurement of the leakage neutron flux and spectrum at the LASL Heapons Neutron Research (WNR) Facility. Our Seforad ${ }^{3} \mathrm{He}$ ion chamter was set up $1 \mathrm{~m}$ from the surface of the MNR highcurrent target shield, and data acquired with a $\mathrm{TN}-4000$ multichannel analyzer system. The measurements were intended to determine the radioJogical safety of increasing the neutron output of WNR. We were expected to provide spectral data in the energy range from 100 to $1500 \mathrm{kev}$ to supplement higher energy measurements made by Group P-3 using a plastic scintillator.

The previous measurements indicated that the neutron spectrum was strongly peaked at $4 \mathrm{MeV}$. This is a very unfavorable distribution for detection by the ${ }^{3} \mathrm{He}$ ion chamber since its fullenergy peak efficiency and the peak-to-total ratio both fall off rapidly above $2 \mathrm{MeV}$.

with $18 \mu \mathrm{A}$ of LAMPF protons incident upon the WNR target, the high-energy neutron counting rate in our detector was extremely low. We recorded a tatal of only 304 pulses in 5344 s corresponding to neutrons with energies between 830 and $3300 \mathrm{kev}$ having risetimes corresponding to full-energy interactions. The expected peak from thermal neutrons was comparatively large; however, 
there was also a pileup distribution of pulses attributed to thermal neutrons that obscured the energy region from $0-800 \mathrm{keV}$. This pileup phenomenon could not be accounted for from the existing thermal-neutron counting rate of 21 pulses/sec, the pulsing of the LAMPF beam, and the time constants ( $6 \mu \mathrm{s}$ integration, $3 \mu \mathrm{s}$ differentiation) of the detector amplifier. It was not observed when the system had previously been checked out with a ${ }^{252} \mathrm{Cf}$ neution source. The observed pulse-height distribution suggests a large number of time-correlated thermal neutrons.
We did not observe enough high-energy neutron pulses to derive a spectrum. They corresponded to a neutron flux in the energy region from 830 to $3300 \mathrm{keV}$ of about $14 \mathrm{n} / \mathrm{cm}^{2} / \mathrm{sec}$ or 0.8 $\mathrm{n} / \mathrm{cm}^{2} / \mu \mathrm{Coul}$. Since there was a relatively large flux of higher-energy neutrons, most of the events observed may be due to wall effects or 3 He recoils giving a partial deposition of neutron energy in the detector.

\section{REFERENCES}

1. H. M. Forehand, private communication (to be published as a Doctorial Dissertation).

2. Q-14-79-308, Group Q-14 Quarterly Progress Report for July 1-September 30, 1979, pp 23-27. 